\title{
Essays on International Economics
}

\author{
Carlos Alberto Pulido Hernandez \\ Mexico City, Mexico
}

M. A. Economics, University of Virginia, 2010

Ph. D. Finance, Instituto Tecnologico de Estudios Superiores de Monterrey (ITESM), 2007

M. A. Economics, Instituto Tecnologico Autonomo de Mexico (ITAM), 2003

B. A. Economics, Instituto Tecnologico Autonomo de Mexico (ITAM), 2003

A Dissertation presented to the Graduate Faculty of the University of Virginia for the Degree of Doctor of Philosophy

Department of Economics

University of Virginia

August, 2015 


\section{Abstract}

The first chapter in this dissertation investigates the effect of oil booms on public saving. By proposing an intertemporal two-period model, where the government finances its expenditure using taxes and oil revenues, I find that an oil boom has a negative effect on the optimal tax rate and an ambiguous effect on current account. On one hand, the "windfall effect" results from a higher level of public saving via oil revenue. On the other hand, the "voracity effect" arises from a larger number of powerful political groups in the economy trying to capture the gains from the boom, which increases public expenditure and deteriorates the current account. I support the theory using international annual data with particular emphasis on OPEC and Non-OPEC in the period 2005-2012. Evidence from data suggests that: (i) oil booms have a positive impact on government spending and current account but a negative impact on tax revenue in both group of countries, and (ii) these effects are stronger in the OPEC, where political cohesion is very high.

The second chapter investigates the relationship between counterfeit software production, government corruption and GDP across countries. By proposing a static general equilibrium model where two software producers and one software consumer interact, I find that output has a negative effect on the equilibrium level of counterfeit software and this effect is attenuated by government corruption. I support the theory with international annual data for 107 countries in the period 2007-2013. By controlling for trade openness and intellectual property rights, the evidence suggests that GDP per capita has a negative impact on the counterfeit software fraction which is reduced in the most corrupt countries.

The last chapter provides a rigorous analysis of pollution emitted by Mexican manufacturing exports for pre- and post-NAFTA periods using the Environmental Kuznets Curve (EKC), an economic concept that predicts a non-monotonic income-pollution relation. I identify weak empirical support for the "pollution haven" hypothesis given the increase in the Mexican's government bargaining power -relative to Mexican powerful private elitesafter NAFTA. Since 1994, Mexican government triggered a process of political liberalization and fight against corruption, where the rise of several political parties improved their ability to impose stringent pollution taxes and tight environmental regulation. 


\section{Acknowledgement}

I would like to express my sincere gratitude to Professors John McLaren, Charles Holt and Kenneth Elzinga.

I also would like to thank Professors Ariell Reshef and William Shobe.

This dissertation is dedicated to my son, Carlos, my wife, Nely, my parents, Laura and Abdon, and my best friends, Perri P. and Nelo. 


\section{Contents}

Chapter 1. Oil booms, political groups and current account in OPEC and Non-OPEC

1.1 Introduction

1.2 Review of Literature.

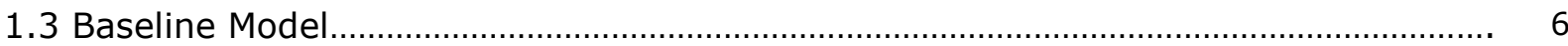

1.3.1 The Consumer's Problem.......................................................................................... 6

1.3.2 The Government's Problem............................................................................... 7

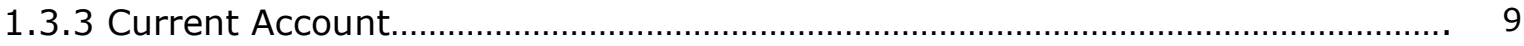

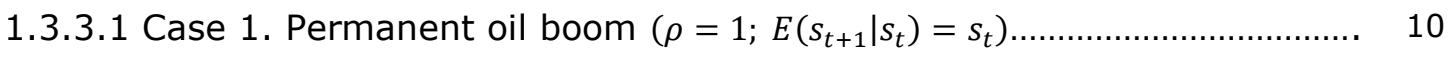

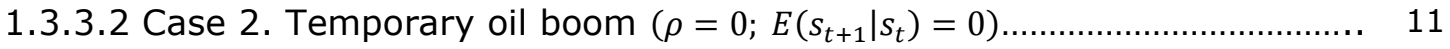

1.3.3.3 Comparing Case I and Case II.................................................................. 11

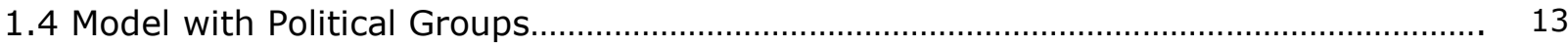

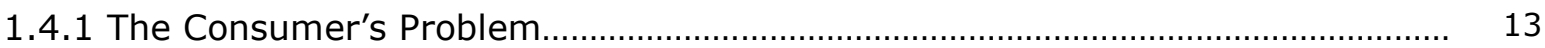

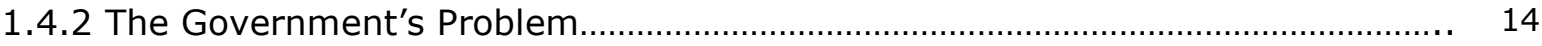

1.4.3 Current Account with Uncoordinated Political Groups........................................ 17

1.4.4 Current Account with Coordinated Political Groups............................................. 19

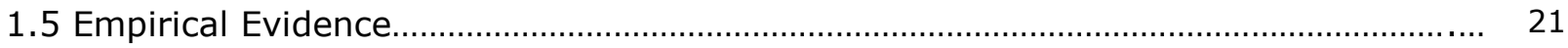

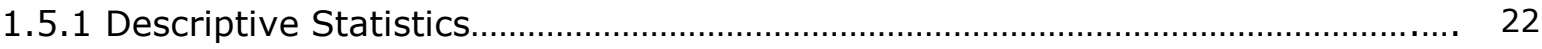

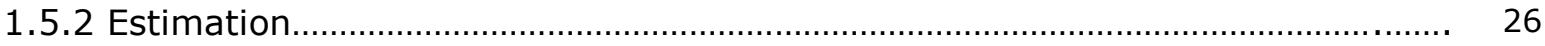

1.5.2.1 Relationship between Oil Revenue and Current Account........................ 26

1.5.2.2 Relationship between Oil Revenue and Public Expenditure

1.5.2.3 Relationship between Oil Revenue and Tax Revenue.............................. 32

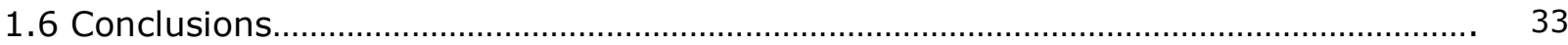

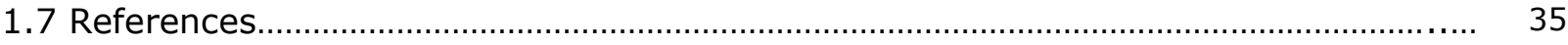

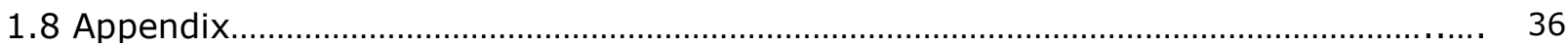

Chapter 2. Counterfeit Software, Corruption and Output: The International Experience

2.1 Introduction 


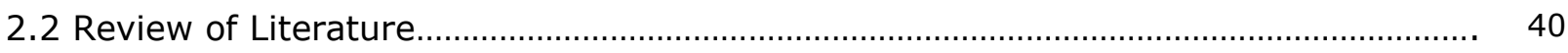

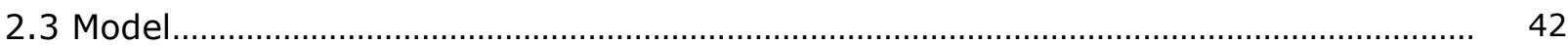

2.3.1 The Consumer's Problem..................................................................................... 43

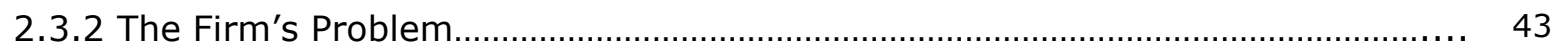

2.3.3 The Government's Problem.................................................................................... 47

2.3.4 The Exporting Countries................................................................................. 47

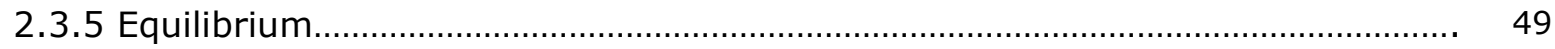

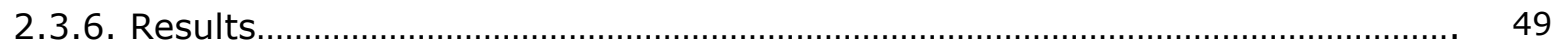

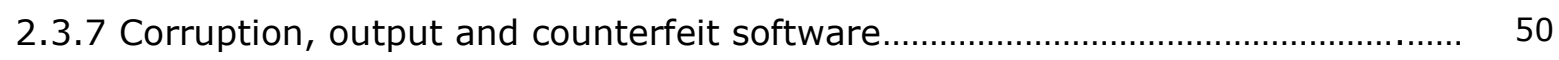

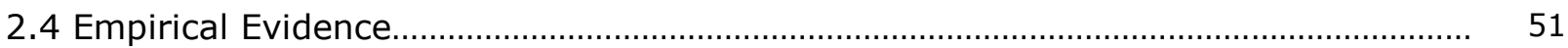

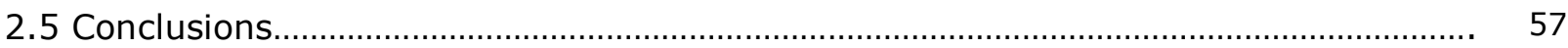

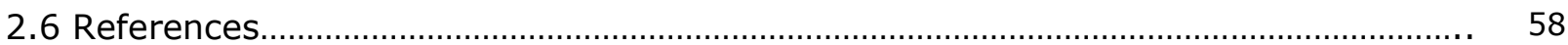

Chapter 3. The Environmental Kuznets Curve: The Mexican Experience after NAFTA

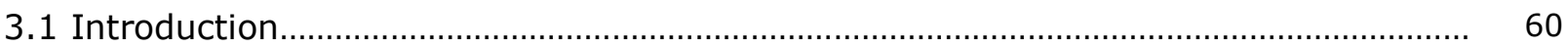

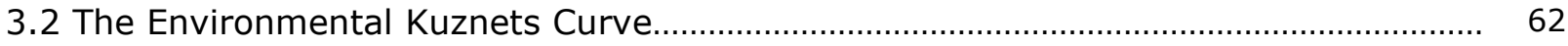

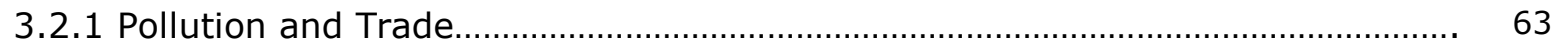

3.2.2 Scale, Composition, and Technical Effects..................................................... 64

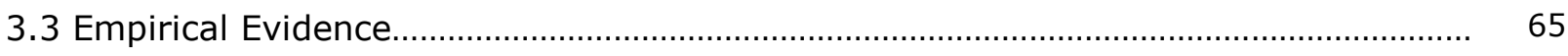

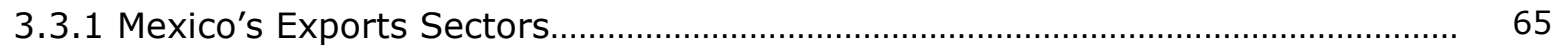

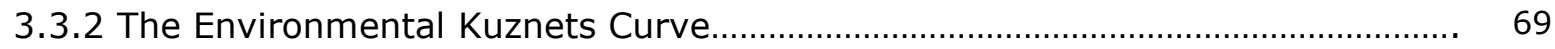

3.3.3 Pollution from Manufacturing Sector............................................................. 74

3.3.4 Estimating the Scale, Composition and Technical Effect.................................... 78

3.3.5 Scale, Composition and Technical Effects in the Top Three Polluting Sectors... 86

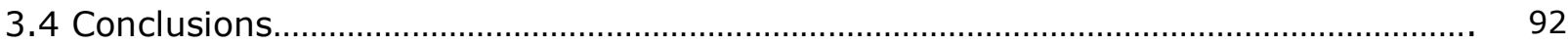

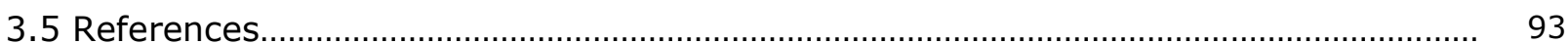

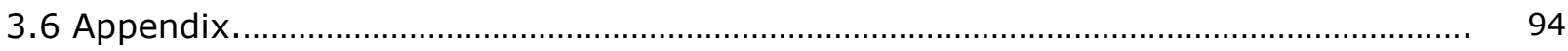




\section{Chapter 1}

\section{Oil booms, political groups and current account in OPEC and Non- OPEC}

\subsection{Introduction}

The public sector is composed by central government, local governments and state-owned enterprises (SOE). Little et al. (1993) define SOE as "organizations that produce goods or services and sell them to consumers, much as privately owned enterprises do." One example of a SOE is a national oil company (NOC): an oil company owned by the government. In principle, a NOC is charged with serving the public interest via supplying energy fuels and associated services, and responsibly managing environmental risk. However, the final purpose of a NOC is generating important revenue streams to finance public deficit. In this sense, it is expected that NOC revenues be related to taxes, public expenditure and current account. Additionally, studying the NOCs around the world gives a good approximation of the degree of oil dependence faced by a country's government. According to a report issued by the World Bank (2008), "NOCs control approximately 90 percent of the world's oil reserves and 75 percent of production."

Consider Figures 1a-1f, which plot the ratio of oil revenue to GDP against three variables (each also expressed as percentage of GDP): (i) government expenditure, (ii) tax revenue and (iii) current account, over the period 2005-2012 for a sample of 56 countries where NOCs are located ${ }^{1}$. The plotting considers two cases. The first case only includes the 44 members of Non-OPEC. In the second case, the plotting contains the whole sample (44 members of Non-OPEC and 12 of OPEC). Also, each graph indicates the correlation coefficient between each pair of variables. By comparing the two scenarios, the plotting that uses the whole sample always reports, in absolute value, a higher correlation. In this sense, the plotting suggests that: (i) in the OPEC and Non-OPEC -where NOCs are located- oil revenue has a positive impact on current account and public expenditure, a negative effect on tax revenue, and (ii) in relation to the Non-OPEC, the OPEC tends to have higher ratios public expenditure/GDP and current account/GDP but lower tax revenue.

\footnotetext{
${ }^{1}$ See Appendix.
} 
Figure 1a. Oil Rents and Public Expenditure (Non-OPEC, Average 2005-2012)

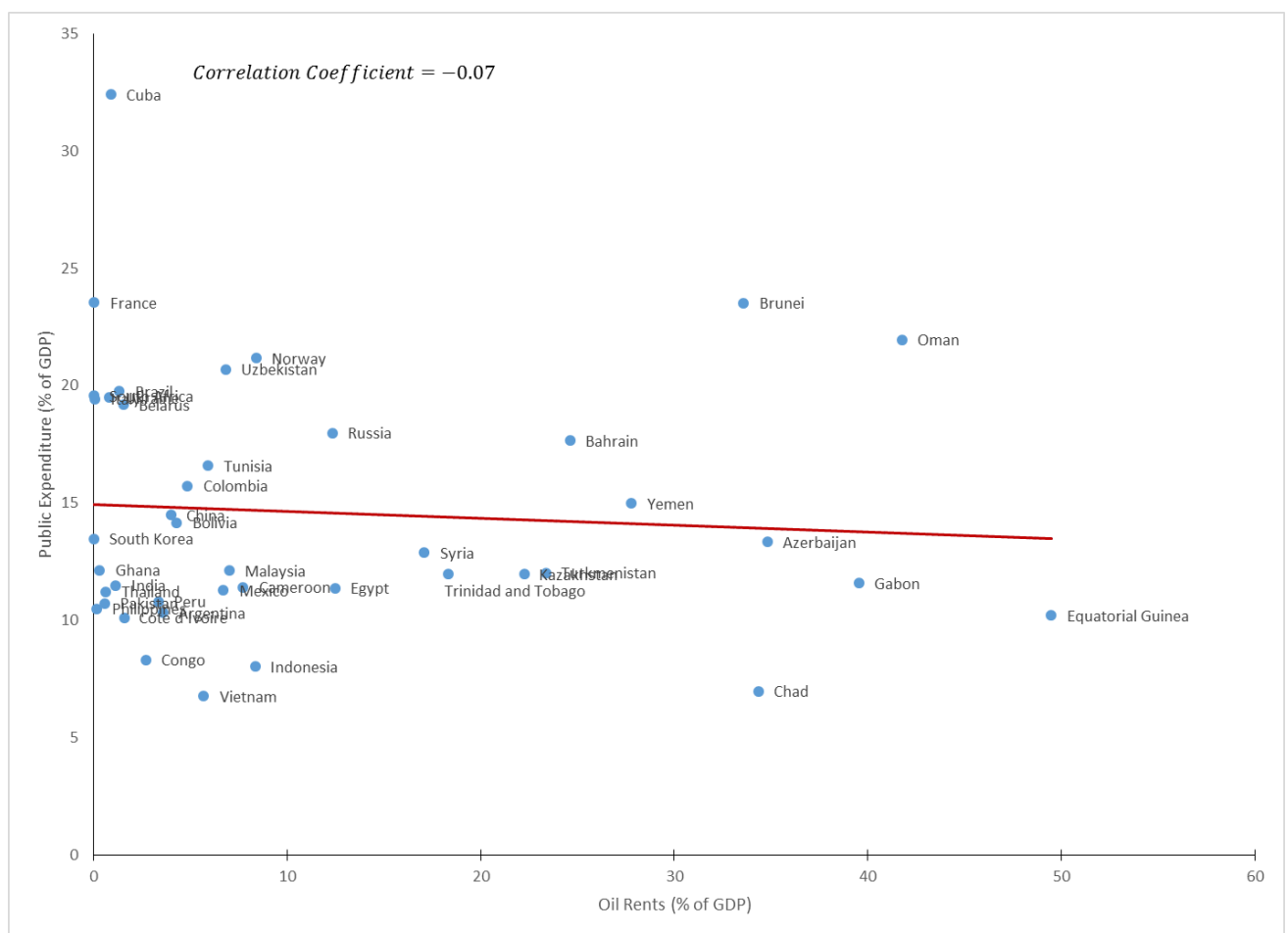

Figure 1b. Oil Rents and Public Expenditure (OPEC and Non-OPEC, Average 20052012)

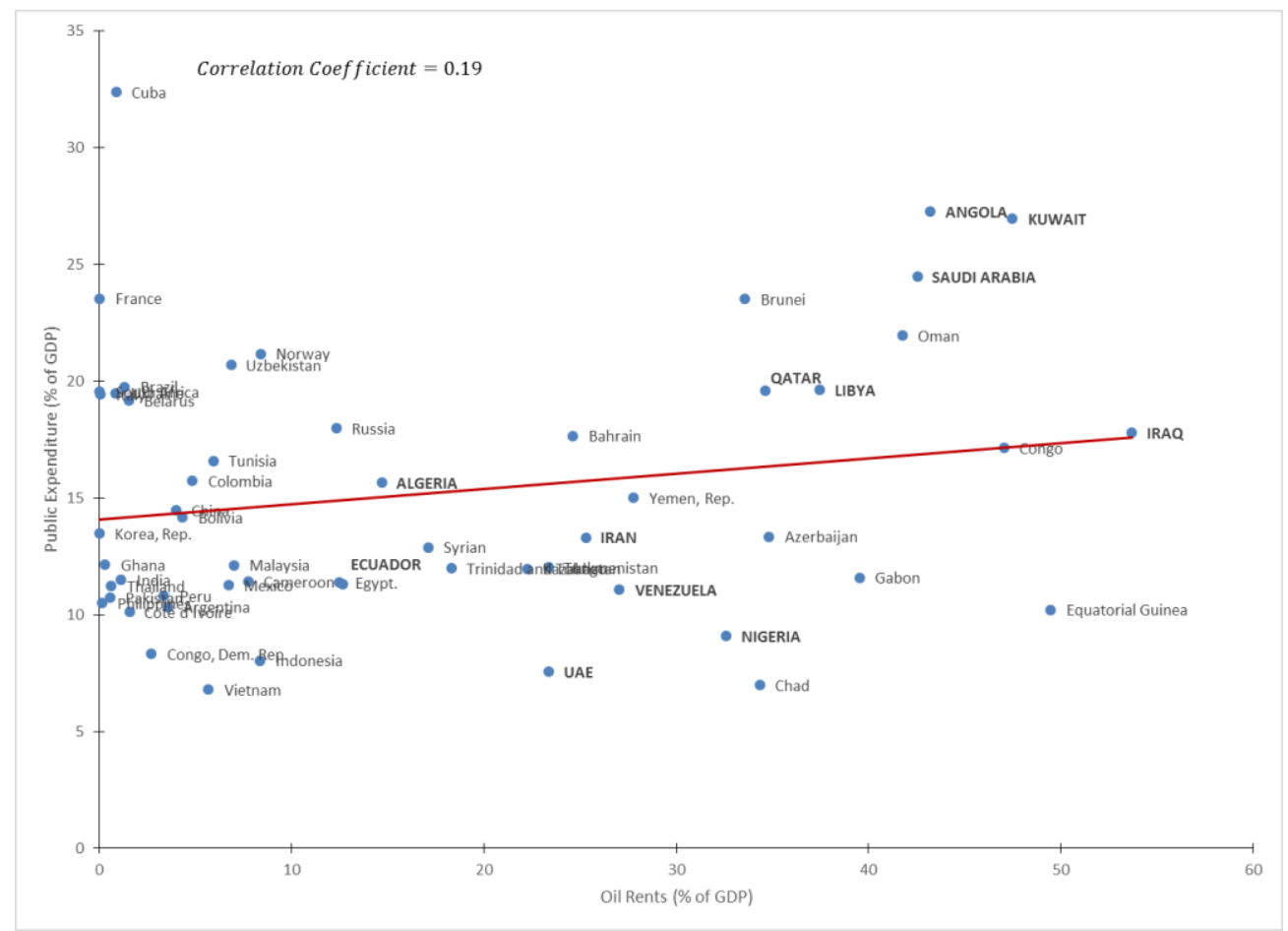


Figure 1c. Oil Rents and Tax Revenue (Non-OPEC, Average 2005-2012)

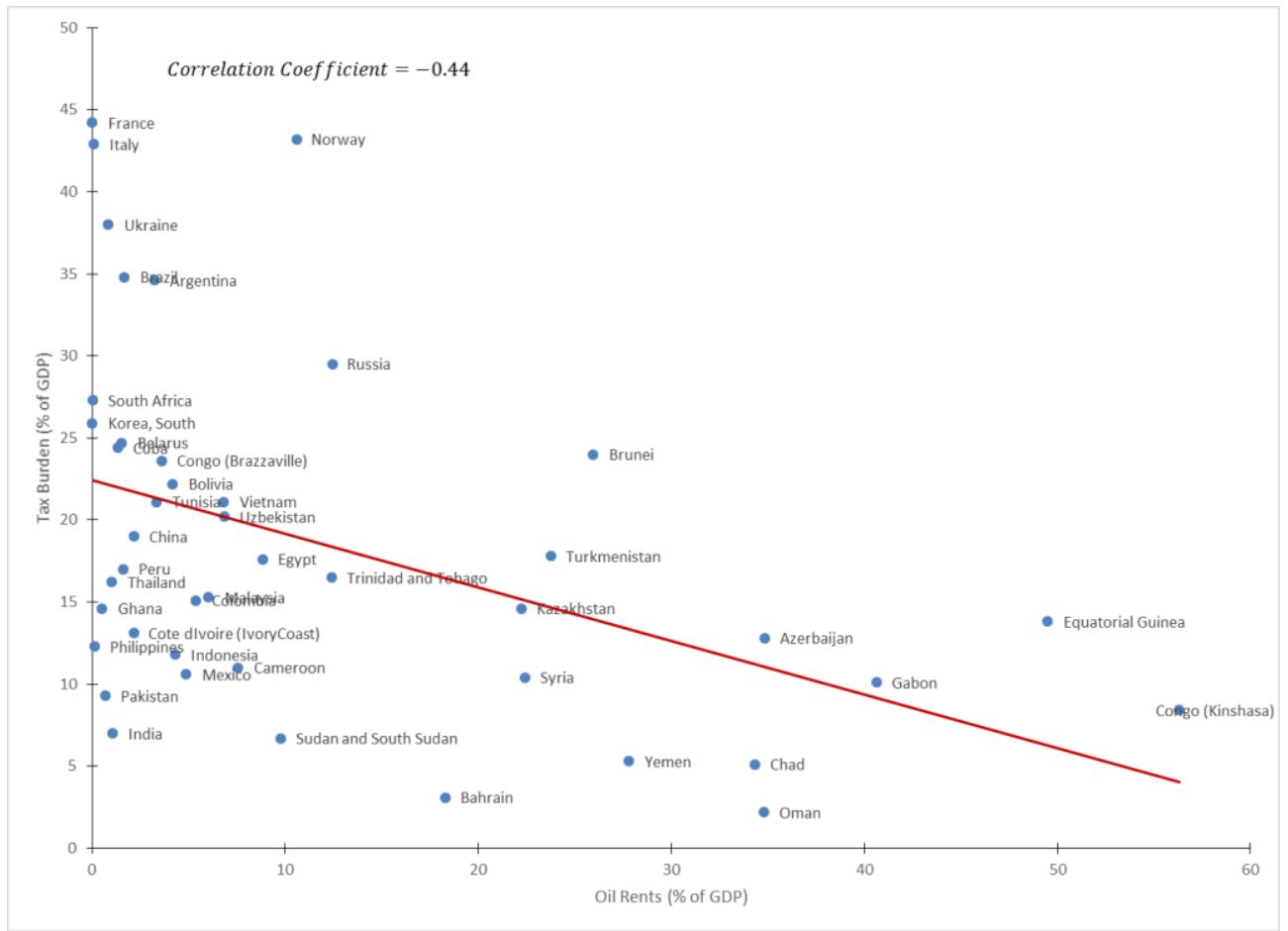

Figure 1d. Oil Rents and Tax Revenue (OPEC and Non-OPEC, Average 2005-2012)

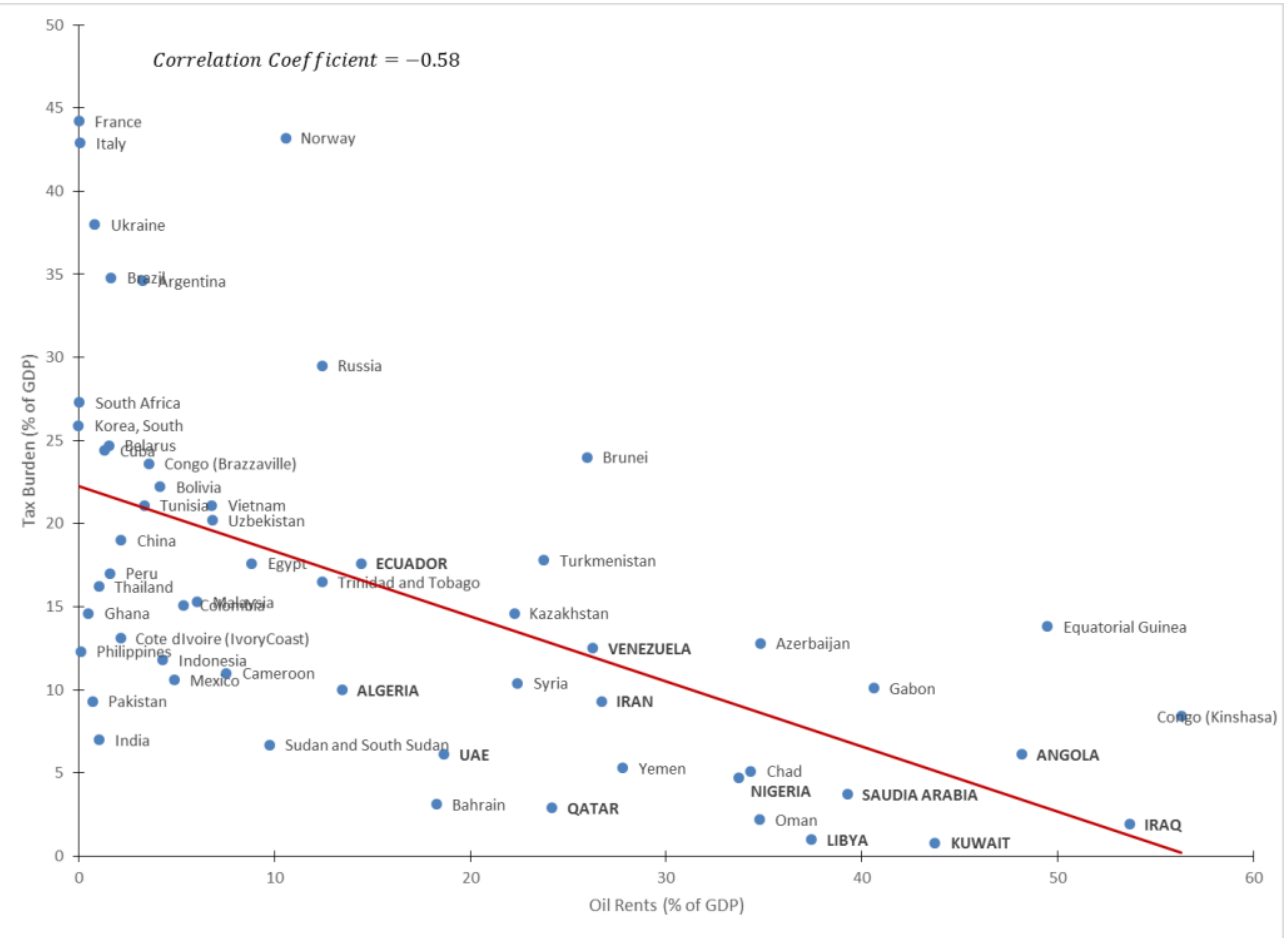


Figure 1e. Oil Rents and Current Account (Non-OPEC, Average 2005-2012)

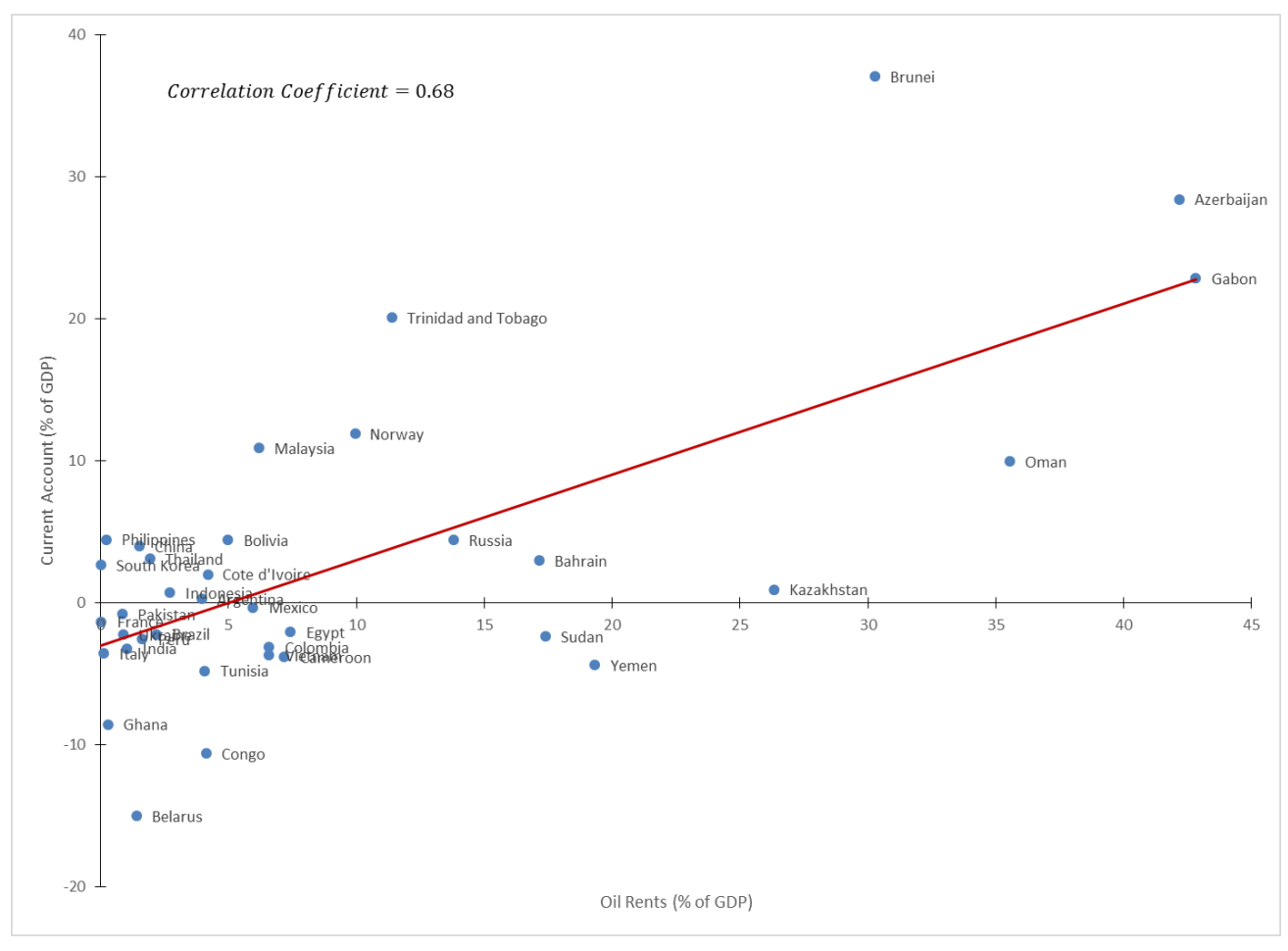

Figure 1f. Oil Rents and Current Account (OPEC and Non-OPEC, Average 20052012)

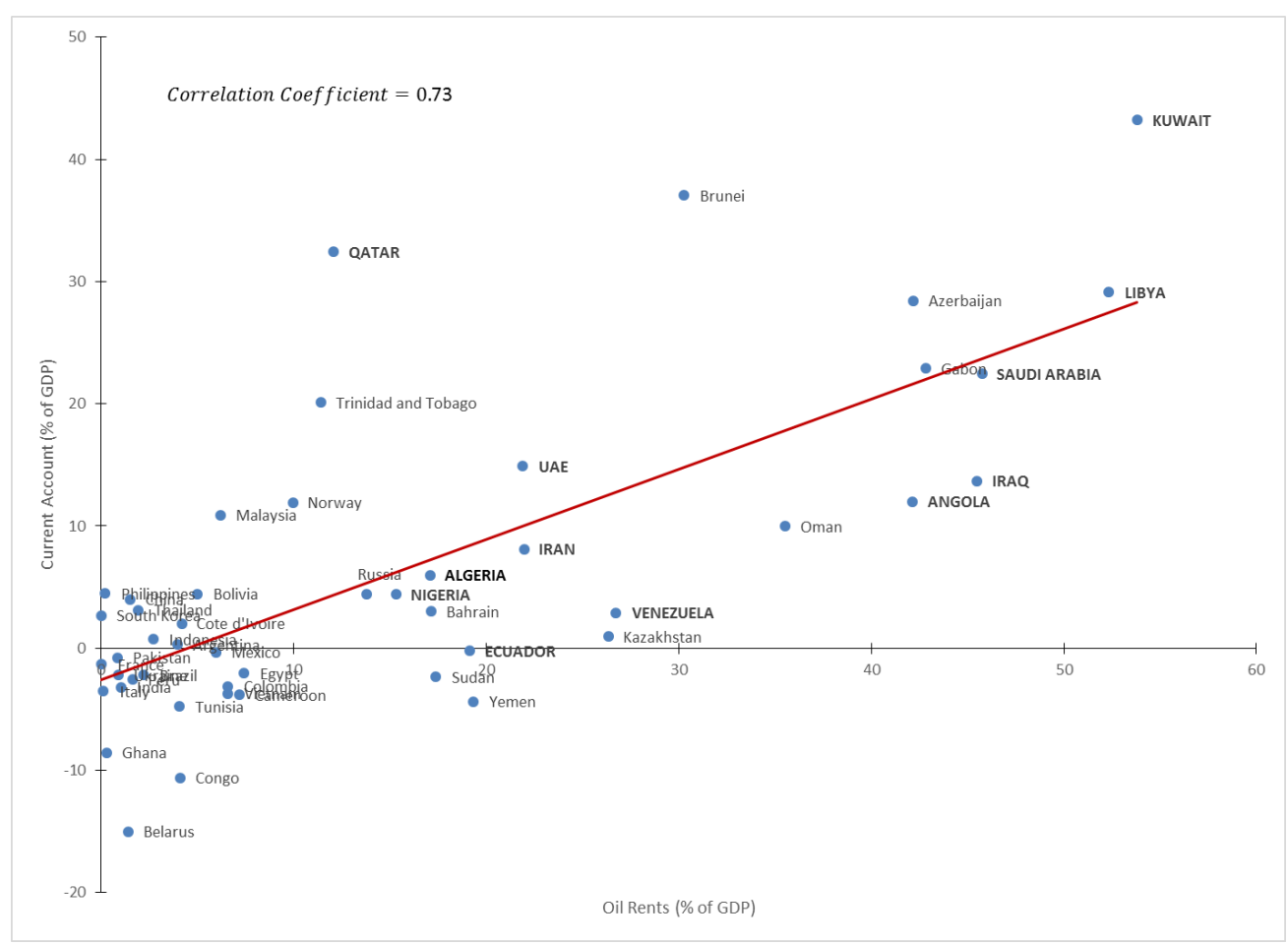


One way to explain these relationships is to examine the role of oil revenue as a source of government financing that impacts the current account through public expenditure and the optimal income tax rate (obtained by maximizing the consumer welfare). I use this approach. The remainder of the paper is organized as follows. The next section provides a brief survey of the literature on oil shocks and current account. Section 3 introduces the model. Section 4 presents the empirical results and section 5 concludes.

\subsection{Review of Literature}

Theoretical and empirical literatures investigating the impact of oil revenue on current account are relevant to my work. The results obtained from both literatures are different and depend, among other factors, on the methodology used and the characteristics of the economy/ies surveyed. In the case of empirical literature, even when most of the studies are mainly based on structural vector autorregresion (in particular, impulse-response functions and variance decomposition), the statistical significance of the current account reaction to oil shocks is determined by the number of countries and years investigated. For example, Chuko et al. (2011) conclude that there is no relationship between oil price shocks and current account for Nigeria (an oil exporting country) during 1970-2008. On the other hand, Allegret et al. (2013) find -on a sample of 27 oil-exporting countries from 1980 to 2010- that current accounts are positively and nonlinear linked to oil price changes.

From the theoretical point of view, models relating oil shocks and current account fall, in general, into one of the following two categories: one-sector open economy models and intertemporal consumption models. In the first category, Schubert (2009) proposes a model only composed by consumers and firms and concludes that oil price positive shocks have two effects on the current account. In the short run, current account deteriorates as private consumption is high given the existence of a "status effect", by which consumers are reluctant to sufficiently reduce their consumption expenditure given a negative wealth impact of an oil price shock. In the long run, as consumption decreases, the current account improves. In the second category, Arbatli (2008) measures the effect of oil shocks on the current account through changes in the marginal propensity to consume. Given that the marginal propensity out of permanent oil shocks is significantly higher than that out of transitory shocks, the study concludes that the current account is more stable when permanent oil shocks occur in the economy.

The most representative empirical and theoretical papers related to my approach are, respectively, Kilian, Rebucci and Spatafora (2009) and the seminal contribution of 
Sachs (1981). Kilian, Rebucci and Spatafora investigate the empirical impact that oil shocks have on the current accounts of oil-exporting and oil-importing countries during 1975-2006. Specifically, the authors study three types of impacts: shocks to the total supply of crude oil ("oil supply shocks"), shocks to the total demand for all industrial commodities including crude oil ("aggregate demand shocks") and shocks to the precautionary demand for oil reflecting expectations about future oil supply shortfalls ("oil specific demand shocks"). Using impulse response functions, the study concludes that the three types of shocks jointly account for $86 \%$ of the variation in the current account corresponding to oil-exporting countries, where the contributions are 12\% (oil supply shocks), $34.4 \%$ (aggregate demand shocks) and $39.3 \%$ (oil specific demand shocks). Given the importance of oil revenue in the determination of the current account, it is reasonable to focus only on the effects that oil revenue has on the current account. In contrast to Kilian, Rebucci and Spatafora, I incorporate a panel econometric specification where oil shocks and tax revenue adjustments are the independent variables explaining changes in the current account.

Sachs (1981) proposes a two-period model of the current account where oil revenue exclusively impacts private saving. Specifically, in the intertemporal budget constraint for consumers, oil revenue is one of the components of the present value of wealth; however, taxes are the only source of the government budget constraint. Therefore, positive shocks on the price and quantity of oil monotonically improve the current account. The model I present is different with respect to his contribution in two aspects. In first place, the current account is ambiguously affected by oil shocks. In second place, oil revenue influences the current account through public saving; in particular, while consumer's endowment is composed only by non-labor income, public expenditure is financed by income taxes and oil revenue.

\subsection{Baseline Model}

\subsubsection{The Consumer's Problem}

Consider an economy where individuals live for two periods: present $(t)$ and future $(t+1)$. In each period, the representative agent derives utility from consuming positive quantities of a private good $c$ and a non-rival public good $g$ that is determined outside the consumer's control. Specifically, the consumer has the following utility function:

$$
U=\log \left(c_{t}\right)+\log \left(g_{t}\right)+\beta\left[\log \left(c_{t+1}\right)+\log \left(g_{t+1}\right)\right],
$$


where $\beta \equiv \frac{1}{1+\delta}$ is the subjective discount factor $(0<\beta<1)$ and $\delta$ is the subjective discount rate $(\delta>0)$. In this setting, $g$ denotes aggregate government purchases of goods and services that provide consumer welfare. The agent faces the following resource constraints:

$$
\begin{gathered}
c_{t}+a_{t}=(1-\tau) y_{1} \\
c_{t+1}=(1+r) a_{t}+(1-\tau) y_{1}
\end{gathered}
$$

where $a$ is private saving, $\tau$ is the income tax rate $(0<\tau<1), y$ is income and $r$ is the interest rate. For simplicity, the consumer takes $\tau, y$ and $r$ as given. The agent chooses the sequence of present and future consumption $\left\{c_{t}, c_{t+1}\right\}$ that maximizes (3.1) subject to (3.2) and (3.3). Formally,

$$
\begin{gathered}
\max _{\left\{c_{t}, c_{t+1}\right\}} U=\log \left(c_{t}\right)+\log \left(g_{t}\right)+\beta\left[\log \left(c_{t+1}\right)+\log \left(g_{t+1}\right)\right], \\
\text { s.t. } \quad c_{t}+\frac{c_{t+1}}{1+r}=(1-\tau) y+\frac{(1-\tau) y}{1+r}
\end{gathered}
$$

The solution of the consumer's problem is given by:

$$
\begin{gathered}
c_{t}^{*}=\left(\frac{1+\delta}{2+\delta}\right)\left(\frac{2+r}{1+r}\right)(1-\tau) y, \\
c_{t+1}^{*}=\left(\frac{2+r}{2+\delta}\right)(1-\tau) y .
\end{gathered}
$$

\subsubsection{The Government's Problem}

Government finances its public expenditure by collecting income taxes, issuing debt and exporting oil. Let $b_{t}$ be the quantity of government bonds issued in period $t$, and $s_{t}, s_{t+1}$ be current and future oil revenue. Formally, the government faces the following budget constraints:

$$
\begin{gathered}
g_{t}=\tau y+b_{t}+s_{t} \\
g_{t+1}+(1+r) b_{t}=\tau y+E\left(s_{t+1}\right)
\end{gathered}
$$


where $E\left(s_{t+1}\right)$ is the expected value of future oil revenue. After combining equations (3.7) and (3.8), the intertemporal budget constraint is:

$$
g_{t}+\frac{g_{t+1}}{1+r}=\tau y+s_{t}+\frac{\tau y+E\left(s_{t+1}\right)}{1+r}
$$

Suppose public spending changes at growth rate $\alpha-1$ from time $t$ to time $t+1$. In other words, $g_{t+1}=\alpha g_{t}$, where $\alpha$ is controled by the government according to its objectives of fiscal policy ( $\alpha>0$ ). Finally, assume that the government's objective is to impose the tax rate and the growth of public expenditure that maximize the utility function (1), taken as given the consumer's optimal sequence $\left\{c_{t}^{*}, c_{t+1}^{*}\right\}$, the parameters $\beta$ and $\delta$, and the economic variables $r, y, s_{t}, E\left(s_{t+1}\right)$. Formally,

$$
\begin{gathered}
\max _{\{\tau, \alpha\}} \quad U=(1+\beta)\left\{\log \left[\left(\frac{2+r}{2+\delta}\right)(1-\tau) y\right]+\log \left(g_{t}\right)\right\}+\log \left[\left(\frac{1+\delta}{1+r}\right) \alpha^{\beta}\right], \\
\text { s.t. } \quad g_{t}=\left(\frac{2+r}{1+\alpha+r}\right) \tau y+\left(\frac{1+r}{1+\alpha+r}\right)\left(s_{t}+\frac{E\left(s_{t+1}\right)}{1+r}\right) .
\end{gathered}
$$

The optimal rates $\tau^{*}$ and $\alpha^{*}$ are given by:

$$
\begin{gathered}
\tau^{*}=\frac{1}{2}-\frac{1}{2 y}\left(\frac{1+r}{2+r}\right)\left(s_{t}+\frac{E\left(s_{t+1}\right)}{1+r}\right), \\
\alpha^{*}=\beta(1+r)=\frac{1+r}{1+\delta}
\end{gathered}
$$

Suppose that: (i) oil revenue at time $t+1$ is uncertain but a particular realization of oil revenue at time $t$ is known to the economy, and (ii) $s_{t+1}$ evolves according to the following $\operatorname{AR}(1)$ process:

$$
s_{t+1}=\rho s_{t}+\varepsilon_{t+1}
$$


where $\rho$ is the serial correlation coefficient between $s_{t+1}$ and $s_{t}$, and $\varepsilon_{t+1}$ is a white noise process satisfying $E\left(\varepsilon_{t+1} \mid s_{t}\right)=0$. In this case, $E\left(s_{t+1} \mid s_{t}\right)=\rho s_{t}$. Given these assumptions, the optimal tax rate $(3.11 a)$ is now:

$$
\tau^{*}=\frac{1}{2}-\frac{1}{2}\left(\frac{1+r+\rho}{2+r}\right) \frac{s_{t}}{y}
$$

By plugging (3.11b) and (3.13) into the government budget constraint, the optimal public expenditure (as a fraction of income) is given by:

$$
\frac{g^{*}}{y}=\frac{(2+r)(1+\delta)}{2(1+r)(2+\delta)}+\frac{(1+r+\rho)(1+\delta)}{2(1+r)(2+\delta)} \frac{s_{t}}{y}
$$

According to equations (3.13) and (3.14), the optimal tax rate and public expenditure are -respectively- decreasing and increasing in the expected present value of oil revenue. Intuitively, an increase in expected oil revenue allows the government to finance a particular level of public expenditure with lower taxes. As the tax base is assumed constant in the model, this implies a lower tax rate. In the same sense, by definition of the government budget constraint, a higher level of expected oil revenue is able to finance additional public expenditure given a specific tax rate.

\subsubsection{Current Account}

Given the equilibrium values of consumption and the optimal values of income tax rate and public expenditure, it is possible to compute the optimal current account in the first period $c a_{t}^{*}$ as the sum of private saving $a_{t}^{*}$ and public saving $-b_{t}^{*}$ :

$$
c a_{t}^{*}=a_{t}^{*}-b_{t}^{*}=\left[\left(1-\tau^{*}\right) y-c_{t}^{*}\right]-\left[g^{*}-\tau^{*} y-s_{t}\right]
$$

where:

$$
\frac{a_{t}^{*}}{y}=\left[\frac{r-\delta}{2(1+r)(2+\delta)}\right]+\left[\frac{(r-\delta)(1+r+\rho)}{2(1+r)(2+r)(2+\delta)}\right] \frac{s_{t}}{y}
$$




$$
-\frac{b_{t}^{*}}{y}=\frac{r-\delta}{2(1+r)(2+\delta)}+\left\{\frac{4+(1+r) \delta+(5+r) r-[4+(3+2 r) \delta+3 r] \rho}{2(1+r)(2+r)(2+\delta)}\right\} \frac{s_{t}}{y} .
$$

After substituting (3.16)-(3.17) into (3.15), the optimal current account is given by

$$
\begin{gathered}
\frac{c a_{t}^{*}}{y}=\frac{r-\delta}{(1+r)(2+\delta)}+ \\
\left\{\frac{(r-\delta)(1+r+\rho)+4+(1+r) \delta+(5+r) r-[4+(3+2 r) \delta+3 r] \rho}{2(1+r)(2+r)(2+\delta)}\right\} \frac{s_{t}}{y} .
\end{gathered}
$$

According to equation (3.18), oil revenue affects linearly the current account. However, the magnitude and sign of the impact will depend on the difference between the interest rate and the subjective discount rate. In the following lines, I describe two cases that result from the interaction between the three factors.

\subsubsection{Case 1. Permanent oil boom $\left(\rho=1 ; E\left(s_{t+1} \mid s_{t}\right)=s_{t}\right)$.}

This corresponds to the case where present and future oil revenue are perfectly correlated. Therefore, the best prediction of $s$ for next period is its current value. In this case, equation (3.18) becomes:

$$
\frac{c a_{t}^{*}}{y}=\frac{r-\delta}{(1+r)(2+\delta)}+\frac{(r-\delta)}{(1+r)(2+\delta)} \frac{s_{t}}{y} .
$$

In this setting, an oil boom has a positive impact on the current account if the interest rate is higher than the subjective discount rate $(r-\delta>0)$. Intuitively, when the consumer has a low time preference (a decrease in the relative valuation on present consumption), then the current account improves with the windfall gain. On the other hand, observe that the "natural resource curse" happens when $r<\delta$. If the economy experiences abundance of oil revenue but the individual is highly impatient, then an oil boom deteriorates the current account. In sum, the current account will be increasing or decreasing on oil revenue depending on the consumer time preferences. 


\subsubsection{Case 2. Temporary oil boom $\left(\rho=0 ; E\left(s_{t+1} \mid s_{t}\right)=0\right)$.}

When $\rho=0$, the future value of oil revenue is not influenced by its current value. This is, there is no temporal dependence in oil revenue. In this case, equation (3.18) becomes:

$$
\frac{c a_{t}^{*}}{y}=\frac{r-\delta}{(1+r)(2+\delta)}+\frac{1}{(2+\delta)} \frac{s_{t}}{y} .
$$

In contrast to a permanent oil boom, a temporary oil boom has an unambiguous positive effect on the current account even if $r<\delta$. Intuitively, if the government expects a temporary oil boom, the magnitudes of changes in the tax rate and public expenditure are lower relative to the changes resulting from a permanent oil boom. As a result, public saving increases and the current account improves.

\subsubsection{Comparing Case I and Case II}

In order to contrast the effect of a permanent or temporary oil boom on the current account, I compute -in both cases- the sensitivities of tax rate, government expenditure, public saving and private saving with respect to oil revenue. Formally, from equations (13), (14), (16) and (17), I obtain:

$$
\begin{gathered}
\left.\frac{\partial \tau^{*}}{\partial\left(\frac{s_{t}}{y}\right)}\right|_{\rho=1}=-\frac{1}{2}<-\frac{1}{2}\left(\frac{1+r}{2+r}\right)=\left.\frac{\partial \tau^{*}}{\partial\left(\frac{s_{t}}{y}\right)}\right|_{\rho=0} \\
\left.\frac{\partial\left(\frac{g^{*}}{y}\right)}{\partial\left(\frac{s_{t}}{y}\right)}\right|_{\rho=1}=\frac{1}{2}\left(\frac{2+r}{1+r}\right)\left(\frac{1+\delta}{2+\delta}\right)>\frac{1}{2}\left(\frac{1+\delta}{2+\delta}\right)=\left.\frac{\partial\left(\frac{g^{*}}{y}\right)}{\partial\left(\frac{s_{t}}{y}\right)}\right|_{\rho=0} \\
-\frac{\left.\partial\left(\frac{b_{t}^{*}}{y}\right)\right|_{\rho\left(\frac{s_{t}}{y}\right)}=\frac{r-\delta}{2(1+r)(2+\delta)}<\frac{4+(1+r) \delta+(5+r) r}{2(1+r)(2+r)(2+\delta)}=-\left.\frac{\partial\left(\frac{b_{t}^{*}}{y}\right)}{\partial\left(\frac{s_{t}}{y}\right)}\right|_{\rho=0}}{}
\end{gathered}
$$




$$
\left.\frac{\partial\left(\frac{a_{t}^{*}}{y}\right)}{\partial\left(\frac{S_{t}}{y}\right)}\right|_{\rho=1}=\frac{r-\delta}{2(2+\delta)(1+r)}>\frac{r-\delta}{2(2+\delta)(2+r)}=\left.\frac{\partial\left(\frac{a_{t}^{*}}{y}\right)}{\partial\left(\frac{s_{t}}{y}\right)}\right|_{\rho=0}
$$

According to equations (3.21)-(3.24), the adjustments of $\tau^{*}, g^{*}, b_{t}^{*}$ and $a_{t}^{*}$ for a permanent oil boom are larger than for a transitory boom. In particular, given a permanent increase in oil revenue the government: (i) has more incentives to substitute oil revenue for taxes to finance public expenditure and (ii) is able to finance more public spending. On one hand, the reduced tax rate implies an increase in consumption and private saving. On the other hand, if the increase in government expenditure is larger than the oil boom, public saving will decline. These two opposite effects on saving lead to a modest improvement in the current account under a permanent oil boom, in comparison to the effect of a temporary boom. Observe that this result is valid for any growth rate of public spending, subjective discount rate and interest rate. Figures $3 a$ and $3 b$ show the diagrams related to equations (19) and (20) for given values of $\alpha, \delta$, and $r$.

Figure 3a. Oil Revenue and Current Account $(r>\delta)$

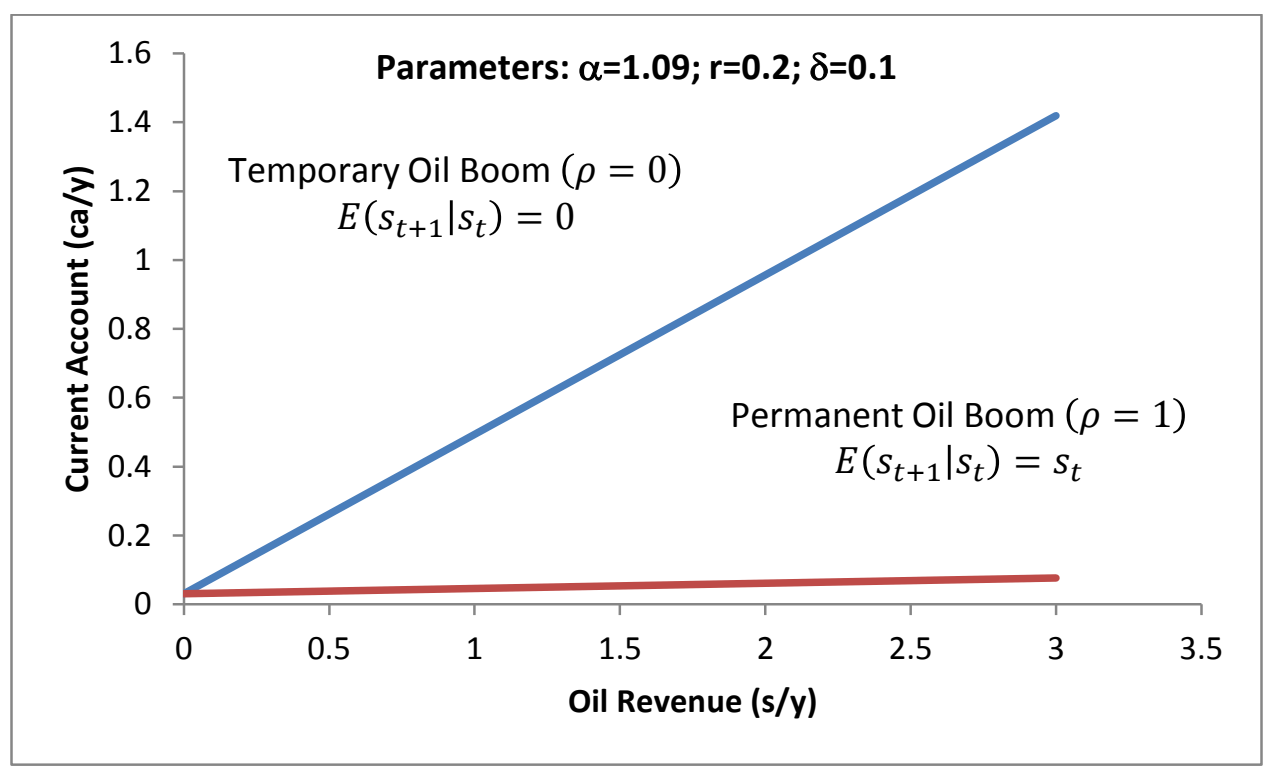


Figure 3b. Oil Revenue and Current Account $(\alpha<1 ; r<\delta)$

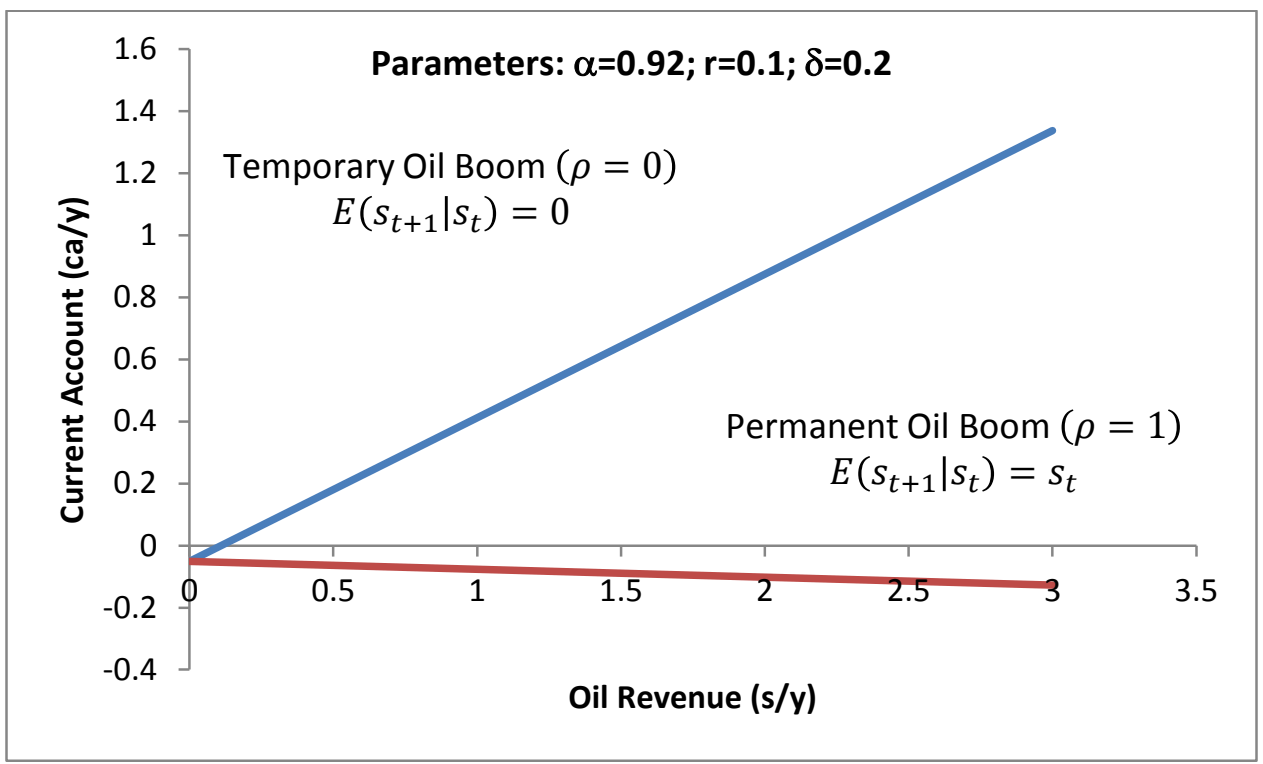

\subsection{Model with Political Groups}

\subsubsection{The Consumer's Problem}

Assume that the government transfers resources to $m$ political groups, where $m \geq 1$. Let $\theta=\frac{\tau}{m}$ represent the extraction rate of consumer's income transferred to powerful political groups in the economy. The rate of extraction is directly proportional to the income tax rate and inversely proportional to the number of groups. Intuitively, the higher is the tax rate, the more incentives have the political groups to demand more resources from the government. On the contrary, an increase in the number of political groups erodes their power concentration and, therefore, reduces their redistributional effect.

Given this information, the consumer solves the following problem:

$$
\begin{gathered}
\max _{\left\{c_{t}, c_{t+1}\right\}} \quad U=\log \left(c_{t}\right)+\log \left(g_{t}\right)+\beta\left[\log \left(c_{t+1}\right)+\log \left(g_{t+1}\right)\right] \\
\text { s.t. } \quad c_{t}+\frac{c_{t+1}}{1+r}=(1-\tau-\theta) y+\frac{(1-\tau-\theta) y}{1+r},
\end{gathered}
$$

where I impose $0<\tau+\theta<1$ and the consumer takes $\theta$ as given. The solution of the consumer's problem is given by: 


$$
\begin{gathered}
c_{t}^{*}=\left(\frac{1+\delta}{2+\delta}\right)\left(\frac{2+r}{1+r}\right)(1-\tau-\theta) y, \\
c_{t+1}^{*}=\left(\frac{2+r}{2+\delta}\right)(1-\tau-\theta) y .
\end{gathered}
$$

\subsubsection{The Government's Problem}

As explained in the section 3.2, the government's objective is to impose the tax rate and the growth of public expenditure that maximizes the consumer's utility function. Additionally, now suppose the government knows that the extraction rate is a direct function of the tax rate but it does not have any influence on the number of political groups in the economy. Therefore, the government solves the following problem:

$$
\begin{gathered}
\max _{\{\alpha, \tau\}} U=(1+\beta)\left\{\log \left[\left(\frac{2+r}{2+\delta}\right)\left(1-\tau-\frac{\tau}{m}\right) y\right]+\log \left(g_{t}\right)\right\}+\log \left[\left(\frac{1+\delta}{1+r}\right) \alpha^{\beta}\right], \\
\text { s.t. } g_{t}=\left(\frac{2+r}{1+\alpha+r}\right) \tau y+\left(\frac{1+r+\rho}{1+\alpha+r}\right) s_{t} .
\end{gathered}
$$

The optimal values of tax rate $\tau^{*}$, growth rate of government spending $\alpha^{*}-1$, public expenditure $g^{*}$ and extraction rate $\theta^{*}$ are given by:

$$
\begin{gathered}
\tau^{*}=\frac{m}{2(1+m)}-\frac{1}{2}\left(\frac{1+r+\rho}{2+r}\right) \frac{s_{t}}{y}, \\
\alpha^{*}-1=\frac{r-\delta}{1+\delta} \\
\frac{g^{*}}{y}=\frac{(2+r)(1+\delta)}{2(1+r)(2+\delta)}\left(\frac{m}{1+m}\right)+\frac{(1+r+\rho)(1+\delta)}{2(1+r)(2+\delta)} \frac{s_{t}}{y},
\end{gathered}
$$




$$
\theta^{*}=\frac{1}{2(1+m)}-\frac{1}{2 m}\left(\frac{1+r+\rho}{2+r}\right) \frac{s_{t}}{y} .
$$

Equation (4.6) indicates that government spending is increasing in oil revenue,

where the sensitivity $\frac{\partial g^{*}}{\partial s_{t}}$ is larger under the presence of a permanent oil boom $(\rho=1)$. Also, the number of political groups has a positive impact on public expenditure, regardless of the amount of oil revenue. Let $\beta^{*} \equiv \tau^{*}+\theta^{*}$ be the tax burden imposed by government to consumer. This is, the tax burden is sum of the tax rate (using to finance public expenditure) and the extraction rate (transferred to the political groups). From equations (4.6) and (4.7), this is equal to:

$$
\beta^{*}=\frac{1}{2}-\frac{1}{2}\left(\frac{1+m}{m}\right)\left(\frac{1+r+\rho}{2+r}\right) \frac{s_{t}}{y},
$$

Given equation (4.8), I propose the first result:

Result 1. Tax burden is increasing in the number of political groups and decreasing in oil revenue.

Observe that:

$$
\begin{gathered}
\frac{\partial \beta^{*}}{\partial m}=\left(\frac{1+r+\rho}{2+r}\right) \frac{s_{t}}{2 y m^{2}}>0, \\
\frac{\partial \beta^{*}}{\partial s_{t}}=-\frac{1}{2 y}\left(\frac{1+m}{m}\right)\left(\frac{1+r+\rho}{2+r}\right)<0 .
\end{gathered}
$$

Intuitively, the larger is the number of groups competing on resources, the lower is the amount they are able to take and the extraction rate decreases. Therefore, the government has incentives to charge a higher tax rate. As this happens, the groups will demand a higher extraction rate. Formally, $m$ has an ambiguous effect on $\theta^{*}$ (equation (4.7)) and a positive effect on $\tau^{*}$ (equation (4.5)). Given the functional forms specified in both equations, the net effect is a positive impact on $\beta^{*}$. 
Finally, as previously indicated, an oil boom allows the government to substitute taxes with oil revenue as a source to finance public spending. Therefore, by imposing a lower tax rate (equation (4.5)), political groups are only able to demand a lower extraction rate (equation (4.7)). Formally, $s_{t}$ has a negative effect on $\beta^{*}$. See Figures $4 \mathrm{a}$ and $4 \mathrm{~b}$.

Figure 4a. Political Groups and Tax Burden

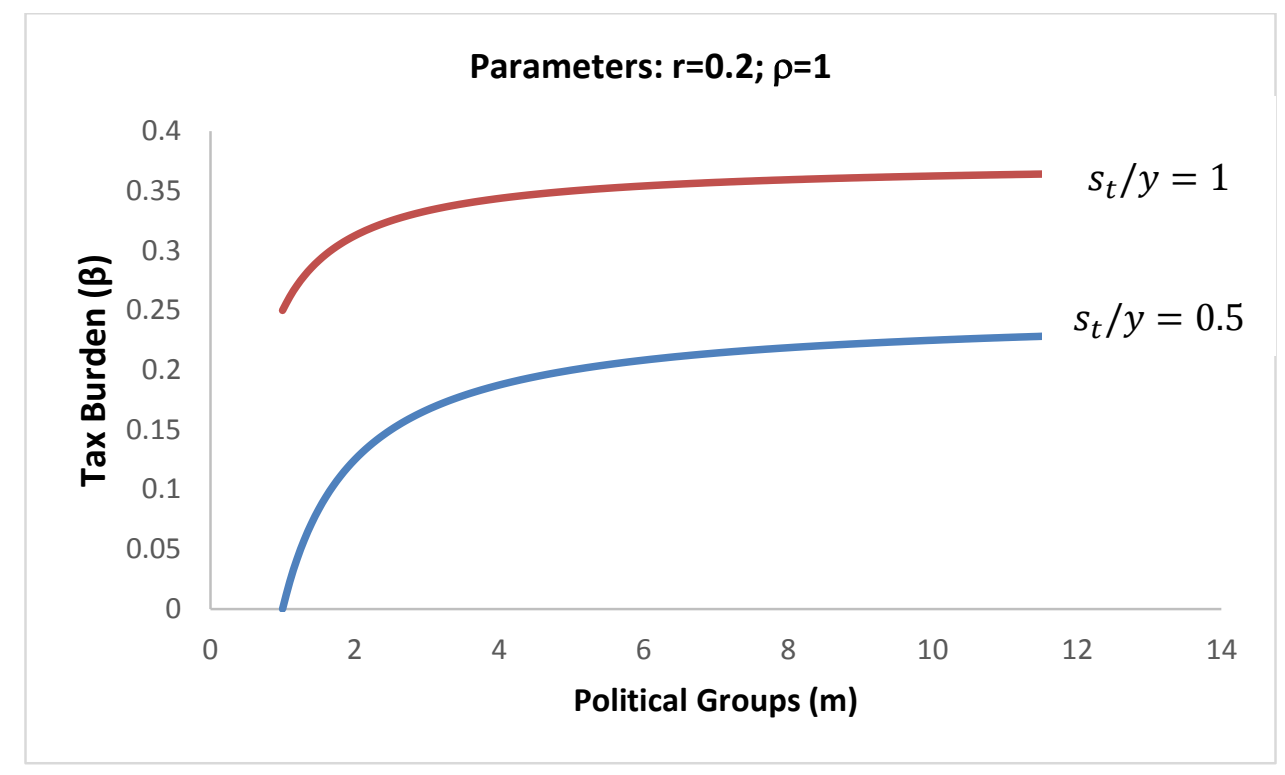

Figure 4b. Oil Revenue and Tax Burden

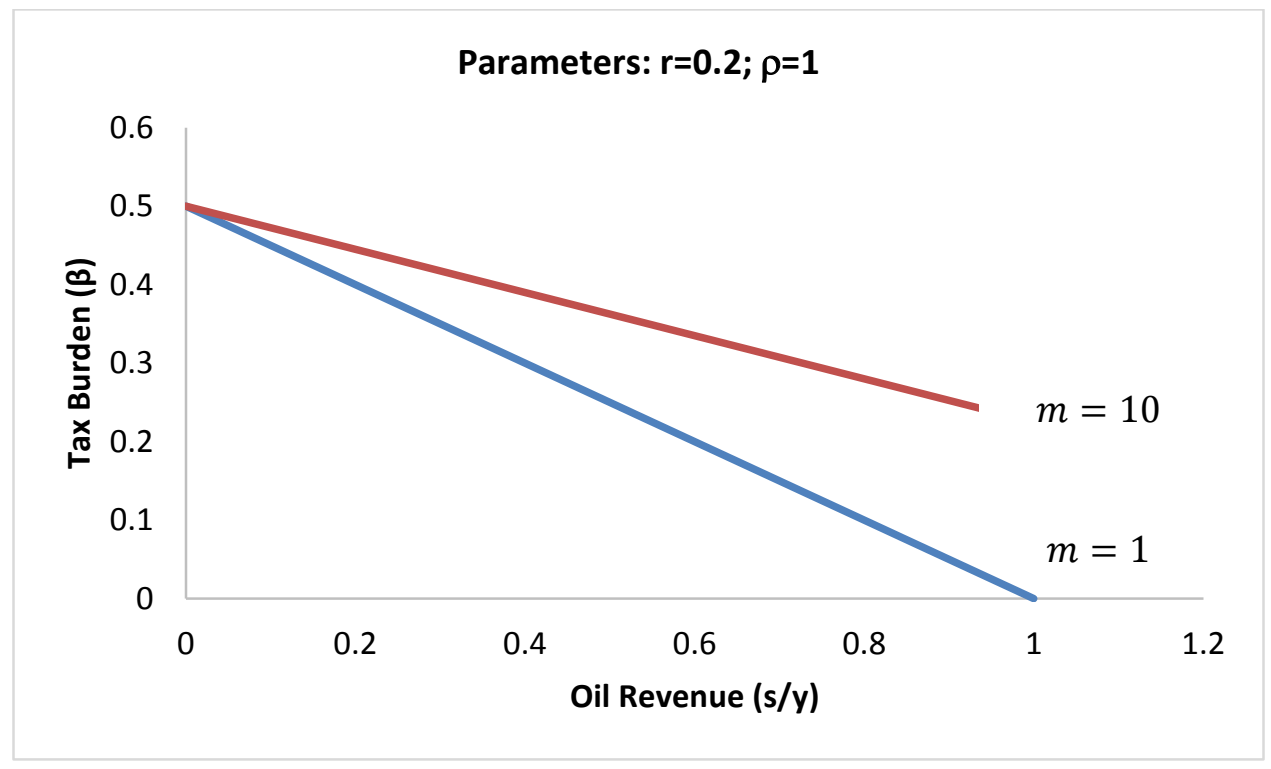




\subsubsection{Current Account with Uncoordinated Political Groups}

Following the same steps as in the section 3.3 (plugging the equilibrium values of consumption (equations (4.2) and (4.3)) and the optimal values of income tax rate, public expenditure and extraction rate into the definitions of private saving and public saving), the current account is expressed as:

$$
\begin{gathered}
\frac{c a_{t}^{*}}{y}=\frac{(r-\delta)}{(1+r)(2+\delta)}\left(\frac{1+2 m}{2+2 m}\right)+ \\
\left\{\frac{\left(\frac{1+m}{m}\right)(r-\delta)(1+r+\rho)+4+(1+r) \delta+(5+r) r-[4+(3+2 r) \delta+3 r] \rho}{2(1+r)(2+r)(2+\delta)}\right\} \frac{s_{t}}{y},
\end{gathered}
$$

where:

$$
\begin{gathered}
\frac{a_{t}^{*}}{y}=\left[\frac{r-\delta}{2(2+\delta)(1+r)}\right]+\left[\frac{(1+m)(r-\delta)(1+r+\rho)}{2 m(2+\delta)(1+r)(2+r)}\right] \frac{s_{t}}{y}, \\
-\frac{b_{t}^{*}}{y}=\frac{m(r-\delta)}{2(m+1)(1+r)(2+\delta)}+\left\{\frac{4+(1+r) \delta+(5+r) r-[4+(3+2 r) \delta+3 r] \rho}{2(1+r)(2+r)(2+\delta)}\right\} \frac{s_{t}}{y} .
\end{gathered}
$$

From equation (4.11), I propose the second result:

Result 2. The current account is increasing in oil revenue and decreasing in the number of political groups.

Formally, in the cases $\rho=1$ and $\rho=0$, I obtain:

$$
\left.\frac{\partial\left(\frac{c a_{t}^{*}}{y}\right)}{\partial\left(\frac{s_{t}}{y}\right)}\right|_{\rho=1}=\frac{r-\delta}{2 m(2+\delta)(1+r)}+\frac{r-\delta}{(2+\delta)(1+r)}>0
$$




$$
\begin{aligned}
& \left.\frac{\partial\left(\frac{c a_{t}^{*}}{y}\right)}{\partial\left(\frac{s_{t}}{y}\right)}\right|_{\rho=0}=\frac{r-\delta}{2 m(2+\delta)(2+r)}+\frac{1}{2+\delta}>0, \\
& \left.\frac{\partial\left(\frac{c a_{t}^{*}}{y}\right)}{\partial m}\right|_{\rho=1}=\frac{(r-\delta)}{2(2+\delta)(1+r)}\left[\frac{1}{(1+m)^{2}}-\frac{1}{m^{2}} \frac{s_{t}}{y}\right]<0 \\
& \left.\frac{\partial\left(\frac{c a_{t}^{*}}{y}\right)}{\partial m}\right|_{\rho=0}=\frac{(r-\delta)}{2(2+\delta)}\left[\frac{1}{(1+r)(1+m)^{2}}-\frac{1}{(2+r) m^{2}} \frac{s_{t}}{y}\right]<0
\end{aligned}
$$

when oil revenue is sufficiently high and $r>\delta$. Observe that the first term on the right hand side of the equations (4.14a) and (4.14b) represents the effect of the number of political groups on public saving and the second term indicates the impact of political groups on private saving. Intuitively, as indicated previously, additional political groups reduce the extraction rate and allows the government to impose a higher tax rate, which reduces disposable income and private saving. Similarly, the higher tax rate increases current government spending, which reduces public saving. Both effects reduce the current account.

By comparing equations (4.14a) and (4.14b), it is easy to see that a temporary oil boom has a larger positive impact on the current account. Intuitively, an increase in $\mathrm{m}$ reduces the extraction rate and increases the tax rate. If the oil boom is temporary, $\tau^{*}$ will have to be high enough to finance -as the only source- government spending. The increase in $\tau^{*}$ reduces private consumption and improves significantly the current account. On the other hand, given a permanent oil boom, income taxes are substituted by oil rents as a source financing public expenditure. As $\tau^{*}$ does not increase, private consumption remains high and the current account does not improve.

Figure 4c shows the current account as a function of oil revenue. Observe that: (i) an increase in the number of political groups deteriorates the current account and (ii) the 
baseline model corresponds to the case when there is a very large number of political groups (the extreme case of perfect competition in the political market).

Figure 4d. Oil Revenue, Uncoordinated Political Groups and Current Account

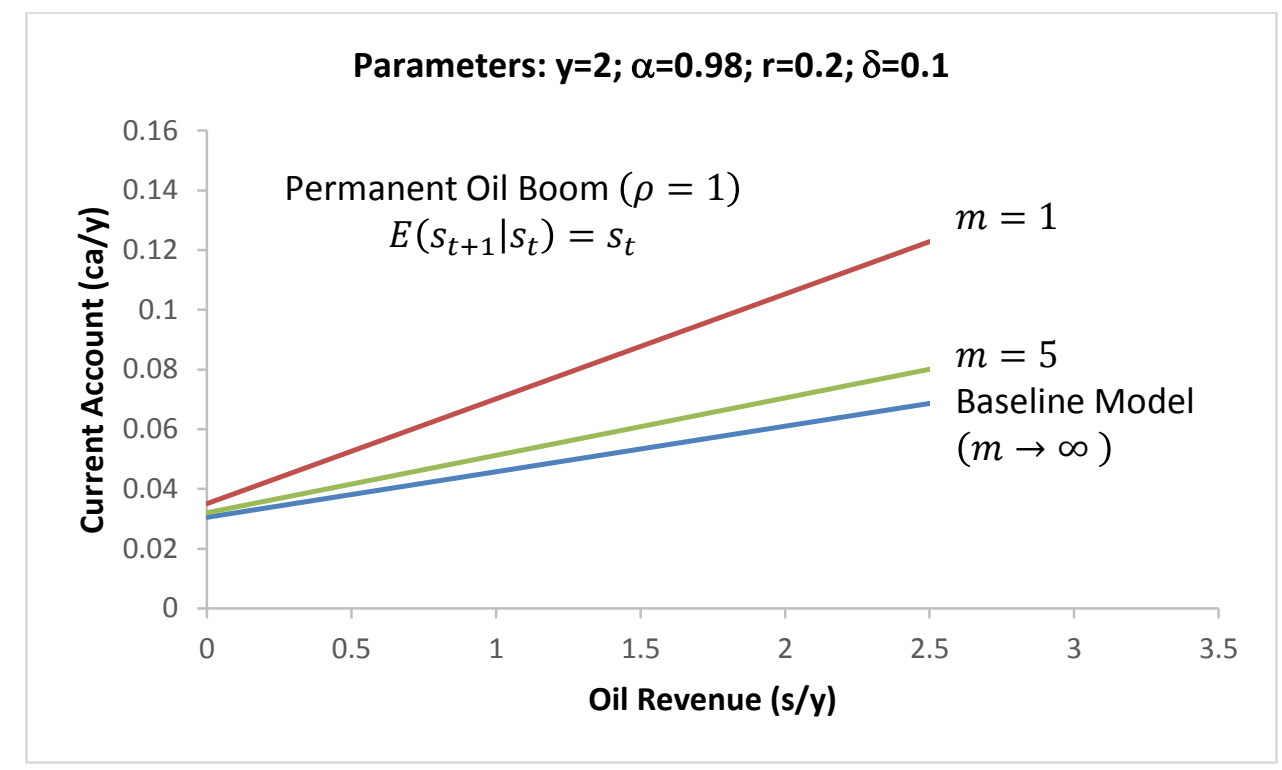

\subsubsection{Current Account with Coordinated Political Groups}

As previously stated, as the number of political groups increases, there are two opposing effects. On one hand, each group can extract a smaller government transfer. On the other hand, a lower extraction rate allows the government to impose a higher tax rate and this encourages groups to demand a higher extraction rate. Therefore, there exists a value of $m^{*}$ that maximizes $\theta^{*}$. Suppose political groups are able to coordinate and decide how many of them will be in the economy. Formally, the political groups agree to solve the following problem:

$$
\max _{\{m\}} \quad \theta^{*}(m)=\frac{1}{2(1+m)}-\frac{1}{2 m y}\left(\frac{1+r+\rho}{2+r}\right) s_{t},
$$

where the political groups take $s_{t}, r, \rho, y$ as given. The value of $m$ that maximizes $\theta^{*}(m)$ is given by: 


$$
m^{*}=\frac{\sqrt{\left(\frac{1+r+\rho}{2+r}\right) \frac{s_{t}}{y}}}{1-\sqrt{\left(\frac{1+r+\rho}{2+r}\right) \frac{s_{t}}{y}}}
$$

where $m^{*}$ is a maximum point and $m^{*} \geq 1$ implies $\frac{1}{4} \leq \frac{s_{t}}{y}\left(\frac{1+r+\rho}{2+r}\right)<1$. Observe that the optimal number of political groups is increasing in oil revenue. That is, an oil boom leads to a reduction in the tax rate as a source to finance public expenditure. In order to increase the tax rate again, more political groups will be created because this decreases the extraction rate and encourages government to raise the tax rate. See Figure $4 \mathrm{~d}$.

Figure 4d. Extraction Rate and Coordinated Political Groups

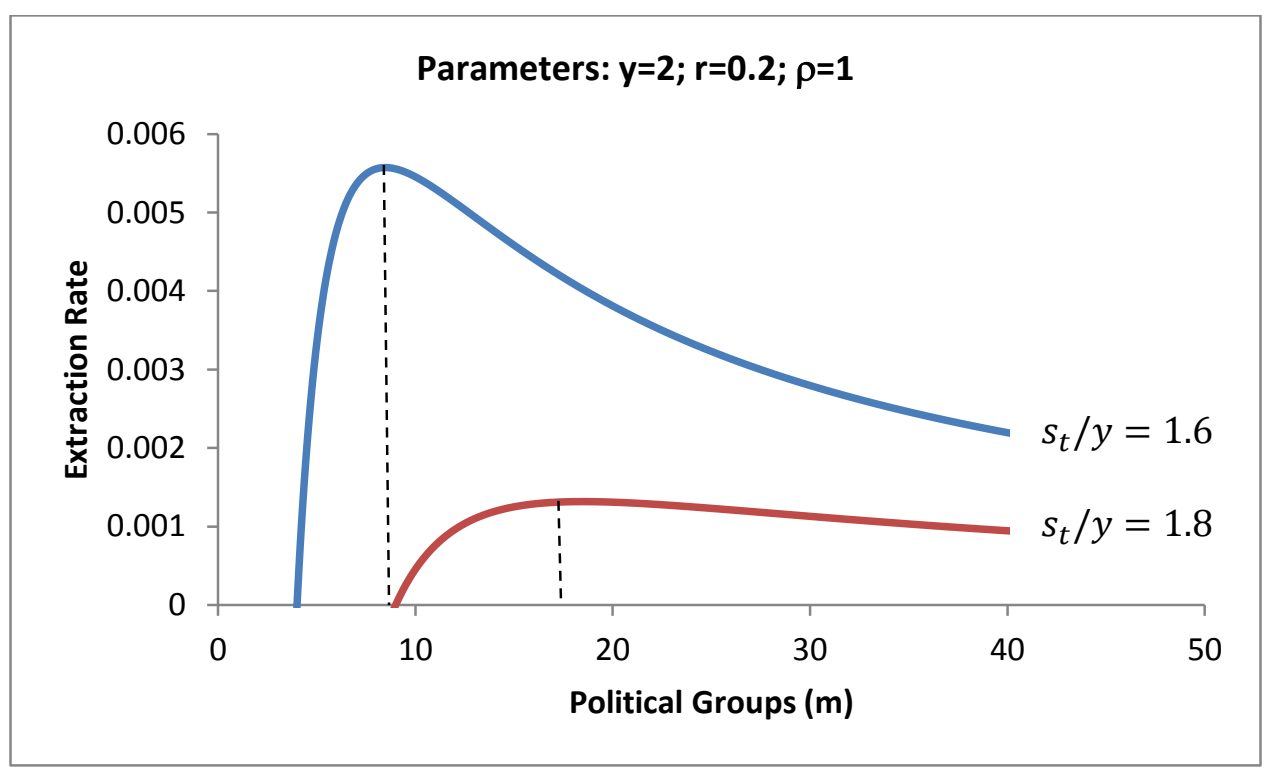

By substituting equation (4.16) into equation (4.11), the current account in the presence of coordinated political groups is:

$$
\begin{aligned}
\frac{c a_{t}^{*}}{y}= & \frac{r-\delta}{2(2+\delta)(1+r)}+\frac{r-\delta}{2(2+\delta)(1+r)}\left[\sqrt{\frac{1+r+\rho}{2+r}}+\frac{1+r+\rho}{2+r}\right] \sqrt{\frac{s_{t}}{y}} \\
& +\left\{\frac{4+(1+r) \delta+(5+r) r-[4+(3+2 r) \delta+3 r] \rho}{2(1+r)(2+r)(2+\delta)}\right\} \frac{s_{t}}{y}
\end{aligned}
$$


According to equation (4.17), if consumer is impatient $(r<\delta)$ the current account is a non-monotonic function of oil revenue when. Initially, when oil revenue is low and there is an oil boom, the number of political groups increases and their extraction rate of resources decreases. In the end, the higher levels of consumption and public expenditure deteriorate the current account. I define this process as the voracity effect. ${ }^{2}$ Eventually, when oil revenue is high and there is an oil boom, the voracity effect is dominated by the direct increase in public saving (via oil revenue) and the current account improves. I define this result as the windfall effect. Depending on which effect dominates, the current account will improve or not. See Figure $4 \mathrm{e}$.

Figure 4e. Oil Revenue, Coordinated Political Groups and Current Account

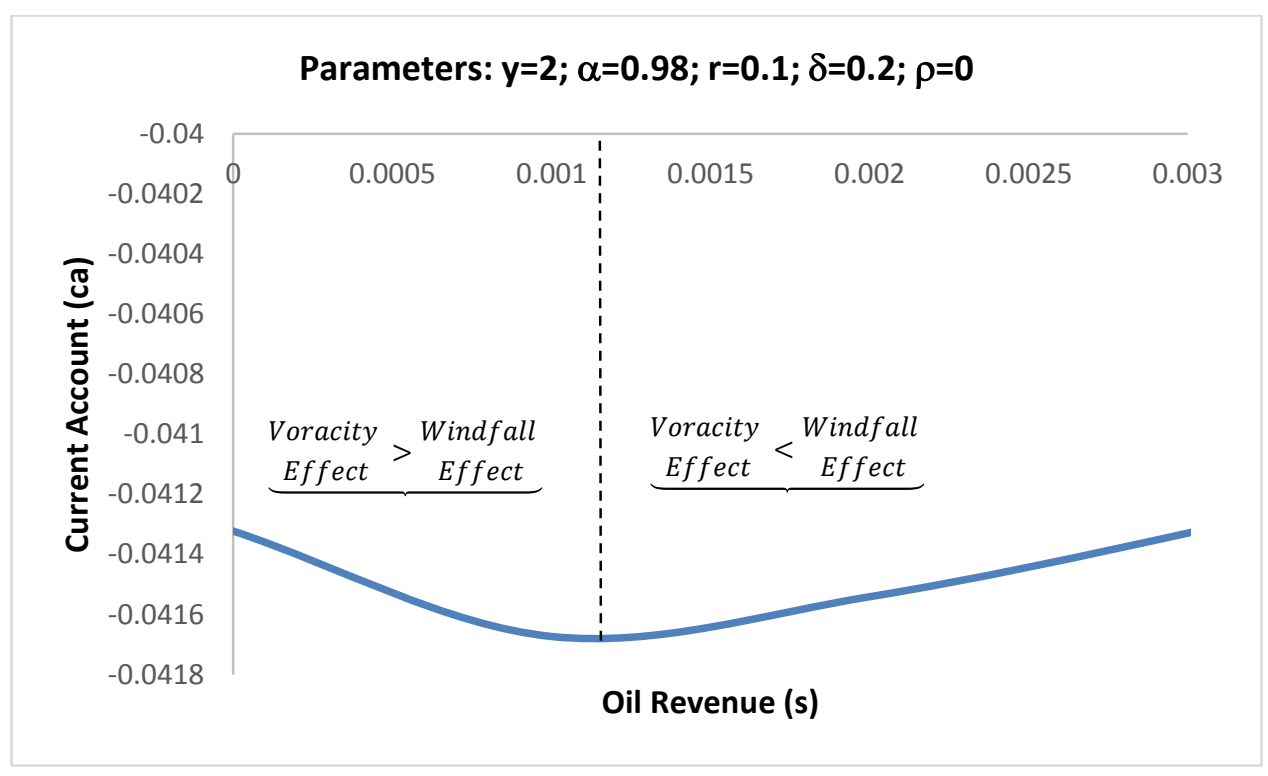

\subsection{Empirical Evidence}

In this section I test the two results of the model using a sample of oil-exporting countries whose governments own oil companies. I divide the sample into two groups of countries: OPEC and non-OPEC. Annual data is provided by the World Bank for the period 2005-2012. I divide the analysis in two parts. In the first part, I provide a descriptive analysis using tables and charts that show the relationship between oil rents, tax revenue, current account and six different components of public expenditure. In the second part, I

\footnotetext{
${ }^{2}$ This term was introduced by Lane and Tornell (1996). In general, the voracity effect arises when a positive shock perversely reduces economic growth through more-than-proportionate fiscal redistribution.
} 
provide an econometric analysis of the impact of oil rent and tax revenue on current account for each subsample of countries.

\subsubsection{Descriptive Statistics}

Currently, there are 56 countries where state-controlled oil companies are located: 12 are OPEC and 44 are non-OPEC. A complete list of all the countries and their respective oil companies are given in the Appendix. I use the following nine economic variables (each expressed as percentage of GDP): oil revenue which is defined as the difference between the value of crude oil production at world prices and total costs of production, current account, tax revenue including tax rates and ability to pay them (for example, compliance costs and the number of tax payments), and six different categories of public expenditure. Under the economic classification, I use public investment as an indicator of capital expenditure and public wages as an indicator of current expenditure. Under the functional classification, I use education expenditure, health expenditure and defense expenditure. Also, I use transfer expenditure as subsidies from the central government to the provincial governments. Finally, I include the Herfindahl Index for Government (HIG) as a political variable. The HIG is defined as the sum of the squares of the seats' shares of all parties in the government. The index ranges from 0 to 1 , with higher scores indicating more political cohesion and thus less fragmentation of power in several political groups. For each country, I compute the mean of each variable for the period 2005-2012. Then I calculate the grand mean for each group of countries. With the exception of the HIG, data was obtained from the World Bank. In Tables 5a and 5b, I describe the variables used in the empirical analysis: 
Table 5a. Description of Variables

\begin{tabular}{|c|c|}
\hline Variable & Definition \\
\hline $\begin{array}{l}\text { Current } \\
\text { Account }\end{array}$ & Sum of the balance of trade and net income from abroad. \\
\hline Oil Revenue & $\begin{array}{l}\text { Difference between the value of crude oil production at world prices and } \\
\text { total costs of production. }\end{array}$ \\
\hline
\end{tabular}

Tax Revenue

Compulsory transfers to the general government sector.

Herfindahl The sum of the squares of the seats' share of all parties in the government.

Index for Formally, $H I G=\sum_{i=1}^{N} \omega_{i}^{2}$, where $\omega_{i}$ is the share of seats of party $\mathrm{i}$ in the

Government coalition government.

(HIG)

Source: World Bank Database of Political Institutions

Total Public Includes all government current expenditures for purchases of goods and Expenditure services (including compensation of employees). It also includes most expenditures on national defense and security.

Public Comprises all additions to the stocks of fixed assets (purchases and ownInvestment account capital formation), less any sales of second-hand and scrapped fixed assets measured at constant prices, done by government units and non-financial public enterprises. Most outlays by government on military equipment are excluded.

Public Sector Compensation of employees consists of all payments in cash, as well as in Wages kind (such as food and housing), to employees in return for services rendered, and government contributions to social insurance schemes such as social security and pensions that provide benefits to employees.

Education

Expenditure

General government expenditure on education (current and capital) is expressed as a percentage of GDP.

Health Public health expenditure consists of recurrent and capital spending from Expenditure government (central and local) budgets, external borrowings and grants (including donations from international agencies and nongovernmental organizations), and social (or compulsory) health insurance funds.

Military Military expenditures includes all current and capital expenditures on the Expenditure armed forces, including peacekeeping forces; defense ministries and other government agencies engaged in defense projects; paramilitary forces, if these are judged to be trained and equipped for military operations; and military space activities.

Subsidies

Subsidies, grants, and other social benefits include all unrequited, nonrepayable transfers on current account to private and public enterprises; grants to foreign governments, international organizations, and other government units; and social security, social assistance benefits, and employer social benefits in cash and in kind. 
Table 5b. Descriptive Statistics

\begin{tabular}{|c|c|c|}
\hline Variable & OPEC & Non-OPEC \\
\hline Current Account & 17.5 & 3.1 \\
\hline Oil Revenue & 29.4 & 10.5 \\
\hline Tax revenue & 6.6 & 19.0 \\
\hline Herfindahl Index for Government & 0.86 & 0.81 \\
\hline \multicolumn{3}{|c|}{ Public Expenditure } \\
\hline Total Public Expenditure & 17.0 & 14.7 \\
\hline \multicolumn{3}{|c|}{ Public Expenditure by Economic Classification } \\
\hline Public Investment & 9.9 & 7.8 \\
\hline Public Sector Wages & 6.6 & 5.3 \\
\hline \multicolumn{3}{|c|}{ Public Expenditure by Functional Classification } \\
\hline Education Expenditure & 3.8 & 4.0 \\
\hline Health Expenditure & 2.1 & 2.8 \\
\hline Military Expenditure & 4.3 & 2.6 \\
\hline \multicolumn{3}{|c|}{ Transfer Expenditure } \\
\hline Subsidies & 6.9 & 9.0 \\
\hline
\end{tabular}

According to Table 5b, oil revenue in OPEC is almost three times oil revenue in nonOPEC even when the number of OPEC represents only one third the number of non-OPEC. This can be explained by the OPEC cartel position in the oil world market where they manage the supply of oil and set the oil price. Also, observe that the HIG is higher in the OPEC, indicating less political fractionalization in this group of countries. Both facts suggest that OPEC protect their oil wealth by imposing -relatively to non-OPEC- stronger central governments and avoiding the existence of political groups.

Given the existence of larger oil revenue and higher political cohesion in OPEC, this group of countries also exhibit, with respect to non-OPEC: (i) larger ratios of current account and total government spending to GDP (the current account in OPEC is almost six times the current account of the non-OPEC), (ii) lower tax revenue (roughly one third compared with the case of non-OPEC), and (iii) different ratios of public expenditure to GDP depending on the category analyzed. I propose three conclusions from this evidence. In first place, oil revenue has a positive impact on government spending and current account (these results are consistent with the equations (3.13), (3.14) and (3.20) derived in the model). In second place, the substitution effect between tax revenue and oil rents is 
stronger in the OPEC, where political fragmentation is lower according to their HIG (this evidence is in line with equations (4.9) and (4.10)). Finally, in third place, OPEC mainly distribute their government spending to capital, current and military expenditure while the non-OPEC governments allocate more resources to transfers, health and education sectors. In particular, the OPEC exhibit -relative to non-OPEC- larger values of public investment and public sector wages. I argue that these two facts result from the political cohesion in OPEC which is strengthened by paying higher wages to public sector workers. In the same sense, as the government is less fractionalized, it is easier to reach political consensus to realize more investment projects instead of transfer public resources as subsidies to political provinces. To maintain political stability, OPEC has focused on defense spending, in detriment of education and health public expenditure. See Figures 5a-5c.

Figure 5a. Oil Revenue, Tax Revenue and Current Account

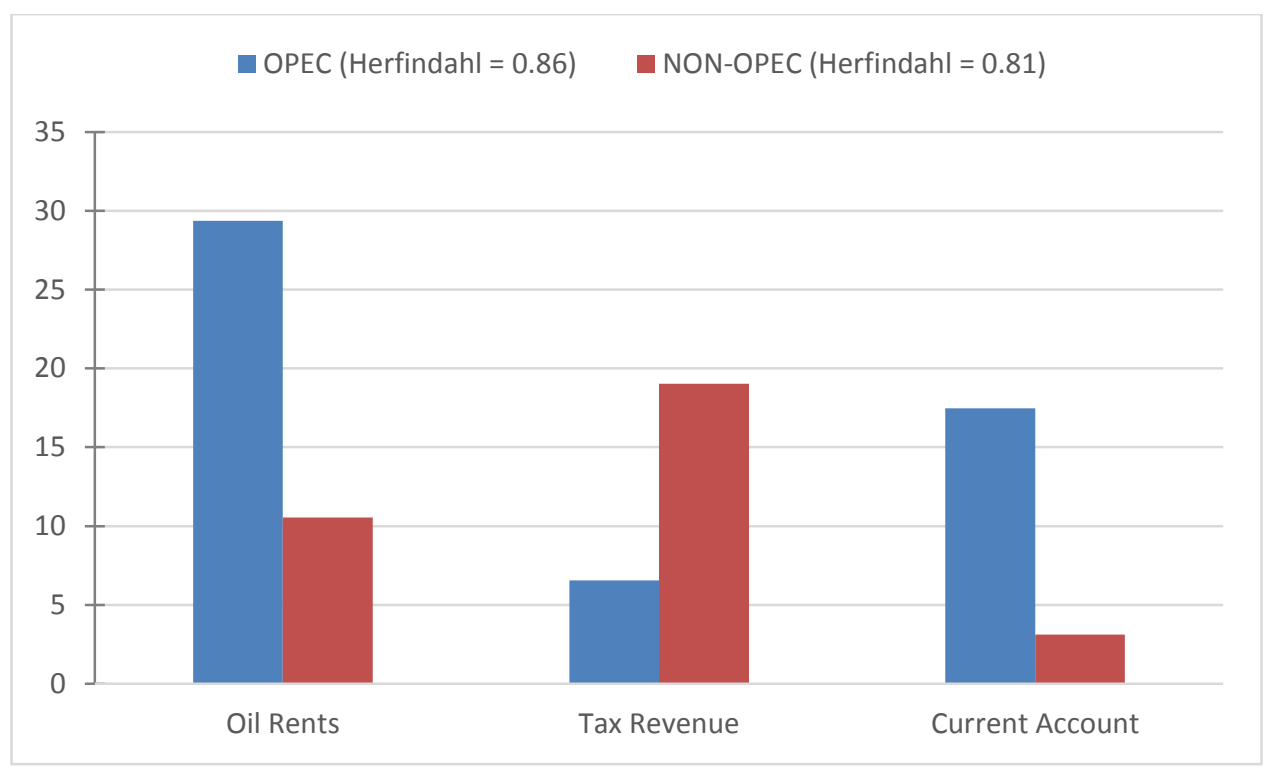


Figure 5b. Oil Revenue and Public Expenditure

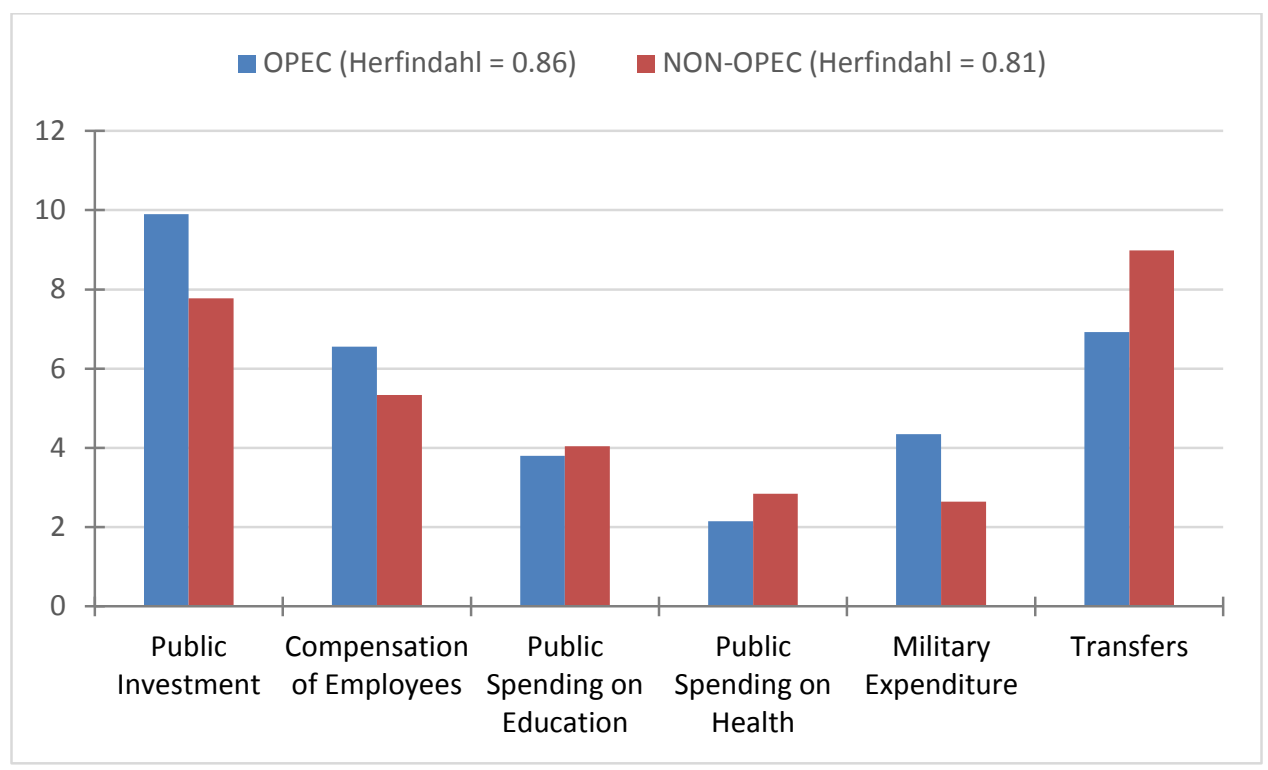

\subsubsection{Estimation}

\subsubsection{Relationship between Oil Revenue and Current Account}

In the next exercise, I quantify the effects of a permanent and a temporary oil boom on the current account in OPEC and non-OPEC. In particular, I propose the following dynamic model for a cross section of each group of countries during the period 1980-2013:

$$
c a_{i t}=\beta_{0}+\beta_{1} s_{i t}+\beta_{2} s_{i t-1}+\alpha c a_{i t-1}+a_{i}+u_{i t}
$$

where $i$ denotes the country and $t$ indicates the time period $(t=1980, \ldots, 2013), c a$ is the ratio current account-GDP, and $s, \tau$ are oil rents and tax revenue (each as a fraction of GDP). Equation (5.1) is dynamic due to the presence of the lagged dependent explanatory variables $s_{i t-1}$ and $c a_{i t-1}$ capturing the effects of a permanent or temporary oil boom. According to Hamilton (2011), significant oil shocks occurred six times during the period 1980-2013. The shocks were negative or positive (boom) and short or long-lasting. See Table $5 c$ and Figure 5c (a red line indicates that an oil shock occurred). 
Table 5c. Historical Oil Shocks (1980-2013)

\begin{tabular}{ccc}
\hline Period & Event & Oil Shock \\
\hline $1980-1981$ & Iran-Iraq War & Positive \\
$1981-1986$ & The Great Price Collapse & Negative \\
$1990-1991$ & First Persian Gulf War & Positive \\
$1997-1998$ & East Asian Crisis & Negative \\
$1999-2000$ & Resumed Growth & Positive \\
2003 & Venezuelan unrest and the second Persian Gulf War & Positive \\
$2007-2008$ & Growing Demand and Stagnant Supply & Positive \\
\hline
\end{tabular}

Figure 5c. Average Oil Revenue as a percentage of GDP (OPEC and Non-OPEC)

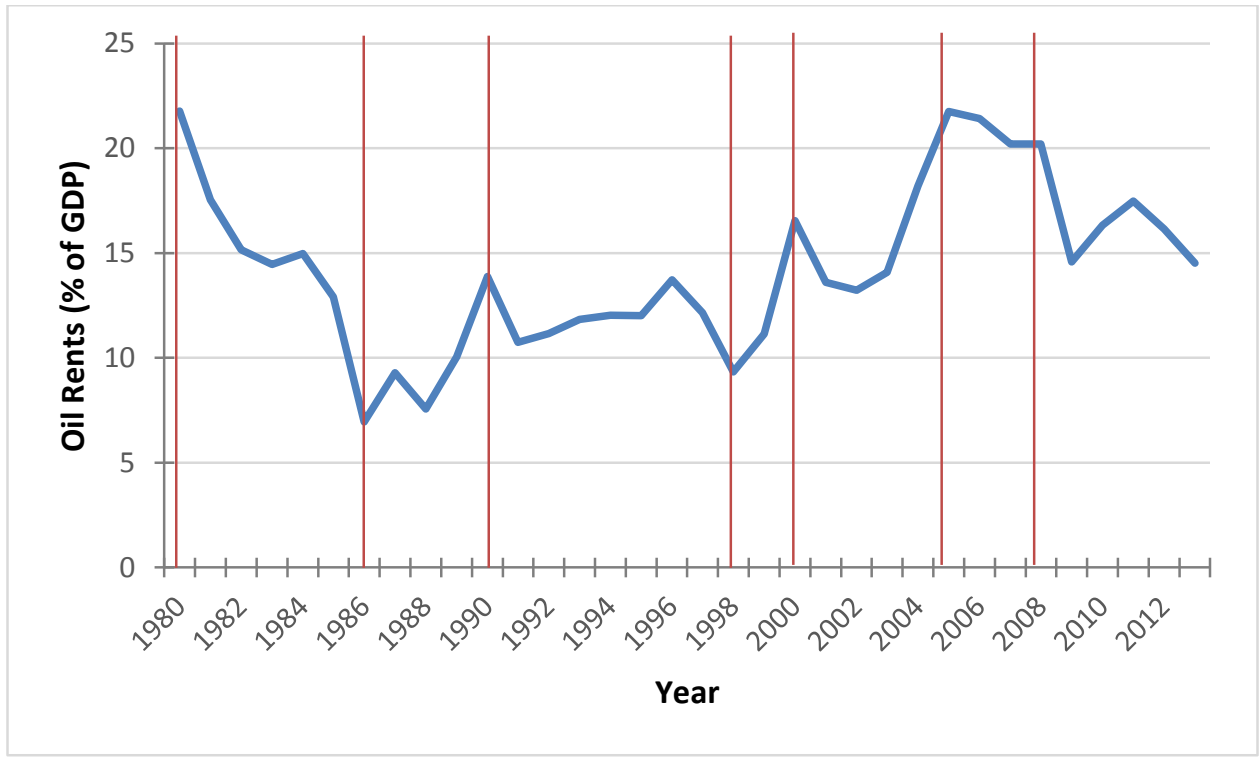

The variable $a_{i}$ is the fixed effect capturing all unobserved, time-constant factors that affect the current account. For example, $a_{i}$ represents the country heterogeneity related to differences in political fragmentation which evolve slowly along time. Finally, $u_{i t}$ is the time-varying error representing unobserved factors that change over time and impact $c a_{i t}$. For instance, $u_{i t}$ contains information about public policy taken by the government in 1980-2013. I estimate this cross sectional equation using the heteroskedasticity and autocorrelation-consistent (HAC) standard errors to rule out a potential correlation between the explanatory variables and the error term. By examining equation (5.1), I measure the dynamic effects of a temporary or permanent oil boom on the current account. In the 
following lines, I describe and interpret the dynamic multipliers in terms of a permanent or temporary shock to oil revenue. Let $\Delta x_{i t}$ denotes the increase in variable $x$ for country $i$ in year $t$, where $x=c a, s$. Thus, if oil revenue increases in $\Delta s_{i t}$, the current account will change in $\Delta c a_{i t}$.

$$
c a_{i t}+\Delta c a_{i t}=\beta_{0}+\beta_{1}\left(s_{i t}+\Delta s_{i t}\right)+\beta_{2} s_{i t-1}+\alpha c a_{i t-1}+\varepsilon_{i t},
$$

where $\varepsilon_{i t} \equiv a_{i}+u_{i t}$. Given (5.1), equation (5.2) reduces to $\Delta c a_{i t}=\beta_{1} \Delta s_{i t}$. For the sake of simplicity, assume that oil rents increase by $1 \%$ in period $t$. Therefore, the effect of a temporary oil boom on the current account is $\Delta c a_{i t}=\beta_{1}$. On the other hand, in order to compute the impact of a permanent oil boom, observe that equation (5.1) also holds for period $t+1$ before the boom:

$$
c a_{i t+1}=\beta_{0}+\beta_{1} s_{i t+1}+\beta_{2} s_{i t}+\alpha c a_{i t}+\varepsilon_{i t+1}
$$

and after the boom:

$$
c a_{i t+1}+\Delta c a_{i t+1}=\beta_{0}+\beta_{1}\left(s_{i t+1}+\Delta s_{i t+1}\right)+\beta_{2}\left(s_{i t}+\Delta s_{i t}\right)+\alpha\left(c a_{i t}+\Delta c a_{i t}\right)+\varepsilon_{i t+1},
$$

Assuming that $\Delta s_{i t}=\Delta s_{i t+1}=1$, the change in the current account in period $t+1$ is $\Delta c a_{i t+1}=\beta_{1}(1+\alpha)+\beta_{2}$. By following the same way of reasoning, after $j$ periods, the change in the current account in period $t+j$ given the oil boom $\Delta s_{i t}=\Delta s_{i t+1}=\cdots=$ $\Delta s_{i t+j}=1 \quad$ is $\quad \Delta c a_{i t+j}=\beta_{1}\left(1+\alpha+\alpha^{2}+\cdots+\alpha^{j}\right)+\beta_{2}\left(1+\alpha+\alpha^{2}+\cdots+\alpha^{j-1}\right)$. In conclusion, the effect of a $1 \%$ permanent oil boom on the current account is $\Delta c a_{i t}=\frac{\beta_{1}+\beta_{2}}{1-\alpha}$. Table $5 d$ summarizes the magnitudes of the permanent and temporary booms: 
Table 5d. Dynamic Effects of Oil Booms on Current Account

\begin{tabular}{c|c|c}
\hline Period & Permanent Boom & Temporary Boom \\
\hline$t$ & $\beta_{1}$ & $\beta_{1}$ \\
$t+1$ & $\beta_{1}(1+\alpha)+\beta_{2}$ & $\alpha \beta_{1}+\beta_{2}$ \\
$t+2$ & $\beta_{1}\left(1+\alpha+\alpha^{2}\right)+\beta_{2}(1+\alpha)$ & $\alpha\left(\alpha \beta_{1}+\beta_{2}\right)$ \\
$t+3$ & $\beta_{1}\left(1+\alpha+\alpha^{2}+\alpha^{3}\right)+\beta_{2}\left(1+\alpha+\alpha^{2}\right)$ & $\alpha^{2}\left(\alpha \beta_{1}+\beta_{2}\right)$ \\
$\ldots$ & $\ldots$ & $\ldots$ \\
\hline Long-run & $\frac{\beta_{1}+\beta_{2}}{1-\alpha}$ & 0 \\
\hline
\end{tabular}

According to Table 5d, a permanent oil boom $\Delta s_{i t}=\Delta s_{i t+1}=\cdots=1$ has a positive and increasing -at decreasing rate- impact on the current account. In the long-run, the accumulated effect is equal to $\frac{\beta_{1}+\beta_{2}}{1-\alpha}$ if $-1<\alpha<1$. On the other hand, a temporary oil boom $\Delta s_{i t}=1$ has a positive but decreasing effect on the current account. In the long-run, the impact vanishes. Table $5 e$ and Figure $5 \mathrm{~d}$ reports the results.

Table 5e. Estimation Results

\begin{tabular}{|c|c|c|c|c|c|c|}
\hline \multirow[t]{2}{*}{ Sample } & \multicolumn{4}{|c|}{ Estimated Parameter } & \multicolumn{2}{|c|}{ Impact Oil Boom } \\
\hline & $\beta_{0}$ & $\beta_{1}$ & $\beta_{2}$ & $\alpha$ & $\begin{array}{l}\text { Permanent } \\
\text { (long-run) }\end{array}$ & $\begin{array}{c}\text { Temporary } \\
\text { (time } t)\end{array}$ \\
\hline OPEC & $\begin{array}{l}-12.2845 \\
(0.0000)\end{array}$ & $\begin{array}{c}0.4309 \\
(0.0000)\end{array}$ & $\begin{array}{c}0.2548 \\
(0.0000)\end{array}$ & $\begin{array}{c}-0.1550 \\
(0.0003)\end{array}$ & 0.5937 & 0.4309 \\
\hline $\begin{array}{l}\text { Non- } \\
\text { OPEC }\end{array}$ & $\begin{array}{c}-0.1102 \\
(0.8583)\end{array}$ & $\begin{array}{c}0.1129 \\
(0.0000)\end{array}$ & $\begin{array}{c}-0.0648 \\
(0.0211)\end{array}$ & $\begin{array}{c}-0.0622 \\
(0.0422)\end{array}$ & 0.0453 & 0.1129 \\
\hline
\end{tabular}

p-values in parenthesis based on HAC standard errors. 
Figure 5d. Dynamic Effects of Oil Booms on Current Account
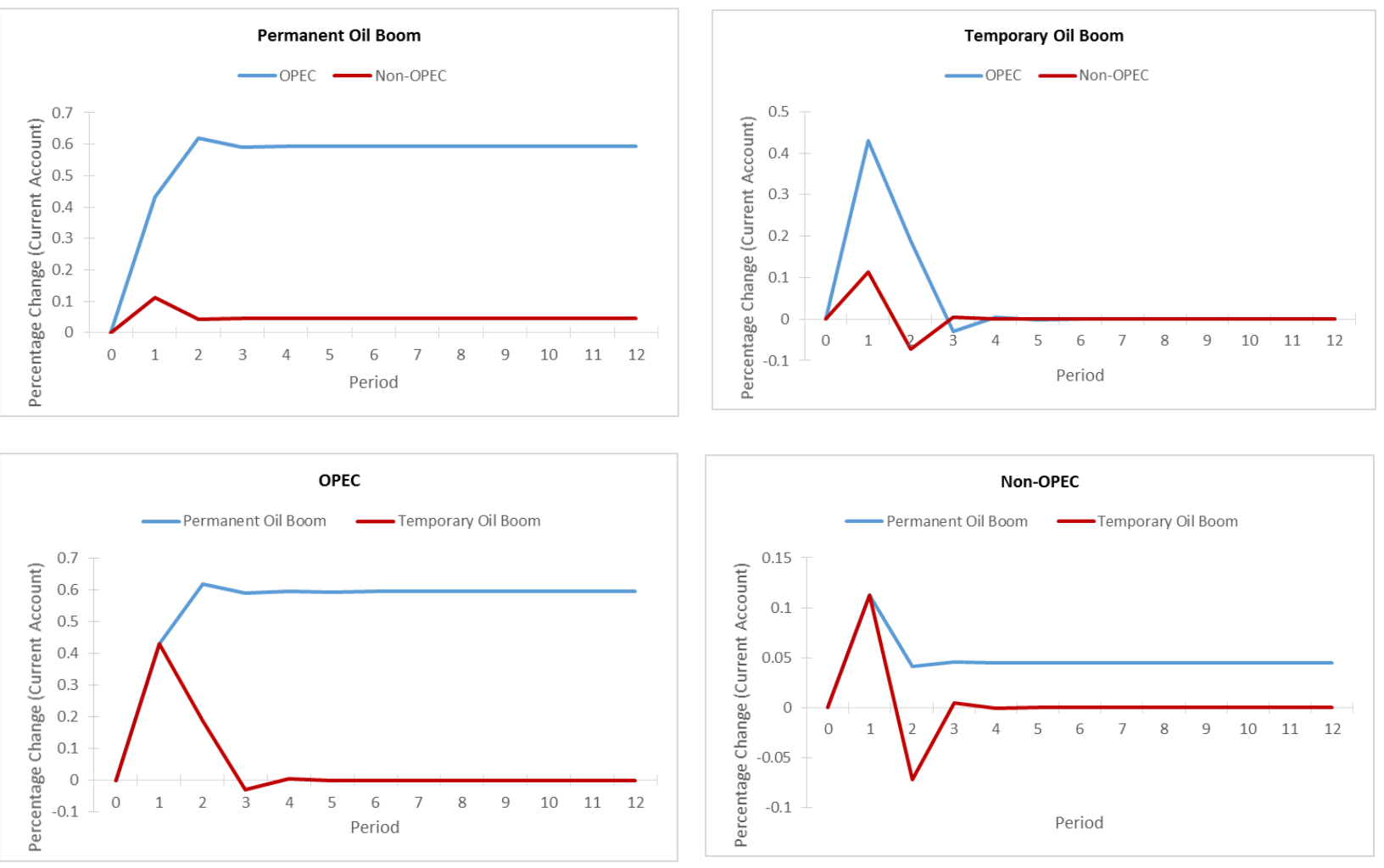

There are two results derived from the regressions. In first place, given a permanent or temporary oil boom, the change in the current account was larger in the OPEC than the adjustment in the Non-OPEC. Specifically, a $1 \%$ permanent boom in oil rents improves the current account in $0.6 \%$ in the OPEC but only $0.05 \%$ in the Non-OPEC. Similarly, a $1 \%$ temporary boom in oil rents increases the current account in $0.4 \%$ (OPEC) and $0.1 \%$ (NonOPEC). Intuitively, as political cohesion is lower in OPEC, there is a larger number of political groups capturing the gains from the oil boom by inflating government spending, and counteracting the initial improvement in the current account via additional public saving. In second place, observe that only in the Non-OPEC the impact in time $t$ resulting from a temporary boom $(0.1 \%)$ is larger than the long-run impact caused by a permanent boom $(0.05 \%)$. The opposite happens in the OPEC: $0.6 \%$ (permanent) versus $0.4 \%$ (transitory). Therefore, equations ( $4.14 \mathrm{a}-\mathrm{d})$ are consistent with Non-OPEC behavior.

\subsubsection{Relationship between Oil Revenue and Public Expenditure}

Given the existence of statistical dependence of the current account on oil revenue and taxes, in the next exercise I quantify the relation between oil revenue and public expenditure (each expressed as percentage of GDP). In particular, for each group of 
countries (OPEC and Non-OPEC) and over the period 1995-2012, I propose the following panel data model:

$$
\log \left(g_{i t}\right)=\mu_{0}+\mu_{1} \log \left(s_{i t}\right)+a_{i}+v_{t}+u_{i t}
$$

where $i$ denotes the country, $t$ indicates the time period $(t=1995, \ldots, 2006), g$ is government expenditure, and $\mu_{1}$ measures the elasticity of public expending with respect to oil rents; that is, the percentage change in $g$ for a given (and small) percentage change in $s$. In this sense, the log-log model specified in (5.5) is useful to compute the relative impact of oil rents on public expenditure (rather than an absolute change measured in a linear model) given that both groups of countries differ significantly in their average oil revenues as shown in Table 5a. Finally, $a_{i}, v_{t}$, and $u_{i t}$ represent the three disturbance terms. In first place, $a_{i}$ is the country intercept encapsulating all the variables that affect $\log \left(g_{i t}\right)$ but do not vary over time. For example, $a_{i}$ represents the country heterogeneity related to differences in wasting public resources -in this case, oil rents- through profligate or inappropriate consumption. In second place, $v_{t}$ is the time-varying intercept capturing all the variables that affect $\log \left(g_{i t}\right)$ and that change over time but are constant across countries. An example would be where a world interest rate shock through the sample period. This change influences $\log \left(g_{i t}\right)$, but in the same way for all countries. Finally, $u_{i t}$ is the error term representing unobserved factors that vary over time and across countries. For instance, $u_{i t}$ contains information about public policy taken by a specific country over the period 1995-2012. In order to estimate (5.5), I propose three fixed effects (FE) models: two using either country or time dummy variables and one containing both. Table $5 f$ reports the results: 
Table 5f. Effect of Oil Booms on Government Expenditure

\begin{tabular}{c|c|c|c}
\hline Group/Model & Country-FE (I) & Year-FE (II) & Both (III) \\
\hline OPEC & $\hat{\mu}_{0}=3.354^{* * *}$ & $\hat{\mu}_{0}=1.246^{* * *}$ & $\widehat{\boldsymbol{\mu}}_{\mathbf{0}}=\mathbf{2 . 0 2 8 ^ { * * * }}$ \\
& $(18.061)$ & $(6.873)$ & $(8.037)$ \\
Obs $=184$ & $\hat{\mu}_{1}=-0.203^{* * *}$ & $\hat{\mu}_{1}=0.433^{* * *}$ & $\widehat{\boldsymbol{\mu}}_{\mathbf{1}}=\mathbf{0 . 1 9 6}^{* *}$ \\
& $(-3.647)$ & $(7.992)$ & $(2.587)$ \\
& $R^{2}=0.689$ & $R^{2}=0.351$ & $R^{2}=0.783$ \\
\hline Non-OPEC & $\hat{\mu}_{0}=2.553^{* * *}$ & $\hat{\mu}_{0}=2.619^{* * *}$ & $\widehat{\boldsymbol{\mu}}_{\mathbf{0}}=\mathbf{2 . 4 9 3}$ \\
& $(209.627)$ & $(160.161)$ & $(175.050)$ \\
Obs $=706$ & $\hat{\mu}_{1}=0.023^{* * *}$ & $\hat{\mu}_{1}=-0.045^{* * *}$ & $\widehat{\boldsymbol{\mu}}_{\mathbf{1}}=\mathbf{0 . 0 8 6}$ \\
& $(2.144)$ & $(-7.103)$ & $(6.449)$ \\
& $R^{2}=0.711$ & $R^{2}=0.078$ & $R^{2}=0.854$ \\
\hline
\end{tabular}

t- statistics in parenthesis based on HAC standard errors.

$*, * *, * * *$ indicate significance at the $90 \%, 95 \%, 99 \%$, respectively.

By comparing the three models, Table $5 f$ indicates that the estimation of $\mu_{1}$ is statistically significant in the three models. In order to obtain robustness, I focus on the third model. Specifically, oil rents impact positively public expenditure and the effect is larger in OPEC (the estimated elasticity is more than double the estimation in Non-OPEC). Also, the estimated intercept is larger in the case of Non-OPEC suggesting that, in the absence of oil booms, the existence of additional political groups demanding additional resources which inflates public spending. Both results are consistent with equation (4.6).

\subsubsection{Relationship between Oil Revenue and Tax Revenue}

To study the tax response to oil shocks, I propose the following panel data regression in OPEC and Non-OPEC during the period 1995-2012:

$$
\log \left(\tau_{i t}\right)=\mu_{2}+\mu_{3} \log \left(s_{i t}\right)+a_{i}+v_{t}+u_{i t}
$$

where $\tau$ denotes tax revenue (as a percentage of GDP), $\mu_{3}$ measures the elasticity of tax revenue with respect to oil rents, $a_{i}$ is an unobserved variable that varies among countries but does not change over time, $v_{t}$ is the time-varying disturbance and $u_{i t}$ is the error representing unobserved factors impacting tax revenue and changing over time and across countries. For example, $u_{i t}$ contains information about tax reforms that change the way taxes are collected and managed by each government in different years. To estimate 
equation (5.6) I use the cross sectional or/and time dummy variables approach. Table $5 \mathrm{~g}$ reports the results:

Table 5g. Effect of Oil Booms on Tax Revenue

\begin{tabular}{|c|c|c|c|}
\hline Group & Country-FE (I) & Time-FE (II) & Both (III) \\
\hline OPEC & $\begin{array}{c}\hat{\mu}_{2}=-0.757 \\
(-0.962)\end{array}$ & $\begin{array}{c}\widehat{\boldsymbol{\mu}}_{\mathbf{2}}=\mathbf{7 . 3 1 3}^{* * *} \\
(2.899)\end{array}$ & $\begin{array}{c}\hat{\mu}_{2}=-1.981 \\
\quad(-1.440)\end{array}$ \\
\hline \multirow[t]{2}{*}{$O b s=93$} & $\begin{array}{c}\hat{\mu}_{3}=0.233 \\
(0.995)\end{array}$ & 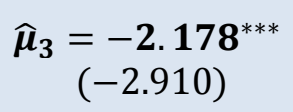 & $\begin{array}{c}\hat{\mu}_{3}=0.599 \\
(1.459)\end{array}$ \\
\hline & $R^{2}=0.951$ & $R^{2}=0.200$ & $R^{2}=0.963$ \\
\hline Non-OPEC & $\begin{array}{c}\hat{\mu}_{2}=1.520^{* * *} \\
(40.784)\end{array}$ & $\begin{array}{c}\widehat{\boldsymbol{\mu}}_{\mathbf{2}}=\mathbf{1 . 6 2 4}^{* * *} \\
(18.939)\end{array}$ & $\begin{array}{c}\hat{\mu}_{2}=1.497^{* * *} \\
(34.131)\end{array}$ \\
\hline \multirow[t]{2}{*}{$O b s=470$} & $\begin{array}{l}\hat{\mu}_{3}=0.008 \\
\quad(0.187)\end{array}$ & $\begin{array}{c}\widehat{\boldsymbol{\mu}}_{3}=-\mathbf{0 . 1 6 0} 0^{* * *} \\
(-4.611)\end{array}$ & $\begin{array}{c}\hat{\mu}_{3}=0.047 \\
(0.789)\end{array}$ \\
\hline & $R^{2}=0.925$ & $R^{2}=0.050$ & $R^{2}=0.927$ \\
\hline
\end{tabular}

By comparing the three models, Table $5 \mathrm{~g}$ indicates that the estimated coefficient of $\mu_{3}$ is statistically significant only in the time-fixed effects model. Thus, global shocks affecting tax policies in all countries are relevant to explain the relationship oil rents-tax revenue; country-specific shocks are not. This suggests that OPEC and Non-OPEC respond to a time-varying shock. Observe that the estimated elasticity tax revenue-oil rents is negative in both group of countries but stronger in the case of OPEC, indicating a larger substitution between the two revenue sources. Finally, the estimated intercept is larger in the case of Non-OPEC where political fractionalization is higher, which is consistent with equation (4.5): in the absence of oil revenue, tax rate is increasing in the number of political groups.

\subsection{Conclusions}

This paper provides insight into the effects that oil booms have on public and private saving. Specifically, I propose a model of intertemporal consumption where a representative consumer, government and political groups interact. On one hand, consumer choses the optimal levels of present and future private consumption that maximizes its utility function, which also depends on the consumption of a public good. On the other hand, government finances its level of public expenditure using income tax revenue and oil rents, and choses the optimal tax rate that maximizes the consumer's utility function. In equilibrium, oil 
revenue has a positive impact on public expenditure and the current account, but a negative effect on the optimal tax burden. The magnitude of these effects depends on: (i) the type of shock on oil revenue (temporary or permanent) and (ii) the number of political groups in the economy. In particular, a temporary boom on oil rents has a positive effect on the current account stronger than the caused by a permanent boom. Also, an increase in the number of political groups increases the tax burden and deteriorates the current account. Therefore, the number of political groups offsets part of the impact produced by an oil boom.

The results derived in the model are empirically tested. In particular, data from OPEC and Non-OPEC -where governments own oil companies- is used to verify that, as the OPEC obtain larger ratios of oil rents to GDP relative to those received by the Non-OPEC, the first group of countries exhibit lower tax revenue and larger current account (as percentages of GDP). In line with this fact, I estimate three panel regressions for the two group of countries. In the first regression, the current account depends on tax revenue and oil rents. In the second and third regressions, government spending or tax revenue depend on oil rents. The results confirm that: (i) for each group, oil and tax revenue have positive impacts on the current account, (ii) in the OPEC, oil revenue has an impact on the current account larger than tax revenue, (iii) an oil boom has a positive (negative) impact on public expenditure (tax revenue), and (iv) this impact is stronger in OPEC. Additionally, the Herfindahl Government Index (an indicator of political cohesion) indicates that the NonOPEC governments are politically more fractionalized and, therefore, allow the existence of more political groups with respect to OPEC. Finally, by computing the different categories of public expenditure, it is revealed that the OPEC allocate oil rents to finance public investment, public sector wages and military expenditure, By contrast, the Non-OPEC use oil proceeds to primarily finance education and health expenditures. 


\subsection{References}

1. Elif C. Arbatli, 2008. "Futures Markets, Oil Prices and the Intertemporal Approach to the Current Account," Working Papers 08-48, Bank of Canada.

2. Jean-Pierre Allegret \& Cécile Couharde \& Dramane Coulibaly \& Valérie Mignon, 2013. "Current accounts and oil price fluctuations in oil-exporting countries: the role of financial development," EconomiX Working Papers 2013-29, University of Paris West - Nanterre la Défense, EconomiX.

3. Backus, David K. \& Crucini, Mario J., 2000. "Oil prices and the terms of trade," Journal of International Economics, Elsevier, vol. 50(1), pages 185-213, February.

4. Chuku A. Chuku \& Usenobong F. Akpan \& Ndifreke R. Sam \& Ekpeno L. Effiong, 2011. "Oil price shocks and the dynamics of current account balances in Nigeria," OPEC Energy Review, Organization of the Petroleum Exporting Countries, vol. 35(2), pages 119-139, 06.

5. Gemmell, N., O. Morrissey and A. Pinar (1998), 'Fiscal Illusion and the Demand for Local Government Expenditures in England and Wales', University of Nottingham: Discussion Papers in Economics No. 98/19.

6. Hamilton, James D., 2011. "Historical Oil Shocks," NBER Working Papers 16790, National Bureau of Economic Research, Inc.

7. I.M.D. Little, Richard N. Cooper, W. Max Corden, and Saraht Rajapatirana. 1993. Boom, Crisis, and Adjustment. London: Oxford University Press.

8. Lane, Philip R \& Tornell, Aaron, 1996. "Power, Growth, and the Voracity Effect," Journal of Economic Growth, Springer, vol. 1(2), pages 213-41, June.

9. Lutz Kilian \& Alessandro Rebucci \& Nikola Spatafora, 2009. "Oil shocks and external balances," Journal of International Economics, Elsevier, vol. 77(2), pages 181-194, April.

10. Jeffrey Sachs, 1981. "The Current Account and Macroeconomic Adjustment in the 1970s," Brookings Papers on Economic Activity, 1, pages 201-268.

11. Stefan Franz Schubert, 2009. "Dynamic Effects of Oil Price Shocks and their Impact on the Current Account, "MPRA Paper 16738, University Library of Munich, Germany.

12. World Bank, 2008. A Citizen's Guide to National Oil Companies. Washington, D.C. 


\subsection{Appendix}

List of Countries where NOCs are located

\begin{tabular}{ccc}
\hline OPEC & Country & NOC \\
\hline 1 & Algeria & Sonatrach \\
2 & Angola & Sonangol \\
3 & Ecuador & Petroecuador \\
4 & Iran & NIOC \\
5 & Iraq & INOC \\
6 & Kuwait & Kuwait Petroleum Corp \\
7 & Libya & Libya National Oil Co. \\
8 & Nigeria & NNPC \\
9 & Qatar & Qatar Petroleum \\
10 & Saudi Arabia & Saudi Aramco \\
11 & United Arab Emirates & ADNOC \\
12 & Venezuela & PDVSA \\
\hline
\end{tabular}

\begin{tabular}{|c|c|c|}
\hline Non-OPEC & Country & Company \\
\hline 1 & Argentina & Enarsa \\
\hline 2 & Azerbaijan & SOCAR \\
\hline 3 & Bahrain & BAPCO \\
\hline 4 & Belarus & Belarusneft \\
\hline 5 & Bolivia & YPFB \\
\hline 6 & Brazil & Petrobras \\
\hline 7 & Brunei & BNPC \\
\hline 8 & Cameroon & $\mathrm{SNH}$ \\
\hline 9 & Chad & SHT \\
\hline 10 & China & CNOCC, Petrochina, Sinopec \\
\hline 11 & Colombia & Ecopetrol \\
\hline 12 & Congo & SNPC \\
\hline 13 & Cote d'Ivoire & PETROCI \\
\hline 14 & Cuba & Cupet \\
\hline 15 & Egypt & EGPC \\
\hline 16 & Equatorial Guinea & GEPetrol \\
\hline 17 & France & Gaz de France \\
\hline 18 & Gabon & SNGP \\
\hline 19 & Ghana & GNPC \\
\hline 20 & India & Gas Authority of India, IOC, ONGC \\
\hline 21 & Indonesia & Pertamina \\
\hline 22 & Italy & Eni \\
\hline 23 & Japan & JOGMEC \\
\hline 24 & Kazakhstan & Kazmunaigas \\
\hline 25 & Korea (South) & KNOC \\
\hline 26 & Malaysia & Petronas \\
\hline 27 & Mexico & Pemex \\
\hline 28 & Norway & StatoilHydro \\
\hline 29 & Oman & PDO \\
\hline 30 & Pakistan & OGDCL \\
\hline 31 & Peru & PetroPeru \\
\hline 32 & Philippines & PNOC \\
\hline
\end{tabular}




\begin{tabular}{|ccc|}
\hline 33 & Russia & Gazprom, Rosneft, Transneft \\
\hline 34 & South Africa & PetroSA \\
35 & Sudan & Sudapet \\
36 & Syria & SPC \\
37 & Thailand & PTT \\
38 & Trinidad and Tobago & National Gas Co., Petrotrin \\
39 & Tunisia & ETAP \\
40 & Turkmenistan & TurkmenNeft \\
41 & Ukraine & Naftogaz Ukrainy \\
42 & Uzbekistan & Uzbekneftegaz \\
43 & Vietnam & Petrovietnam \\
\hline 44 & Yemen & Yemen General Corp. \\
\hline
\end{tabular}




\section{Chapter 2}

\section{Counterfeit Software, Corruption and Output: The International Experience}

\subsection{Introduction}

This paper investigates the relationship between counterfeit software, government corruption and GDP across countries. In this context counterfeit software is defined as the making of unauthorized copies of copyrighted software and government corruption is defined as the use of public power to foster the production and use of counterfeit software. Consider Figures 1a-1b, which plot the GDP per capita (obtained from World Bank, WB) against the counterfeit software fraction (obtained from Business Software Alliance, BSA) for two groups of 54 countries each in the year $2013^{3}$. In the first group, the Corruption Perceptions Index (CPI) constructed by Transparency International is below the overall median. In the second group, the CPI is above it. The CPI ranks countries on a scale from 0 (very clean) to 10 (highly corrupt). The plotting suggests that: (i) the countries with higher GDP tend to have a lower fraction of counterfeit software, and (ii) according to the correlation coefficient, this inverse relationship is more robust in the group of least corrupt countries.

3 Note: GDP per capita expressed in 2005 USD (thousands). Counterfeit software fraction computed as the percentage of total software that is unlicensed.

Source: International Monetary Fund (IMF) and Business Software Alliance (BSA). 
Figure 1a. GDP Per Capita and Counterfeit Software Fraction (Least Corrupt Countries)

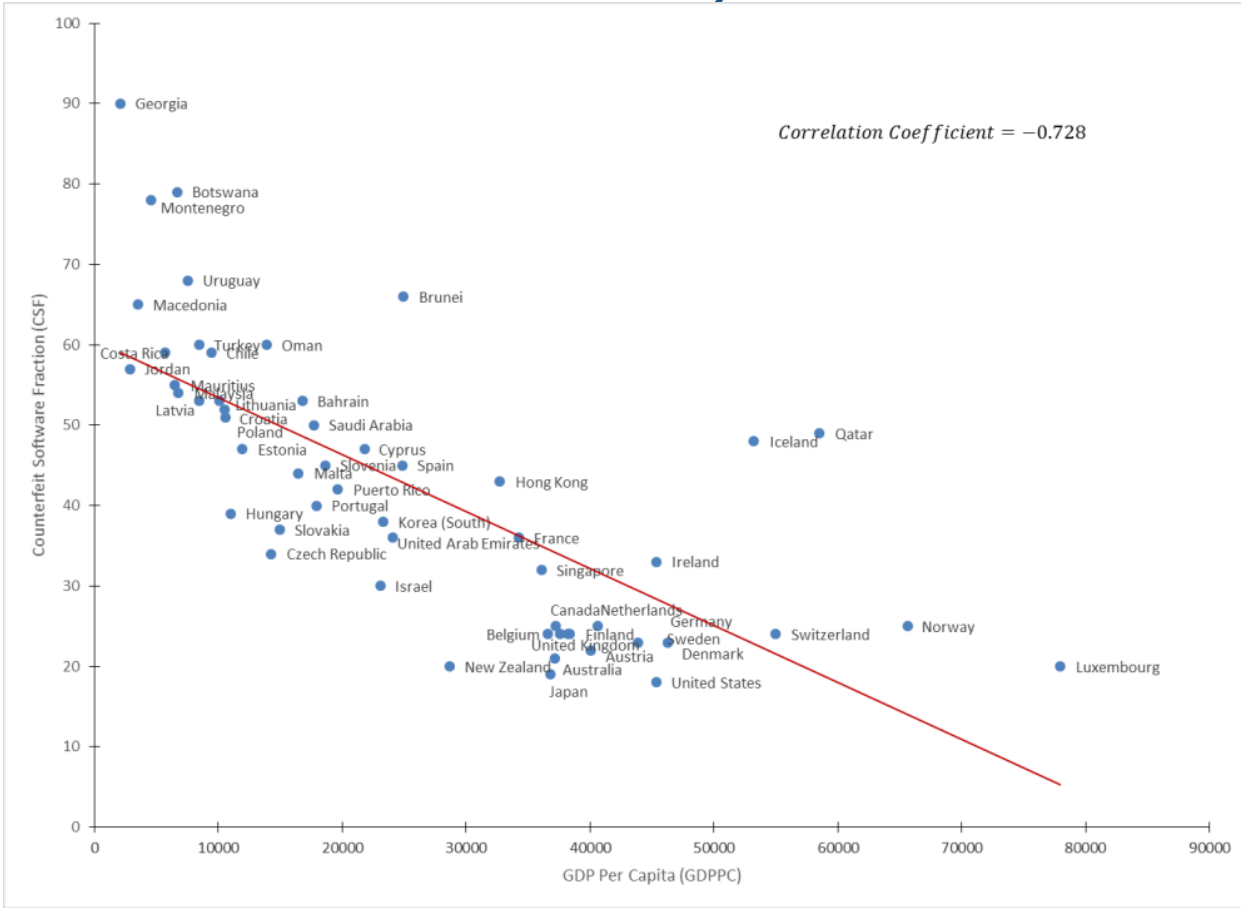

Figure 1b. GDP Per Capita and Counterfeit Software Fraction (Most Corrupt Countries)

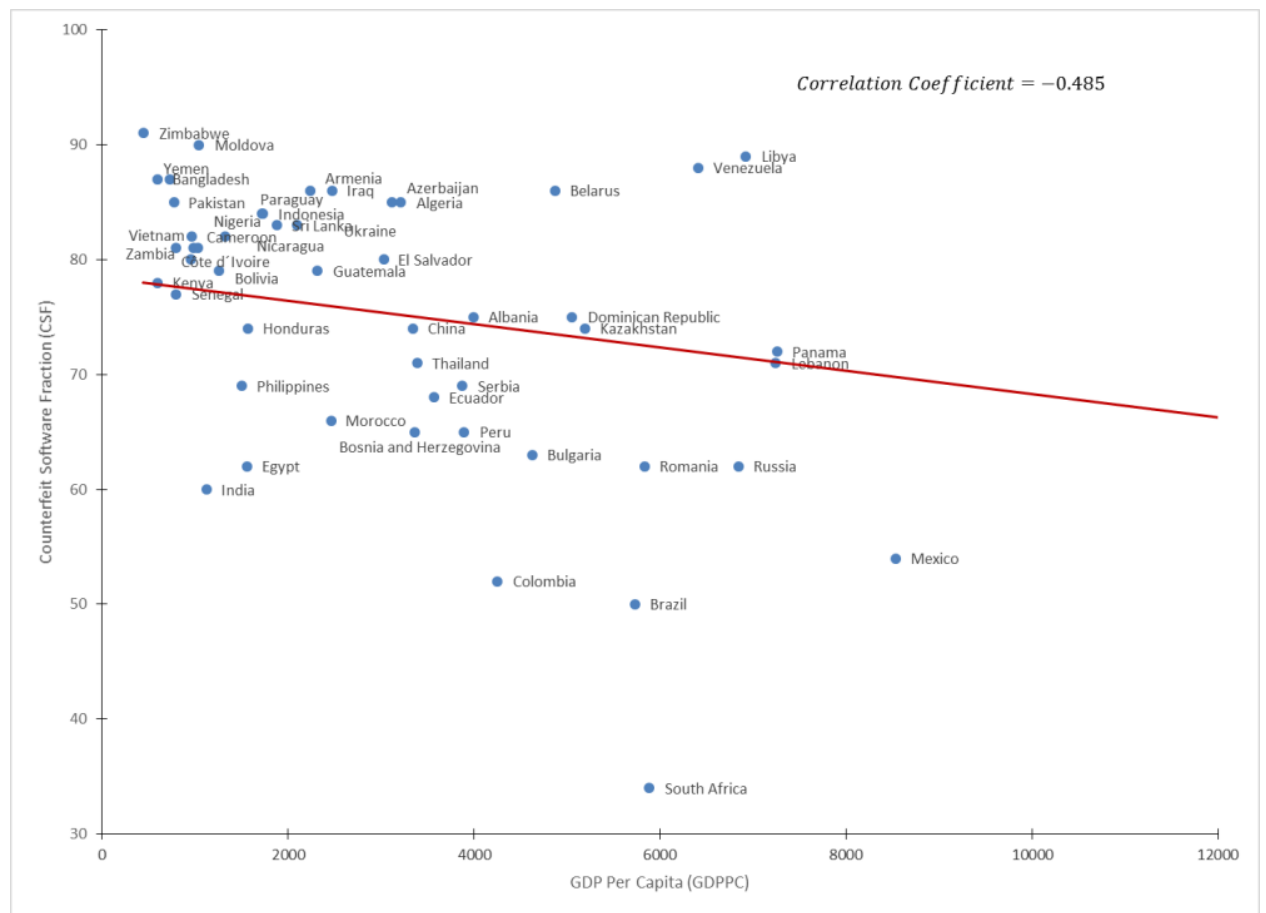

To compute the counterfeit software fraction, BSA subtracts how much PC software was legally acquired from how much PC software was deployed during the year 2013 by 
consumers and firms. Therefore, Figures $1 a-1 b$ indicate that counterfeit software is both an inferior good and an inferior input. Intuitively, as GDP increases, households are more willing to consume legitimate software instead of counterfeit software and firms tend to substitute legitimate software for counterfeit software as a factor of production.

Finally, Figures $1 \mathrm{a}-1 \mathrm{~b}$ show that the inverse relationship between income and counterfeit software is moderate in the most corrupt countries. To explain this evidence, observe that the countries facing high political corruption are also the countries having low or middle income. Consequently, households and firms: (i) have incentives to demand only counterfeit software, which is cheaper than legal software, and (ii) can access to more varieties of counterfeit software, given that corrupt governments usually allow -either by receiving bribes or relaxing sanctions to software piracy- the production and consumption of counterfeit products.

In conclusion, one way to explain the relationship between the use of counterfeit software, corruption and income is to examine the role of counterfeit software as an inferior input with positive marginal productivity and incorporate government corruption as an element that affects the equilibrium provision of counterfeit software. I use this approach in my paper. In particular, I propose a firm's production function using labor, legitimate software and counterfeit software as inputs, where labor and software are complementary inputs, legitimate and counterfeit software are substitute inputs, legitimate software is a normal input and counterfeit software is an inferior factor of production. Additionally, government allows the use of counterfeit software and adjusts its price depending on its level of corruption. If government is corrupt, it receives a bribe from the firm. If government is clean, it imposes a sanction to the firm. In this sense, the firm considers corruption as a random variable. In equilibrium, corruption impacts both the equilibrium level of counterfeit software and the sensitivity of counterfeit software with respect to income.

The remainder of the paper is organized as follows. The next section provides a very brief survey of the literature on counterfeit software and economic development. Section 3 introduces the model. Section 4 presents the empirical results and section 5 concludes.

\subsection{Review of Literature}

Economic literature on counterfeit software, government corruption and economic development is scarce, even when counterfeiting software is an increasing economic activity 
in the world 4 . In general, studies of counterfeit from an empirical point of view fall broadly into two types: (a) those that examine the relationship between counterfeit software and economic development (see Andres [2006a] and [2006b], Bezmen and Depken [2006], Depken and Simmons [2004], Ding and Liu [2009], Gopal and Sanders [2000], Holm [2003], Marshall [2007], Peitz and Waelbroeck [2006], Yang and Sonmez [2007]), and (b) those that study the effects of corruption on counterfeit software (Banerjee, Khalid and Strum [2005], Goel and Nelson [2009], and Robertson, Gilley and Crittenden [2008]). However, none of these empirical papers focus on the simultaneous relationship between the three variables. In this sense, my paper serves as an attempt to explore this interaction.

The most representative empirical papers from each one of the two types mentioned above are Bezmen and Depken [2006], Gopal and Sanders [2000], and Robertson, Gilley and Crittenden [2008]. Bezmen and Depken [2006] use panel data (77 countries covering the years 1995, 2000 and 2002) to run a regression between the counterfeit software fraction (the percent of total software installed that is unlicensed) and the United Nations Human Development Index (HDI), a measurement between zero and one that includes real per capita GDP, life expectancy, access to clean water and health care, and personal and political freedom. They found a negative and significant linear relationship between the HDI and the counterfeit software fraction. However, given the composition of the index, the pure contribution of the counterfeit software fraction to the real GDP per capita cannot be determined. On the contrary, my paper is explicitly focused on the relationship between counterfeit software and GDP per capita.

Gopal and Sanders [2000] use data from 65 countries and relate real GDP per capita with the counterfeit software fraction. In particular, they segment the data in two groups using a GDP per capita equal to 6000 USD per year as a threshold. They find that: (i) there is an inverse and significant linear relationship between the GDP and the counterfeit software fraction for both groups of countries, and (ii) the estimated slope coefficient is more negative for the countries with GDP less than 6000 annual USD. The authors conclude that the counterfeit software is an inferior good. In my study, I use the CPI -instead of the GDP- as a threshold to estimate the effect of GDP on counterfeit software in two different groups of countries: the most and least corrupt. Also, In order to check the robustness of the empirical model, I introduce two other key explanatory institutional determinants of the counterfeit software: economic freedom and intellectual property rights. My results are opposite to the obtained by Gopal and Sanders, as I find that the relationship between

\footnotetext{
${ }^{4}$ In 2010, the Business Software Alliance (BSA) published in 2010 a study which concludes that the counterfeit software fraction in the world was 42 percent, which remains the second highest global rate in the study's history. In the same line, the BSA indicates that "the commercial value of PC software piracy leapt 14 percent globally in 2010 to $\$ 59$ billion. This figure has nearly doubled in real terms since 2003."
} 
counterfeit software and GDP per capita is more negative in the case of the least corrupt countries, which are -simultaneously- the countries with higher GDP per capita.

Robertson, Gilley, and Crittenden [2008] propose three hypothesis involving counterfeit software, corruption and economic freedom: (i) economic freedom has a negative effect on corruption, (ii) corruption has a positive effect on software piracy rates, and (iii) economic freedom indirectly reduces counterfeit software. Unfortunately, even when they examine empirically the three hypothesis using cross-section data (77 countries for the year 1999), their results are not complemented with a theoretical framework. On the contrary, I propose a model where government intervention and the software production costs are the main factors driving the equilibrium levels of corruption and counterfeit software. Finally, I test the model using more recent cross-section data (107 countries for the period 1995-2013).

\subsection{Model}

The model is composed of three countries: two software exporting countries and one software importing country. In particular, country A produces legitimate software, country B produces counterfeit software and country $E$ imports both types of software. Country $E$ consists of many identical firms and consumers. For simplicity, I only model the behavior of three agents: a representative firm, a representative consumer and the government. The firm uses labor, legitimate and counterfeit software to produce a final good. The consumer demands the final good and supplies labor to the firm. The government monitors perfectly the use of counterfeit software and has two options when the firm uses it: take a bribe from the firm or sanction it, where each option reports revenue to the government. The firm maximizes expected profits, the government maximizes revenues and the consumer maximizes utility.

There are two key features in the model: (i) the incorporation of counterfeit software as an inferior input into the firm's production function, and (ii) the existence of an optimal level of government's corruption that affects the equilibrium level of counterfeit software. In particular, I assume that the government does not ban the use of counterfeit software and it has only two policies to raise revenue: sanctioning the firm or being bribed by it. The relative importance of each policy is a function of the level of government's corruption. Therefore, government revenue is a function of corruption. Finally, the model assumes that: (i) the sanction amount is higher than the bribe amount, and (ii) it is easier to collect a bribe than a sanction. This trade-off implies a positive level of corruption in equilibrium. 
By imposing equilibrium conditions in the final good and factor markets, seven variables (wage, prices and quantities of both types of software, consumption and output) are expressed as functions of the level of government's corruption. Finally, by computing the sensitivities (derivatives) of counterfeit software with respect to the level of corruption and the legitimate software production cost, I find the following three results: (i) counterfeit software is decreasing in output, (ii) this negative relationship depends on the level of corruption and (iii) counterfeit software is decreasing in the legitimate software production cost.

\subsubsection{The Consumer's Problem}

The representative consumer in country $E$ has the following utility function:

$$
U(C, L)=\ln C+\ln L,
$$

where $C$ is consumption of a final good and $L$ is leisure. The consumer is endowed with $H=$ 1 unit of time, which can be allocated between work $N^{S}$ and leisure, and supplies labor to the firm located in country E. Each unit of labor is rented to the firm at given wage $w$. The consumer chooses $C$ and $L$ that maximize (1) subject to the following resource and nonnegativity constraints:

$$
\begin{gathered}
C=\frac{w}{P}(1-L), \\
C \geq 0, \quad 0 \leq L \leq 1,
\end{gathered}
$$

where $P$ is the price of the final good. The first order condition of the problem is $C=\frac{w L}{P}$. After substituting this condition into the resource constraint and solving for the labor supply $N^{S} \equiv 1-L$, I obtain $N^{S}=\frac{1}{2}$.

\subsubsection{The Firm's Problem}

Given the information provided in Section 1, empirical evidence reveals the existence of a negative income effect on counterfeit software. Thus, I propose a specific production function that allows for counterfeit software as an inferior input. In particular, the representative firm in country $E$ has the production function given by:

$$
Y=F\left(X_{A}^{D}, X_{B}^{D}, N^{D}\right)=\left(X_{A}^{D}+X_{B}^{D}\right)^{\alpha}\left(N^{D}\right)^{\beta}-0.5\left(X_{B}^{D}\right)^{2},
$$


where $Y$ is output of the final good, $X_{A}^{D}$ and $X_{B}^{D}$ are the demands for legitimate and counterfeit software, $N^{D}$ is the labor demand, and $\alpha, \beta$ are positive parameters satisfying $0<\alpha, \beta<1$ and $\alpha+\beta<1$. As I assume perfect competition in Equation (4) is a special case of the production function proposed by Epstein and Spiegel (2000). In order to be considered a production function, the marginal productivities of $X_{A}^{D}$ and $X_{B}^{D}$ must be positive. The marginal productivity of $X_{A}^{D}$ is:

$$
\frac{\partial Y}{\partial X_{A}^{D}}=\frac{\alpha\left(N^{D}\right)^{\beta}}{\left(X_{A}^{D}+X_{B}^{D}\right)^{1-\alpha}}>0 .
$$

The marginal productivity of $X_{B}^{D}$ is calculated as follows:

$$
\frac{\partial Y}{\partial X_{B}^{D}}=\frac{\alpha\left(N^{D}\right)^{\beta}}{\left(X_{A}^{D}+X_{B}^{D}\right)^{1-\alpha}}-X_{B}^{D}>0,
$$

where I impose that the following condition is satisfied:

$$
X_{A}^{D}<\left[\frac{\alpha\left(N^{D}\right)^{\beta}}{X_{B}^{D}}\right]^{\frac{1}{1-\alpha}}-X_{B}^{D} .
$$

Observe that labor and software are imperfect complements in the production function, but the two types of software are substitutes. The firm rents labor at wage $w$ and buys each unit of legitimate and counterfeit software from the exporting countries at prices $p_{A}$ and $p_{B}$ to maximize expected profits $\pi_{f}^{e}\left(X_{A}^{D}, X_{B}^{D}, N^{D}\right)$, where $w, p_{A}$ and $p_{B}$ are taken as given. The government in country $E$ always monitors the use of counterfeit software but does not always punish its use. In particular, assume there are two types of bureaucrats in the government: corrupt and non-corrupt. Corrupt agents are present in the model in measure $\theta$, non-corrupt agents are present in measure $1-\theta$, and all agents of a given type are identical. Corrupt agents extract a bribe $f$ from the firm, non-corrupt agents charges a sanction $s$ to the firm $(0<f<s<1)$, and the bribe is the product of a Nash bargaining solution between government and the firm and (see Besley and McLaren (1993)). Formally, the optimal bribe solves: 


$$
\max _{\{f\}}(s-f)^{1-\lambda} f^{\lambda}
$$

where $s-f$ and $f$ are the bargain surplus of the firm and government. The solution of (8) is given by:

$$
f^{*}=\lambda s,
$$

where $\lambda$ is the bargaining power of government. Given this information, the firm solves:

$$
\max _{\left\{X_{A}^{D}, X_{B}^{D}, N^{D}\right\}} \pi_{f}^{e}=P F\left(X_{A}^{D}, X_{B}^{D}, N^{D}\right)-p_{A} X_{A}^{D}-\phi p_{B} X_{B}^{D}-w N^{D},
$$

where I impose that country $E$ is a small open economy selling the final good in the world market at a competitive given price $P, \pi_{f}^{e}$ are the expected profits and $\phi \equiv \theta\left(1+f^{*}\right)+$ $(1-\theta)(1+s)=1+[1-\theta(1-\lambda)] s$. I obtain the factor demands $N^{D}, X_{A}^{D}$ and $X_{B}^{D}$ from the first order conditions:

$$
\begin{gathered}
\frac{\partial \pi_{f}^{e}}{\partial N^{D}}=0 \Rightarrow w=\frac{\beta P\left(X_{A}^{D}+X_{B}^{D}\right)^{\alpha}}{\left(N^{D}\right)^{1-\beta}} \\
\frac{\partial \pi_{f}^{e}}{\partial X_{A}^{D}}=0 \Rightarrow p_{A}=\frac{\alpha P\left(N^{D}\right)^{\beta}}{\left(X_{A}^{D}+X_{B}^{D}\right)^{1-\alpha}} \\
\frac{\partial \pi_{f}^{e}}{\partial X_{B}^{D}}=0 \Rightarrow p_{B}=\frac{P}{\phi}\left[\frac{\alpha\left(N^{D}\right)^{\beta}}{\left(X_{A}^{D}+X_{B}^{D}\right)^{1-\alpha}}-X_{B}^{D}\right] .
\end{gathered}
$$

By substituting (12) into (13), I derive the equilibrium value of $X_{B}^{D}$ :

$$
X_{B}^{*}=\frac{p_{A}-\phi p_{B}}{P}
$$

where I assume that $p_{A}>\phi p_{B}$, the price of legitimate software is greater than the price of counterfeit software including the government intervention through the sanction or bribed received. By imposing equilibrium in the labor market, $N^{S}=N^{D}=N^{*}=\frac{1}{2}$. Finally, I substitute $X_{B}^{*}$ in (12) to get $X_{A}^{*}$ : 


$$
X_{A}^{*}=\frac{\eta}{p_{A}^{\frac{1}{1-\alpha}}}-\frac{p_{A}}{P}+\frac{\phi p_{B}}{P}
$$

where $\eta \equiv\left[\frac{\alpha P}{2^{\beta}}\right]^{\frac{1}{1-\alpha}}$. Observe that $X_{A}^{*}$ and $X_{B}^{*}$ are functions of $p_{A}$ and $p_{B}$, but they do not depend on $w$. On the other hand, by plugging equations (14) and (15) into equation (11), it is easy to see that $w$ depends on $p_{A}$. Thus, equilibrium wage is obtained in the labor market (where an inelastic labor supply equals a downward sloping labor demand), equilibrium software prices are determined exclusively from a Bertrand market structure define in section 3.4, and changes in $p_{A}$ shifts the labor demand and affects the equilibrium wage. Without loss of generality, assume that the term $\frac{\eta}{p_{A^{\frac{1-\alpha}{1-\alpha}}}}$ is linearly approximated around $p_{A}=$ 1. In this case, equation (15) becomes:

$$
\begin{gathered}
X_{A}^{*}=\left(\frac{2-\alpha}{1-\alpha}\right) \eta-\left[\frac{\eta P+1-\alpha}{(1-\alpha) P}\right] p_{A}+\frac{\phi p_{B}}{P} . \\
Y=\left(\frac{\alpha}{2^{\frac{\beta}{\alpha}} p_{A}}\right)^{\frac{\alpha}{1-\alpha}} P^{\frac{\alpha}{1-\alpha}}-0.5\left(\frac{p_{A}-\phi p_{B}}{P}\right)^{2} \Rightarrow \frac{\partial Y}{\partial P}>0 .
\end{gathered}
$$

From equations (14), (15) and (17), I conclude that $X_{A}^{*}$ is normal input and $X_{B}^{*}$ is inferior input. Formally,

$$
\begin{gathered}
\frac{\partial X_{A}^{*}}{\partial Y}=\frac{\partial X_{A}^{*}}{\partial P} \frac{1}{\frac{\partial Y}{\partial P}}=\left\{\left[\frac{2-\alpha-p_{A}}{(1-\alpha)^{2}}\right]\left(\frac{\alpha}{2^{\beta}}\right)^{\frac{1}{1-\alpha}} P^{\frac{\alpha}{1-\alpha}}+\frac{p_{A}-\phi p_{B}}{P^{2}}\right\} \frac{1}{\frac{\partial Y}{\partial P}}>0 \\
\frac{\partial X_{B}^{*}}{\partial Y}=\frac{\partial X_{B}^{*}}{\partial P} \frac{1}{\frac{\partial Y}{\partial P}}=\frac{-\left(p_{A}-\phi p_{B}\right)}{P^{2}} \frac{1}{\frac{\partial Y}{\partial P}}<0 .
\end{gathered}
$$


Intuitively, an increase in the international price for the final good encourages the production of additional output. As indicated by equations (5) and (6), the marginal productivity of legitimate software is higher that the marginal productivity of counterfeit software. Therefore, the firm will substitute $X_{B}^{*}$ with $X_{A}^{*}$ to increase output, moving $X_{B}^{*}$ and $Y$ in opposite directions.

\subsubsection{The Government's Problem}

The objective of the government in country $\mathrm{E}$ is to maximize its expected revenue $\pi_{g}^{e}$ coming from the sanction and the bribe. Formally, government chooses the probability of corruption and the sanction rate $\{\theta, s\}$ that maximize $\pi_{g}^{e}$. Formally,

$$
\max _{\{\theta, s\}} \quad \pi_{g}^{e}=\left[\theta f^{*}+(1-\theta) s\right] p_{B}^{*} X_{B}^{*}
$$

where $p_{B}^{*}$ and $X_{B}^{*}$ are the equilibrium price and quantity determined in the counterfeit software market. Suppose that more ethical behavior for government leads to impose a higher penalty on the use of counterfeit software. Formally, let $s=1-\theta$ be the one-to-one relation between the sanction rate and the probability of law enforcement. Using this assumption and the fact $f^{*}=\lambda s$, equation (20) reduces to:

$$
\max _{\{s\}} \quad \pi_{g}^{e}=\left[\lambda s+(1-\lambda) s^{2}\right] p_{B}^{*} X_{B}^{*}
$$

\subsubsection{The Exporting Countries}

There are two exporting countries: A and B. Each country has only one firm that produces software to the representative firm located in E. Country A produces legitimate software and country B produces counterfeit software, according to the demand functions (14) and (16). Let $c_{A}$ and $c_{B}$ be the unitary production costs, where $c_{A}>c_{B}$. Given the above information, each firm simultaneously chooses the software price that maximizes its profit $\pi_{i}(i=A, B)$, taking as given the rival's price, $\alpha, \beta, P$ and $\phi$. In other words, I assume a Bertrand duopoly with heterogeneous goods. Formally,

$$
\max _{\left\{p_{A}\right\}} \quad \pi_{A}=\left(p_{A}-c_{A}\right) X_{A}^{*}=\left(p_{A}-c_{A}\right)\left\{\left(\frac{2-\alpha}{1-\alpha}\right) \eta-\left[\frac{\eta P+1-\alpha}{(1-\alpha) P}\right] p_{A}+\frac{\phi p_{B}}{P}\right\},
$$




$$
\max _{\left\{p_{B}\right\}} \pi_{B}=\left(p_{B}-c_{B}\right) X_{B}^{*}=\left(p_{B}-c_{B}\right)\left(\frac{p_{A}-\phi p_{B}}{P}\right) .
$$

The reaction functions are given by:

$$
\begin{gathered}
\frac{\partial \pi_{A}}{\partial p_{A}}=0 \Rightarrow p_{A}=\frac{(2-\alpha) \eta P}{2(\eta P+1-\alpha)}+\frac{c_{A}}{2}+\frac{(1-\alpha) \phi}{2(\eta P+1-\alpha)} p_{B} \\
\frac{\partial \pi_{B}}{\partial p_{B}}=0 \Rightarrow p_{B}=\frac{c_{B}}{2}+\frac{p_{A}}{2 \phi} .
\end{gathered}
$$

After solving equations (25) and (26) I obtain the equilibrium prices and quantities:

$$
\begin{gathered}
p_{A}^{*}=2\left[\frac{(2-\alpha) \eta P+(\eta P+1-\alpha) c_{A}}{4 \eta P+3(1-\alpha)}\right]+\left[\frac{(1-\alpha) \phi c_{B}}{4 \eta P+3(1-\alpha)}\right] \\
p_{B}^{*}=\frac{1}{\phi}\left[\frac{(2-\alpha) \eta P+(\eta P+1-\alpha) c_{A}}{4 \eta P+3(1-\alpha)}\right]+\left[\frac{2(\eta P+1-\alpha) c_{B}}{4 \eta P+3(1-\alpha)}\right] \\
X_{A}^{*}=\left(\frac{2-\alpha}{1-\alpha}\right) \eta-\frac{1}{P}\left(\frac{2 \eta P+1-\alpha}{1-\alpha}\right)\left[\frac{(2-\alpha) \eta P+(\eta P+1-\alpha) c_{A}}{4 \eta P+3(1-\alpha)}\right]+\frac{\phi}{P}\left[\frac{(\eta P+1-\alpha) c_{B}}{4 \eta P+3(1-\alpha)}\right] \\
X_{B}^{*}=\frac{1}{P}\left[\frac{(2-\alpha) \eta P+(\eta P+1-\alpha) c_{A}}{4 \eta P+3(1-\alpha)}\right]-\frac{\phi}{P}\left[\frac{(2 \eta P+1-\alpha) c_{B}}{4 \eta P+3(1-\alpha)}\right]
\end{gathered}
$$




\subsubsection{Equilibrium}

A competitive equilibrium is a set of quantities $\left\{C^{*}, Y^{*}, N^{*}, X_{A}^{*}, X_{B}^{*}\right\}$ and prices $\left\{w^{*}, p_{A}^{*}, p_{B}^{*}\right\}$ that satisfy the following conditions:

1. The representative consumer chooses $C$ and $L$ optimally given $P$ and $w$.

2. The representative firm chooses $N^{D}, X_{A}^{D}$ and $X_{B}^{D}$ optimally given $P, w, p_{A}$ and $p_{B}$.

3. The markets clear: $Y^{*}=C^{*}, N^{D}=N^{S}=N^{*}$, and $X_{i}^{D}=X_{i}^{S}=X_{i}^{*}(i=A, B)$, and

4. Exporting country $\mathrm{A}$ chooses $p_{A}$ optimally given $p_{B}$ and exporting country $\mathrm{B}$ chooses $p_{B}$ optimally given $p_{A}$.

\subsubsection{Results}

By substituting the definition of (27) and (29) into (21), the government's problem is:

$$
\max _{\{s\}} \quad \pi_{g}^{e}=(\phi-1)\left(\frac{K}{\phi}+M\right)\left(\frac{K}{P}-\frac{\phi}{P} N\right)
$$

where $K \equiv \frac{(2-\alpha) \eta P+(\eta P+1-\alpha) c_{A}}{4 \eta P+3(1-\alpha)}, \quad M \equiv \frac{2(\eta P+1-\alpha) c_{B}}{4 \eta P+3(1-\alpha)}$ and $N \equiv \frac{(2 \eta P+1-\alpha) c_{B}}{4 \eta P+3(1-\alpha)}$. For the sake of simplicity, assume that the cost of producing counterfeit software is negligible such that $c_{B}^{2} \approx 0$. In this case, $M N \approx 0$ and the government's problem (31) is simply:

$$
\max _{\{s\}} \quad \pi_{g}^{e}=K(N-M)\left[1+\lambda s+(1-\lambda) s^{2}\right]+K^{2}\left[1+\lambda s+(1-\lambda) s^{2}\right]^{-1}
$$

The first order condition is:

$$
\frac{\partial \pi_{g}^{e}}{\partial s}=0 \Rightarrow s^{*}=\frac{-\lambda+\sqrt{\lambda^{2}-4(1-\lambda)\left[1-\sqrt{\frac{(2-\alpha) \eta P+(\eta P+1-\alpha) c_{A}}{(1-\alpha) c_{B}}}\right]}}{2(1-\lambda)}
$$

Observe that $\frac{\partial s^{*}}{\partial c_{B}}<0$ and $\frac{\partial s^{*}}{\partial c_{A}}>0$. Intuitively, a reduction in the cost of producing counterfeit software (or an increase in the cost of producing legitimate software) implies an increase in the equilibrium quantity $X_{B}^{*}$ and a reduction in the equilibrium price $p_{B}^{*}$. 
Therefore, in order to raise revenue, government will impose a higher sanction rate $s^{*}$, which results in obtaining additional resources from a penalty or a bribe.

\subsubsection{Corruption, output and counterfeit software}

Given the above information, I propose three results based on equations (20) and (30):

Result 1: if there is a one-to-one relation between the sanction rate and the measure of non-corrupt bureaucrats ( $s=1-\theta$ ), then the equilibrium quantity of counterfeit software $X_{B}^{*}$ is increasing in the number of corrupt agents $\theta$. Formally,

$$
\frac{\partial X_{B}^{*}}{\partial \theta}=\frac{(2 \eta P+1-\alpha)[\lambda+2(1-\lambda)(1-\theta)] c_{B}}{4 \eta P^{2}+3(1-\alpha) P}>0
$$

Result 2: if there is a one-to-one relation between the sanction rate and the measure of non-corrupt bureaucrats $(s=1-\theta)$, then an increase in the number of corrupt bureaucrats $\theta$ implies a reduced negative income effect on $X_{B}^{*}$. Formally, by plugging equations (26) and (27) into equation (19), I verify that counterfeit software is an inferior input:

$$
\frac{\partial X_{B}^{*}}{\partial Y}=-\frac{\partial P}{\partial Y} \frac{1}{P^{2}}\left[\frac{(2-\alpha) \eta P+(\eta P+1-\alpha) c_{A}}{4 \eta P+3(1-\alpha)}\right]-\frac{\partial P}{\partial Y} \frac{\phi}{P^{2}}\left[\frac{(2 \eta P+1-\alpha) c_{B}}{4 \eta P+3(1-\alpha)}\right]<0 .
$$

Therefore,

$$
\frac{\partial\left(\frac{\partial X_{B}^{*}}{\partial Y}\right)}{\partial \theta}=\frac{\partial P}{\partial Y} \cdot \frac{(2 \eta P+1-\alpha)[\lambda+2(1-\lambda)(1-\theta)] c_{B}}{4 \eta P^{3}+3(1-\alpha) P^{2}}>0
$$

See Figure 2. 
Figure 2. Corruption and Income Effect on Counterfeit Software

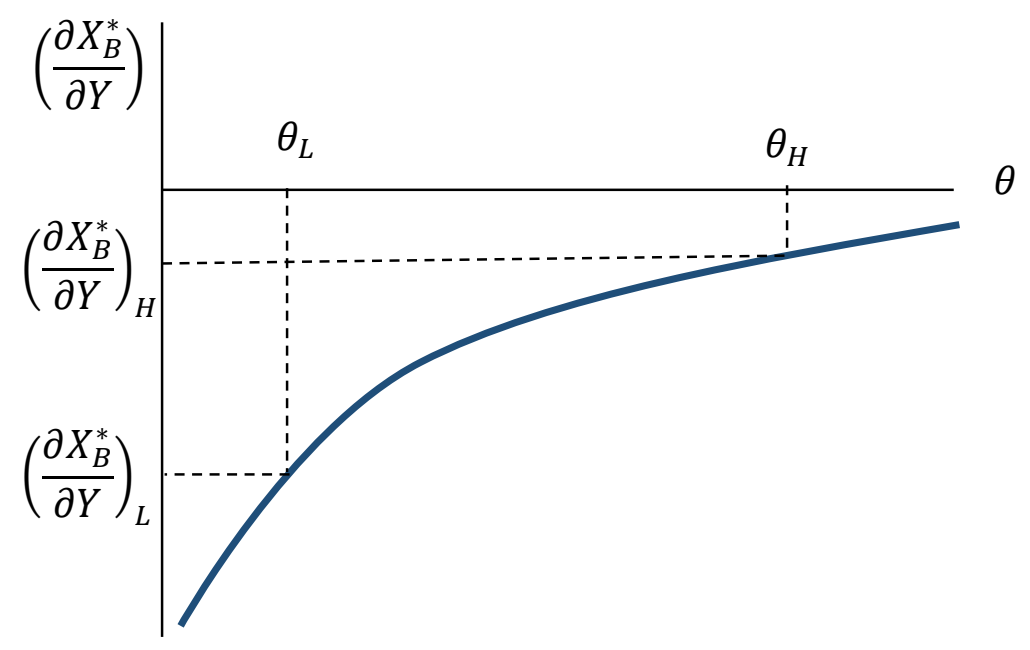

According to Figure 2, as the number of corrupt bureaucrats increases from $\theta_{L}$ to $\theta_{H}$, the negative income effect increases (this is, it is closer to zero) from $\left(\frac{\partial X_{B}^{*}}{\partial Y}\right)_{L}$ to $\left(\frac{\partial X_{B}^{*}}{\partial Y}\right)_{H}$.

Result 3: if there is a one-to-one relation between the sanction rate and the measure of non-corrupt bureaucrats $(s=1-\theta$ ), then a decrease in the production cost of legitimate software $c_{A}$ implies a decrease in the equilibrium quantity of counterfeit software $X_{B}^{*}$. Formally,

$$
\frac{\partial X_{B}^{*}}{\partial c_{A}}=\frac{1}{P}\left[\frac{\eta P+1-\alpha}{4 \eta P+3(1-\alpha)}\right]>0
$$

\subsection{Empirical Evidence}

In this section I test the three results of the model using international data from the World Bank, Transparency International and the Business Software Alliance for 107 countries in the period 2007-2013. I use the following six variables: real GDP per capita (expressed in 2005 dollars), the corruption perceptions index CPI (based on surveys from 10 independent institutions), the counterfeit software fraction (computed as the percentage of total software that is unlicensed), the cost to import COST and the patents rights index PRI. I separate the analysis in two parts. In the first part, I divide the sample into two groups of countries according to their CPI and using the median as the threshold. In the second part, I run a panel data regression using the counterfeit software fraction as the dependent variable and the GDP, COST and PRI as explanatory variables. In the following lines, I describe the variables used in the empirical analysis: 
Table 1. Descriptive Statistics

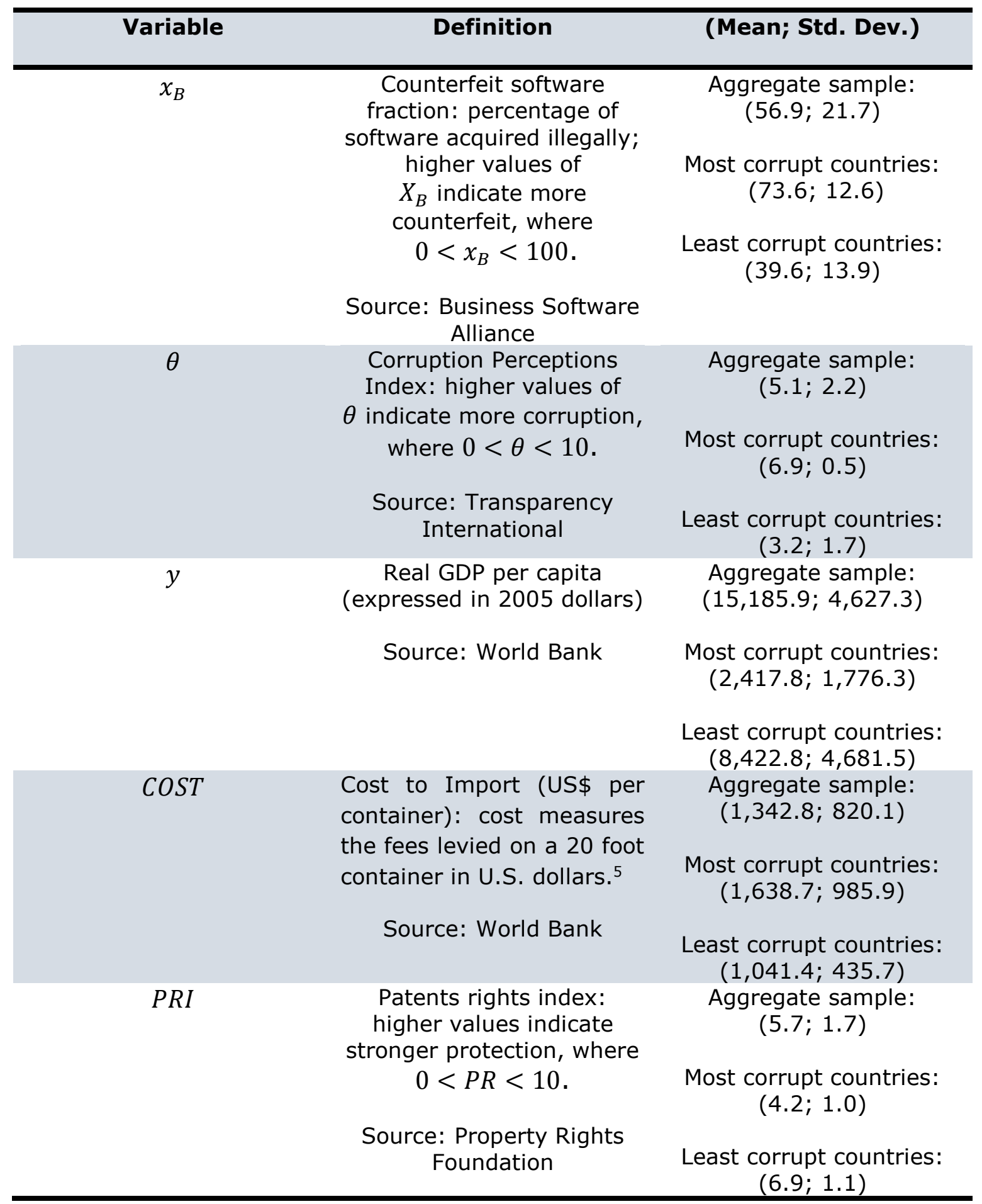

\footnotetext{
${ }^{5}$ All the fees associated with completing the procedures to import the goods are included These include costs for documents, administrative fees for customs clearance and technical control, customs broker fees, terminal handling charges and inland transport. The cost measure does not include tariffs or trade taxes. Only official costs are recorded.
} 
Given the information above, I propose the following panel data model:

$$
\log \left[\frac{\left(x_{B}\right)_{i t}}{100-\left(x_{B}\right)_{i t}}\right]=\mu_{0}+\mu_{1} y_{i t}+\mu_{2} \operatorname{COST}_{i t}+\mu_{3} P R I_{i t}+a_{i}+v_{t}+u_{i t}
$$

where $i$ denotes the country, $t$ indicates the time period $(t=2005, \ldots, 2013)$, and I use a logit transformation for $x_{B}$ because the dependent variable (counterfeit software fraction) is bounded: a percentage between zero and 100 . Finally, $a_{i}, v_{t}$, and $u_{i t}$ represent the three disturbance terms. In first place, $a_{i}$ is the country intercept encapsulating all the variables that affect $\log \left[\frac{\left(x_{B}\right)_{i t}}{100-\left(x_{B}\right)_{i t}}\right]$ but do not vary over time. For example, $a_{i}$ represents the country heterogeneity related to differences in using counterfeit software: individuals' moral attitudes to pirate modify its production and consumption. In second place, $v_{t}$ is the timevarying intercept capturing all the variables that affect $\log \left[\frac{\left(x_{B}\right)_{i t}}{100-\left(x_{B}\right)_{i t}}\right]$ and that change over time but are constant across countries. An example would be where a technological change in the software industry through the sample period. This change influences the use of counterfeit software, but in the same way for all countries. Finally, $u_{i t}$ is the error term representing unobserved factors that vary over time and across countries. For instance, $u_{i t}$ contains information about public policy taken by a specific country over the period 20052013. In order to estimate (29), I propose the fixed effects model containing country and time dummy variables. Table 2 reports the results:

Table 2. Estimation Results

\begin{tabular}{|c|c|c|c|c|c|}
\hline Model/Variable & Intercept & PRI & $\mathbf{y}$ & COST & $\begin{array}{c}\text { Adjusted } \\
\mathbf{R}^{2} \\
\end{array}$ \\
\hline $\begin{array}{c}\text { Full Sample } \\
\text { Observations }=334\end{array}$ & $\begin{array}{c}3.2 \\
(0.0000)\end{array}$ & $\begin{array}{c}-0.4 \\
(0.0000)\end{array}$ & $\begin{array}{l}-9.4 \mathrm{E}-06 \\
(0.0009)\end{array}$ & $\begin{array}{l}7.3 \mathrm{E}-05 \\
(0.0809)\end{array}$ & 0.8 \\
\hline $\begin{array}{l}\text { Least Corrupt } \\
\text { Countries }\end{array}$ & $\begin{array}{c}3.4 \\
(0.0000)\end{array}$ & $\begin{array}{c}-0.5 \\
(0.0000)\end{array}$ & $\begin{array}{l}-1.3 \mathrm{E}-08 \\
(0.0000)\end{array}$ & $\begin{array}{c}0.0002 \\
(0.0119)\end{array}$ & 0.7 \\
\hline Observations $=168$ & & & & & \\
\hline $\begin{array}{l}\text { Most Corrupt } \\
\text { Countries }\end{array}$ & $\begin{array}{c}3.03 \\
(0.0000)\end{array}$ & $\begin{array}{c}-0.4 \\
(0.0000)\end{array}$ & $\begin{array}{l}-1.1 \mathrm{E}-05 \\
(0.1505)\end{array}$ & $\begin{array}{l}-2.1 \mathrm{E}-06 \\
(0.9633)\end{array}$ & 0.5 \\
\hline Observations $=166$ & & & & & \\
\hline
\end{tabular}


Table 2 indicates that: $(i)$ there is a negative relationship between the real GDP per capita and the counterfeit software fraction, and (ii) this relationship is statistically significant only in the subsample containing the least corrupt countries: On the contrary, for the most corrupt countries, changes in GDP per capita have no effect on counterfeit software. One explanation of this result is the following: countries facing high levels of political corruption are, typically, low-income countries. Therefore, higher per capita income does not improve the ability to pay for legitimate software, and hence the use of counterfeit software is unaffected. On the other hand, given political corruption is low in high-income countries, the government is permanently implementing policies to control this activity. Therefore, an increase in GDP per capita reduces the consumption of counterfeit software. Observe that this evidence is consistent with Results 1 and 2.

The International Property Rights Index (PRI) is composed by three elements: Legal and Political Environment, Physical Property Rights and Intellectual Property Rights. These three components include, among other variables, control of corruption and copyright piracy. Therefore, an increase in the PRI implies additional support for rule of law and patent protection. According to Table 2, the counterfeit software fraction is decreasing in the PRI for the whole sample. Additionally, this effect is stronger for the least corrupt countries. The existence of better quality of law enforcement, police and courts in this group of countries could explain the difference. Observe that this evidence is consistent with Result 3: a higher PRI encourages technology creation, reducing the cost of producing legitimate software. As a result, the use of counterfeit software decreases.

The Cost to Import measures the fees levied on a 20 foot container in U.S. dollars. All the fees associated with completing the procedures to import the goods are included. A lower cost indicates the absence -or reduction- of tariff barriers that affect imports of goods and services. Therefore, I interpret this information as follows: a decrease in COST facilitates the imports of substitute goods to counterfeit software. In particular, as the variety of legitimate software increases, the use of counterfeit software decreases. Observe that this negative impact is only statistically significant for the least corrupt countries, where the use of counterfeit software is lower.

To quantify the marginal effects of the independent variables on the piracy rate, observe that equation (29) can be expressed as:

$$
\frac{\left(x_{B}\right)_{i t}}{100-\left(x_{B}\right)_{i t}}=e^{z_{i t}} \Rightarrow\left(x_{B}\right)_{i t}=\frac{100}{1+e^{-z_{i t}}},
$$


where $\quad z_{i t} \equiv \mu_{0}+\mu_{1} y_{i t}+\mu_{2} \operatorname{COST}_{i t}+\mu_{3} P R I_{i t}+a_{i}+v_{t}+u_{i t} . \quad$ Let $\quad F\left(z_{i t}\right) \equiv \frac{100}{1+e^{-z_{i t}}}$. Therefore, the sensitivity of the counterfeit software fraction with respect to the independent variable $k_{i t}$ is:

$$
\frac{\partial\left(x_{B}\right)_{i t}}{\partial k_{i t}}=F^{\prime}\left(z_{i t}\right) \cdot \frac{\partial z_{i t}}{\partial k_{i t}}
$$

where $F^{\prime}\left(z_{i t}\right) \equiv \frac{100 e^{-z_{i t}}}{\left(1+e^{\left.-z_{i t}\right)^{2}}\right.}$ and $k_{i t}=y_{i t}, \operatorname{COST}_{i t}, P R I_{i t}$. The corresponding marginal effect in the estimated model is:

$$
\frac{\partial\left(\hat{x}_{B}\right)_{i t}}{\partial k_{i t}}=F^{\prime}\left(\hat{z}_{i t}\right) \cdot \frac{\partial \hat{z}_{i t}}{\partial k_{i t}}
$$

where $\hat{z}_{i t} \equiv \hat{\mu}_{0}+\hat{\mu}_{1} y_{i t}+\hat{\mu}_{2} \operatorname{COST}_{i t}+\hat{\mu}_{3} P R I_{i t}$. For the sake of simplicity, I use $F^{\prime}(\bar{z})$, where $\bar{z} \equiv \hat{\mu}_{0}+\hat{\mu}_{1} \bar{y}+\hat{\mu}_{2} \overline{C O S T}+\hat{\mu}_{3} \overline{P R I}$ and the bar denotes the average value. Table 3 reports the marginal effects at the sample means.

\begin{tabular}{|c|c|c|c|}
\hline Model/Variable & $\overline{\text { PRI }}$ & $\mathbf{y}$ & COST \\
\hline Full Sample & $\begin{array}{l}-12.941 \\
(0.0000)\end{array}$ & $\begin{array}{l}-0.0002 \\
(0.0009)\end{array}$ & $\begin{array}{c}1.7827 \mathrm{E}-03 \\
(0.0809)\end{array}$ \\
\hline \multicolumn{4}{|l|}{ Observations $=334$} \\
\hline $\begin{array}{l}\text { Least Corrupt } \\
\text { Countries }\end{array}$ & $\begin{array}{l}-13.8979 \\
(0.0000)\end{array}$ & $\begin{array}{l}-0.0003 \\
(0.0001)\end{array}$ & $\begin{array}{c}4.8443 \mathrm{E}-03 \\
(0.0119)\end{array}$ \\
\hline \multicolumn{4}{|l|}{ Observations $=168$} \\
\hline $\begin{array}{l}\text { Most Corrupt } \\
\text { Countries }\end{array}$ & $\begin{array}{l}-8.3084 \\
(0.0000)\end{array}$ & $\begin{array}{l}-0.00017 \\
(0.2409)\end{array}$ & $\begin{array}{c}-5.2318 \mathrm{E}-05 \\
(0.9633)\end{array}$ \\
\hline Observations $=160$ & & & \\
\hline
\end{tabular}

Table 3. Marginal Effects (Unit Change in Each Independent Variable)

According to Table 3, if real GDP per capita increases in 1,000 U.S. dollars, then the counterfeit software fraction reduces in $0.2 \%$ for the full sample, $0.3 \%$ for the sample of 
least corrupt countries but it remains unchanged in the most corrupt countries. Similarly, the cost to import only has a statistical significant impact on the counterfeit software fraction for the full sample and the group of least corrupt countries: if the cost to import rises in 100 U.S. dollars, then the counterfeit software fraction decreases in $0.1 \%$ and $0.4 \%$, respectively. Finally, one percent increase in the PRI reduces the use of counterfeit software in both groups of countries: $13.8 \%$ (least corrupt countries) and $8.3 \%$ (most corrupt).

Finally, I obtain the change in the number of standard deviations of counterfeit software given an increase in one standard deviation of each independent variable, from the sample mean. In particular, Table 2 reports the standard deviation of PRI, y and COST in units. Then, I compute the marginal effects (in \%) from changing these standard deviations based on the estimations showed in Table 3. Finally, I relate these marginal effects to the standard deviation of counterfeit software fraction (also in \%) for each group of countries. Table 4 summarizes the results.

Table 4. Marginal Effects (Standard Deviation Change in Each Independent Variable)

\begin{tabular}{cccc}
\hline Model/Variable & PRI & $\mathbf{y}$ & COST \\
\hline Full Sample & $-21.9 \%$ & $-0.9 \%$ & $1.4 \%$ \\
& {$[1.01]$} & {$[0.04]$} & {$[0.06]$} \\
Observations $=334$ & $(0.0000)$ & $(0.0009)$ & $(0.0809)$ \\
Least Corrupt & $-15.2 \%$ & $-1.3 \%$ & $2.1 \%$ \\
Countries & {$[1.09]$} & {$[0.09]$} & {$[0.15]$} \\
Observations $=168$ & $(0.0000)$ & $(0.0001)$ & $(0.0119)$ \\
Most Corrupt & $-8.3 \%$ & $-0.7 \%$ & $-0.05 \%$ \\
Countries & {$[0.6]$} & {$[0.06]$} & {$[0.004]$} \\
Observations $=166$ & $(0.0000)$ & $(0.2409)$ & $(0.9633)$ \\
$\begin{array}{l}\text { Number of Standard Deviations in the dependent variable in brackets. } \\
\text { p-value in parenthesis based on HAC standard errors. }\end{array}$ & \\
\end{tabular}

Table 4 shows that an increase of one standard deviation in PRI reduces the counterfeit software fraction in 1.01 (21.9\%), $1.09(15.2 \%)$ and $0.65(8.3 \%)$ standard deviations for the full sample, least corrupt countries and most corrupt countries, respectively. Similarly, an increase of one standard deviation in y reduces the counterfeit software fraction in $0.04(0.92 \%)$ and $0.09(1.38 \%)$ standard deviations for the full sample and least corrupt countries. Finally, an increase of one standard deviation in COST increases the counterfeit software fraction in $0.06(1.46 \%)$ and $0.15(2.11 \%)$ standard deviations for the full sample and least corrupt countries. I conclude that: (i) patents rights, cost to import and income per capita affect, in decreasing order of importance, the use of counterfeit 
software, and (ii) the estimated impact of each of the three independent variables is, in absolute value, larger and more statistically significant in the case of least corrupt countries.

\subsection{Conclusions}

This paper investigates the relationship between counterfeit software production, government corruption and GDP across countries. By proposing a static general equilibrium model where two software producers and one software consumer interact, I find that output has a negative effect on the equilibrium level of counterfeit software and this effect is attenuated by government corruption. I support the theory with international annual data for 107 countries in the period 2007-2013. By controlling for trade openness and intellectual property rights, the evidence suggests that: (i) real GDP per capita has a negative impact on the counterfeit software fraction, (ii) this effect is statistically significant only in the least corrupt countries, (iii) intellectual property rights reduce, through technological innovation, the use of counterfeit software, and (iv) trade openness discourages its use by expanding the variety of available goods substitute to counterfeit software. 


\subsection{References}

(1) Bezmen, Trisha L. and Depken II, Craig A., 2006. "The Impact of Software Piracy on Economic Development," Manuscript.

(2) Gopal, Ram D. and Sanders, Lawrence, 2006. "Global software piracy: you can't get blood out of a turnip." Communications of the ACM, 43 (9), p. 82-89.

(3) Andrés, A.R. 2006a. "Software Piracy and Income Inequality." Applied Economics Letters 13: $101-105$.

(4) Andrés, A.R. 2006b. "The Relationship between Copyright Software Protection and Piracy: Evidence from Europe." European Journal of Law and Economics 21: 29-51.

(5) Banerjee, D., A.M. Khalid, and J.E. Strum. 2005. "Socio-Economic Development and Software Piracy: An Empirical Assessment." Applied Economics 37: 2091-2097.

(6) Banerjee, D.S. 2006. "Enforcement Sharing and Commercial Piracy." Review of Economic Research on Copyright Issues 3: 83-97.

(7) Besley, Timothy \& John McLaren. 1993. "Taxes and Bribery: The Role of Wage Incentives." Economic Journal 103: 119-141.

(8) Bezmen, T.L., and C.A. Depken. 2006. "Influences on Software Piracy: Evidence from the Various United States." Economics Letters 90: 356-361.

(9) Business Software Alliance (BSA). 2011. Piracy Study. Ninth Annual BSA and IDC Global Software.

(10) Business Software Alliance (BSA). 2009. What is Software Piracy, 2009. http://www.bsa.org/Piracy\%20Portal.aspx (accessed May 2009).

(11) Depken, C.A., and L.C. Simmons. 2004. "Social Construct and the Propensity for Software Piracy." Applied Economics Letters 11: 97-100.

(12) Ding, C.G., and N.-T. Liu. 2009. "Productivity Changes of Asian Economies by Taking into Account Software Piracy." Economic Inquiry 47: 135-145.

(13) Epstein, Gil S \& Spiegel, Uriel, 2000. "A Production Function with an Inferior Input," Manchester School, University of Manchester, vol. 68(5), pages 503-15, September.

(14) Goel, R.K., and M.A. Nelson. 2009. "Determinants of Software Piracy: Economics, Institutions, and Technology." Journal of Technology Transfer 34: 637-658.

(15) Gopal, R.D., and G.L. Sanders. 1998. "International Software Piracy: Analysis of Key Issues and Impacts." Information Systems Research 9: 380-397.

(16) Gujarati, D. 2004. Basic Econometrics. The McGraw-Hill Companies.

(17) Holm, H.J. 2003. "Can Economic Theory Explain Piracy Behavior?" The B.E. Journal of Economic Analysis \& Policy 3: 1-15.

(18) Marshall, A. 2007. "Causes, Effects and Solutions of Piracy in the Computer Software Market." Review of Economic Research on Copyright Issues 4: 63-86. 
(19) Peitz, M., and P. Waelbroeck. 2006. "Piracy of Digital Products: A Critical Review of the Theoretical Literature." Information Economics and Policy 18: 449-476.

(20) Robertson, C., K.M. Gilley, and W.F. Crittenden. 2008. "Trade Liberalization, Corruption and Software Piracy." Journal of Business Ethics 78: 623-634.

(21) Yang, D., and M. Sonmez. 2007. "Economic and Cultural Impact on Intellectual Property Violations: A Study of Software Piracy." Journal of World Trade 41: 731-750. 


\section{Chapter 3}

\section{The Environmental Kuznets Curve: The Mexican Experience after NAFTA}

\subsection{Introduction}

Since its creation in 1994, the North American Free Trade Agreement (NAFTA) has generated debate about its effects on the environment. On one hand, environmentalists believe trade liberalization leads to more pollution through fewer environmental protections regulating heavy polluting industries (the "pollution havens" hypothesis). On the other hand, economists argue that, by enriching its three member countries with higher income, a structure of output towards cleaner goods and a reduction in pollution intensity, free trade leads to environmental improvement. Both statements are supported by the Environmental Kuznets Curve (EKC), an economic concept that predicts a non-monotonic income-pollution relation, where pollution is defined as the introduction of contaminants into the natural environment. Specifically, the EKC shows an inverted U-shaped: rising income increases pollution until a certain threshold, after which pollution declines.

Grossman and Krueger (1991) first reported the existence of the EKC. These authors investigated the potential environmental impacts of the impending NAFTA and found that, for different air and water pollutants, concentrations increased with per capita GDP at low levels of income, but decreased with GDP growth at higher levels of income. In average, the turning point for these pollutants occurs when per capita GDP is $\$ 8,000$ in 1985 dollars.

In order to explain the EKC shape, the change in total pollution is commonly decomposed into three effects: scale, composition and technique. If the scale of all economic activities increases, then changes in income have a positive impact on pollution. If the scale effect is not uniform (some economic sectors grow more than others), then the change in the composition of goods produced may increase or decrease pollution depending on the quantity of pollution intensive goods produced. Finally, if the economy uses a less pollution-intensive production technique, then higher income leads to falling pollution. The interaction between the three effects determines the sign of the income-pollution relationship.

In recent years, papers on the relationship EKC-trade in China and United States have been published. Two important studies are Dean and Lovely (2008) and Levinson (2008). Dean and Lovely showed that China's industrial output and exports have become cleaner over time as a consequence of fragmentation in production (the organization of 
production in which different stages of production are divided among different suppliers that are located in different countries) and FDI. Levinson concluded that pollution emitted by U.S. manufacturers declined markedly over the past several decades, even as real manufacturing output increased, as a consequence of changing production processes. More importantly, Levinson develops an innovative methodology to decompose the change in total pollution into the three effects. I use his methodology in my paper.

Once trade liberalization policies are introduced into the economy, the "pollution haven" hypothesis predicts that the government will relax its environmental policy to attract foreign direct investment. See Copeland and Taylor (2004) for a complete survey of the literature on environment, economic growth, trade liberalization and policy implications. Corruption is one example of these policies. Usually, political corruption hinders the implementation of stringent pollution control laws. If firms perceive that the government can be bribed, they can -simultaneously- comply with mild regulations and avoid significant costs (see Lopez and Mitra (2000)).

Even when a number of theoretical studies have modeled the three effects affecting the income-pollution relation through the EKC, empirical studies estimating their magnitudes in Mexico before and after NAFTA are rare. Therefore, the objective of this paper is to provide a rigorous analysis of the decomposition of the estimated pollution expansion linked to Mexican manufacturing exports into the three effects for the periods 1980-1994 and 1995-2012. I find an amplified scale effect, a relatively constant composition effect, and a reduced technical effect after NAFTA. In doing so, I identify weak empirical support for the "pollution haven" hypothesis given the increase in the Mexican's government bargaining power - relative to Mexican powerful private elites- after NAFTA. Since 1994, Mexican government triggered a process of political liberalization and fight against bribery and corruption, where the rise of several political parties improved their ability to impose -through formal trade agreements- more stringent pollution taxes and tight environmental regulation (see Cameron and Wise (2004)).

In order to explain the above information, I propose a simple static model to derive an EKC. The model incorporates two features to the EKC: it is a function of trade openness -instead of per capita income- and it is determined by the bargaining power between government and polluting firms. In this context, trade openness is directly related to the number of firms in the economy and bargaining power is defined as the relative ability of government to impose pollution taxes equal or closest to the marginal damage caused by this negative externality. Such ability depends directly on a Nash bargaining solution where 
the government and polluting firms maximize the Nash product: the government seeks to maximize the pollution tax and the polluting firm seeks to maximize the difference between the Pigouvian tax and the effective tax rate.

The remainder of the paper is organized as follows. The next section introduces the EKC. Section 3 presents the empirical results and section 4 concludes.

\subsection{The Environmental Kuznets Curve}

Consider an economy composed of $n$ sectors. Let $y_{i}$ and $p_{i}$ be the output and pollution levels produced in sector $(i=1, \ldots, n)$. In particular, pollution depends directly on the size of sector $i$ according to the following function:

$$
p_{i}=\alpha_{i} y_{i}
$$

where $\alpha_{i} \geq 0$ is the pollution intensity in sector $i$. Assume that a larger economic sector involves using a more efficient technology, and a reduction of pollution intensity. Formally,

$$
\alpha_{i}=1-\beta_{i} y_{i}
$$

where $\beta_{i}$ is a positive parameter indicating technological change in sector $i$. By substituting equation (2) into (1), I obtain:

$$
p_{i}=y_{i}-\beta_{i} y_{i}^{2}
$$

Define aggregate output and total pollution as $Y=\sum_{i=1}^{n} y_{i}$ and $P=\sum_{i=1}^{n} p_{i}$, respectively. Finally, assume each sector produces a fraction $\theta_{i}$ of total output. This is, $y_{i}=$ $\theta_{i} Y$, where $0 \leq \theta_{i} \leq 1$ and $\sum_{i=1}^{n} \theta_{i}=1$. By using this information and equation (3), total pollution can be expressed as:

$$
P=Y-Y^{2} \sum_{i=1}^{n} \beta_{i} \theta_{i}^{2}
$$

As an example, suppose there are only two sectors in the economy. In this case, equation (4) reduces to:

$$
P=Y-\left[\beta_{1} \theta_{1}^{2}+\beta_{2}\left(1-\theta_{1}\right)^{2}\right] Y^{2}
$$




\subsubsection{Pollution and Trade}

Suppose that trade openness leads to a greater number of firms in the economy producing output. Then, by assuming that all the sectors produce the same quantity $y_{i}=y_{\text {, it }}$ possible to express total pollution as a function of the total number of firms $n$ and output by sector $y$. Thus, $Y=n y$ and equation (5) is expressed as:

$$
P=n y-\left[\beta_{1} \theta_{1}^{2}+\beta_{2}\left(1-\theta_{1}\right)^{2}\right] n^{2} y^{2} .
$$

Equation (6) is known as the Environmental Kuznets Curve (EKC): when the economy is incipient, an increasing number of firms leads to a higher level of pollution such that gross pollution (represented by $n y$ ) dominates the pollution abatement function (represented by $\left.\left[\beta_{1} \theta_{1}^{2}+\beta_{2}\left(1-\theta_{1}\right)^{2}\right] n^{2} y^{2}\right)$; on the other hand, when the economy is prosperous, the abatement technology leads to a net pollution decreasing in $n$. Therefore, there exists a specific number of firms that maximizes pollution. Formally,

$$
\frac{\partial P}{\partial n}=0 \Rightarrow n^{*}=\frac{1}{2\left[\beta_{1} \theta_{1}^{2}+\beta_{2}\left(1-\theta_{1}\right)^{2}\right] y}
$$

Figure 1 shows the graph associated to equation (13):

Figure 1. EKC as a Function of Trade Openness

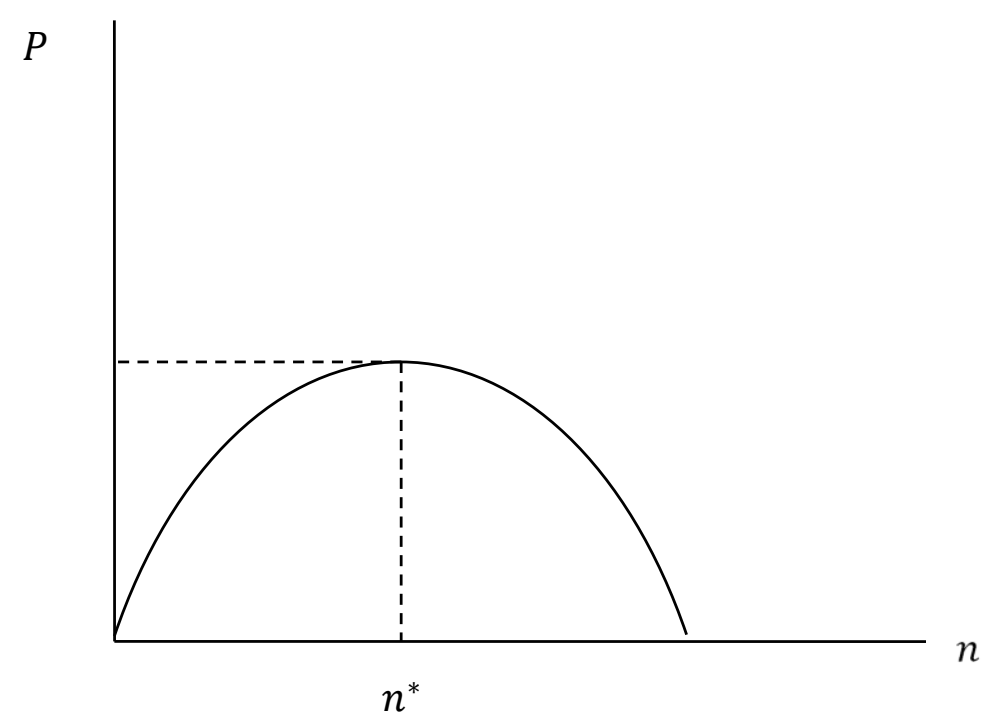




\subsubsection{Scale, Composition, and Technical Effects}

Equation (6) incorporates three elements related to the scale $(y)$, composition $\left(\theta_{i}\right)$, and technical $\left(\beta_{i}\right)$ effects. Assume that a developing economy is characterized by a small amount of resources abating pollution $\left(\left[\beta_{1} \theta_{1}^{2}+\beta_{2}\left(1-\theta_{1}\right)^{2}\right] n^{2} y^{2}\right.$ small $)$ and a developed one spends a large amount of resources $\left(\left[\beta_{1} \theta_{1}^{2}+\beta_{2}\left(1-\theta_{1}\right)^{2}\right] n^{2} y^{2}\right.$ large). In the following lines, I compute each effect:

Scale Effect. As income increases and assuming a developing economy, gross pollution (the first term of the RHS in equation (6)) is larger than the abatement function (the second term). Therefore, net pollution $P$ increases. Formally, for a developing economy:

$$
\frac{\partial P}{\partial y}=n\left\{1-2\left[\beta_{1} \theta_{1}^{2}+\beta_{2}\left(1-\theta_{1}\right)^{2}\right] n y\right\}>0
$$

Composition Effect. A change in the shares of output by sector can increase or decrease total pollution depending on the fraction of dirty goods produced. For example, if sector 1 is cleaner -relative to sector 2 - and it represents a larger share of total output $\left(\beta_{1}>\beta_{2}\right.$ and $\left.\theta_{1}>\theta_{2}\right)$, then an increase in its share reduces total pollution. Formally,

$$
\frac{\partial P}{\partial \theta_{1}}=-2\left[\beta_{1} \theta_{1}^{2}-\beta_{2} \theta_{2}^{2}\right] n^{2} y^{2}<0,
$$

On the other hand, equation (9) shows that the composition effect is equal to zero if technology and the shares of output are the same in both sectors.

Technical Effect. Technological change counteracts the scale effect -obtained from an increase in output- by reducing pollution intensity and, therefore, total pollution. Formally,

$$
\frac{\partial P}{\partial \beta_{i}}=-\theta_{i}^{2} n^{2} y<0 \text {. }
$$

Table 1 summarizes the information indicated above: 


\section{Table 1.}

\begin{tabular}{ccc}
\hline Effect & Economy & Sign \\
Scale & Developing & Positive \\
\hline Composition & Developing/Developed & Ambiguous \\
Technical & Developing/Developed & Negative \\
\hline
\end{tabular}

\subsection{Empirical Evidence}

\subsubsection{Mexico's Exports Sectors}

With exception of the manufacturing exporting sector, the rest of Mexico's exports sectors has shown a decreasing trend from 1980 to 2012. In 1980, the agricultural, crude oil, and mining industry exports represented $10 \%, 70 \%$, and $3.5 \%$ of total exports, respectively. In 2012 , the same sectors only accounted for $3 \%, 10 \%$, and $1 \%$. The introduction of NAFTA did not play an important role to revert this situation. During the pre-NAFTA period (19801994), the agricultural, oil, and mining sectors represented -in average- $7 \%, 45 \%$, and $2 \%$, respectively. However, the same sectors only amounted to $3 \%, 12 \%$, and $0.6 \%$. See Figure 2.

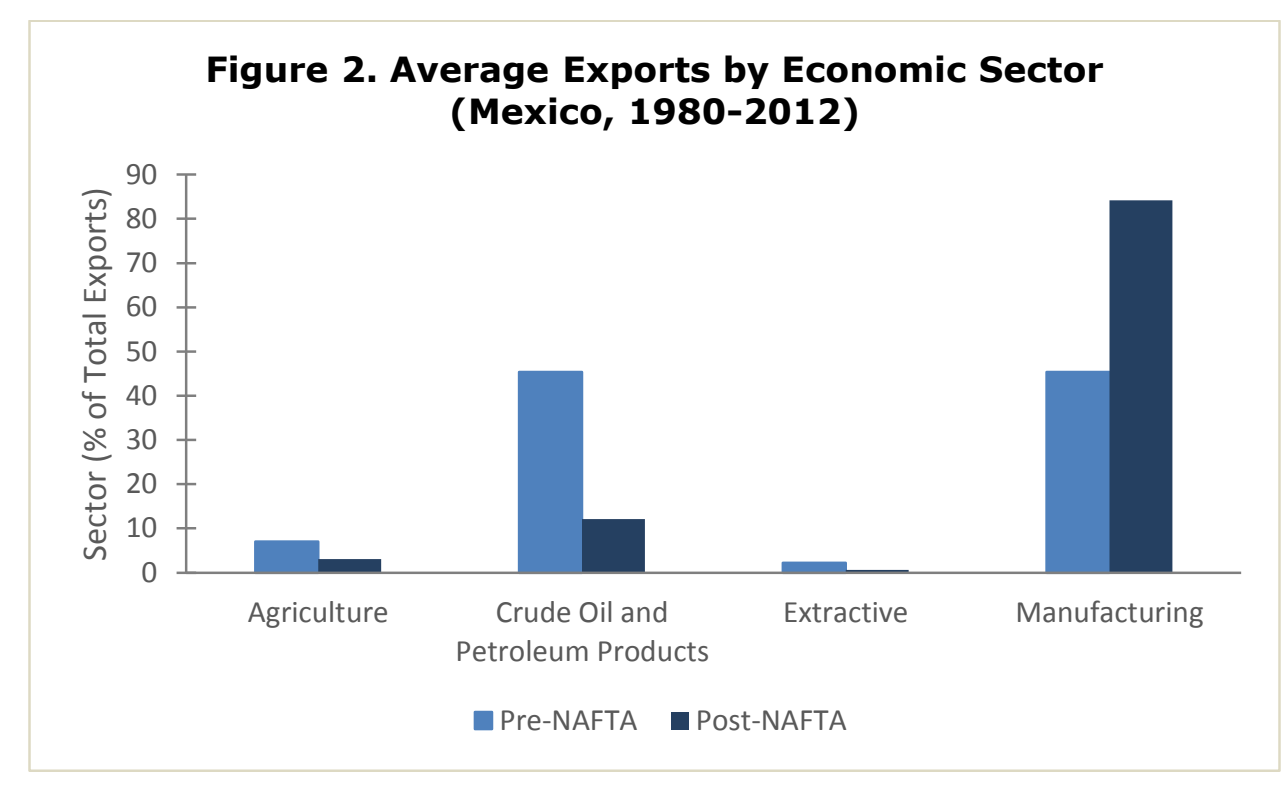

In the following lines, I briefly describe the evolution of the three divisions during the period studied.

Agricultural sector. An analysis conducted by Malaga and Williams (2006) reveals that Mexico's comparative advantage in vegetables, livestock, and livestock products has 
been eroding since the late 80 s and early $90 \mathrm{~s}$. To explain the lack of competitiveness, Malaga and Williams point out three structural factors prevailing over the implementation of NAFTA (problems in the distribution and availability of water, undeveloped transportation infrastructure, and underinvestment in new technology) and two effects resulting from NAFTA: (i) growing liberalization of world agricultural markets competitors of Mexico (in particular, Central and South-America), and (ii) stringent food safety and phytosanitary measures related to imported Mexican agricultural and food products. As a consequence, the share of agricultural exports has been falling since 1987 and did not recover after 1995. See Figure 3.

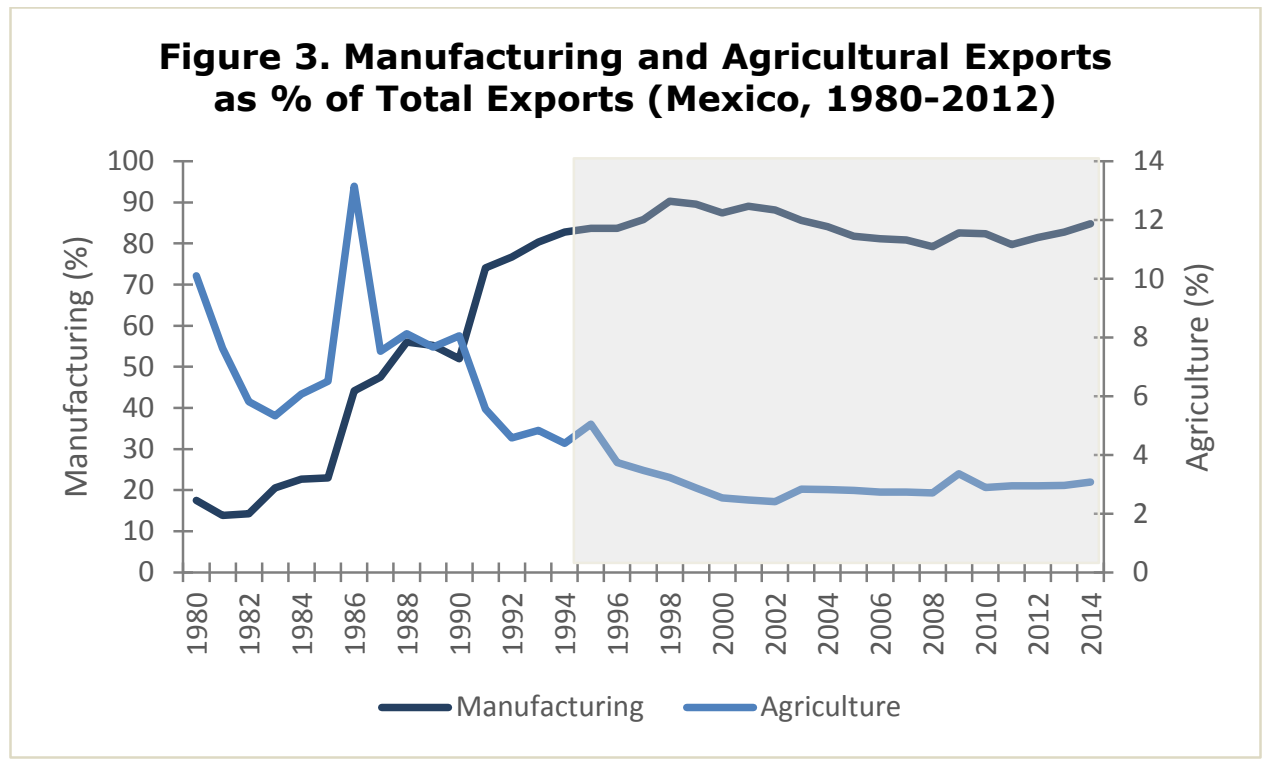

Crude Oil. Oil reserves, production, and exports and reserves have dropped since the mid-80s (see Atala (2013)). Cantarell complex, a supergiant oil field in Mexico and one of the largest oil fields in the world, reduced output from 1.16 million barrels per day in 1981 to 1 million barrels per day in 1995. Similarly, Cantarell represented 63\% of Mexico's total crude oil production in 2004, but only $17 \%$ in 2013 . Thus, even when probable reserves increased from $20.6 \%$ to $41.1 \%$, possible and proved reserves declined, respectively, from $36.4 \%$ to $27.6 \%$, and from $43.1 \%$ to $31.2 \%$. As a result, oil exports as a share of total exports, fell since 1982. See Figure 4. 
Figure 4. Manufacturing and Oil Exports as \% of Total Exports (Mexico, 1980-2012)

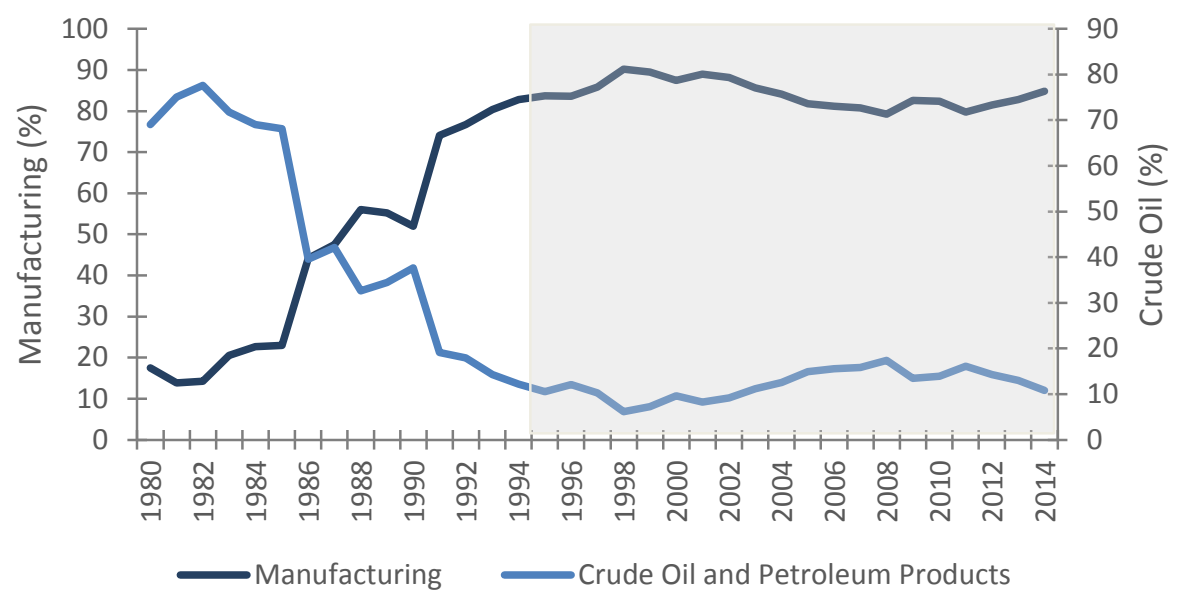

Mining industry. Although for the past 10 years, the mining sector has contributed on average, $5 \%$ of the GDP, government incentives to promote activity in this area are low (see Moreno (2012)). Two reasons that explain the disincentives are: (i) negative social and environmental impacts of mining: the nature of the activity generates pollution and conflict with the communities (desert areas where rural poverty exists) where the mines are located, and (ii) low government revenue (fees and royalties levied on the exploitation of mineral resources) from the mining sector, which do not compensate the negative externalities produced by the sector. Consequently, the mining industry's contribution to total exports has regularly decreased since 1989 . See Figure 5.

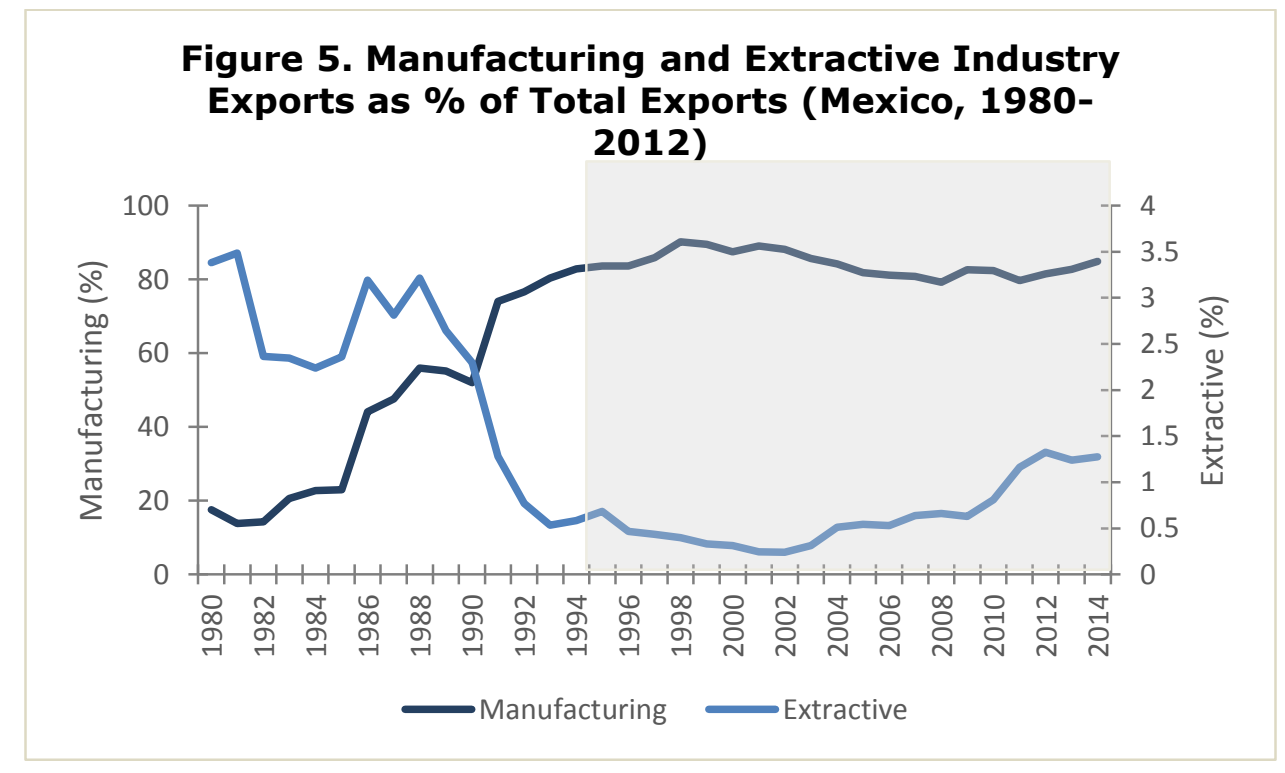


Manufacturing Sector. In contrast to the previous three sectors, trade liberalization in Mexico began in the mid-80s by joining the General Agreement on Tariffs and Trade (GATT) and reduce (or eliminate) tariffs, and import and export licenses (see Lopez-Cordova (2003)). In 1995, NAFTA consolidated the liberalization of the Mexican economy in some particular sectors. Table 2 shows that: (i) before and after NAFTA, diversification in manufacturing exports is concentrated in sector VIII (Metallic products, machinery and equipment) and sector $\mathrm{V}$ (Chemical substances, petroleum derivatives and plastics), and (ii) NAFTA accelerated the diversification in manufacturing exports towards economic sectors II (Textiles, clothing and leather) and VIII (Metallic products, machinery and equipment).

Table 2.

\begin{tabular}{|c|c|c|}
\hline \multicolumn{3}{|c|}{$\begin{array}{c}\text { Diversification of Manufacturing Exports (Mexico, 1980-2012) } \\
\text { Average Percentage of Total }\end{array}$} \\
\hline Sector & $\begin{array}{l}\text { Pre-NAFTA } \\
\text { 1980-1994 } \\
\text { Mean }\end{array}$ & $\begin{array}{l}\text { Post-NAFTA } \\
\text { 1995-2013 } \\
\text { Mean }\end{array}$ \\
\hline I. Food, beverages and tobacco & 8.1 & 3.2 \\
\hline II. Textiles, clothing and leather & 5.8 & 6.1 \\
\hline III. Wood industry and products & 1.4 & 0.5 \\
\hline $\begin{array}{l}\text { IV. Paper, paper products, prints } \\
\text { and editorials }\end{array}$ & 1.8 & 0.9 \\
\hline $\begin{array}{l}\text { V. Chemical substances, } \\
\text { petroleum derivatives and plastics }\end{array}$ & 10.4 & 6.2 \\
\hline $\begin{array}{l}\text { VI. Nonmetallic mineral products, } \\
\text { except petroleum derivatives and } \\
\text { coal }\end{array}$ & 3.4 & 1.4 \\
\hline VII. Basic metallic industries & 9.6 & 5.8 \\
\hline $\begin{array}{c}\text { VIII. Metallic products, machinery } \\
\text { and equipment }\end{array}$ & $\mathbf{5 7 . 0}$ & 72.9 \\
\hline $\begin{array}{l}\text { IX. Other manufacturing } \\
\text { industries }\end{array}$ & 2.4 & 2.8 \\
\hline
\end{tabular}

A study conducted by Arsenault, Rose, Azulay and Phillips (2003) revealed that air pollution in Mexico is produced by severed levels of carbon dioxide, sulfure dioxide, particle matter, and ozone, and heavy levels of lead and nitrous dioxide. In particular, Table 3 reports carbon dioxide emissions in two economic sectors (manufacturing and agriculture) before and after NAFTA. 
Table 3.

\begin{tabular}{|clcc}
\hline \multicolumn{4}{c}{$\begin{array}{c}\text { Historical CO2 Emissions by Sector (Mexico, 1980-2012) } \\
\text { Average Percentage of Total CO2 Emissions }\end{array}$} \\
\hline Sector & \multicolumn{1}{c}{ Definition } & $\begin{array}{c}\text { Pre-NAFTA } \\
\mathbf{1 9 8 0 - 1 9 9 4}\end{array}$ & $\begin{array}{c}\text { Post-NAFTA } \\
\mathbf{1 9 9 5 - 2 0 1 2}\end{array}$ \\
\hline Manufacturing & $\begin{array}{l}\text { CO2 emissions from } \\
\text { manufacturing } \\
\text { industries } \\
\text { construction. and }\end{array}$ & 21.9 & 14.7 \\
\hline $\begin{array}{l}\text { CO2 emissions from } \\
\text { commercial/institutional } \\
\text { activities, residential, } \\
\text { agriculture/forestry, } \\
\text { and fishing. }\end{array}$ & & \\
\hline
\end{tabular}

Table 3 shows that: (i) as the manufacturing exporting sector rose over the period 1981-2012, CO2 emissions are primarily generated by this sector, and (ii) after NAFTA went into effect, the share of $\mathrm{CO} 2$ emissions from the manufacturing sector declined. Both results suggest that the manufacturing exporting sector is the main factor driving pollution in Mexico, and therefore, it is the industry studied in this paper.

\subsubsection{The Environmental Kuznets Curve}

Since its creation in 1994, the North American Free Trade Agreement (NAFTA) generated debate about its effects on Mexico's natural environment. On one hand, environmentalists believe trade liberalization lead to more pollution given the existence of political corruption authorizing mild environmental protections on dirty industries (the "pollution havens" effect). On the other hand, economists argue that, by enriching Mexico with higher income, a structure of production towards cleaner goods and a reduction in pollution intensity, free trade improves the environment. Both statements are supported by the Environmental Kuznets Curve (EKC), an economic concept that predicts a non-monotonic income-pollution relation. Specifically, the EKC shows an inverted U-shaped: rising income increases pollution until a certain threshold, after which pollution diminishes.

In this section I estimate the EKC using Mexican data for the period 1980-2011. I use seven variables: total observed pollution, trade openness ratio, environmental protection expenditure, corruption perceptions index, democracy index, Herfindahl political competition index, and population density. Then, I run a multiple linear regression using pollution as the dependent variable and the economic, political, and geographical variables as explanatory variables. Table 4 describes each variable. 
Table 4.

\begin{tabular}{|c|c|c|}
\hline Variable & Definition & (Mean; St. Dev.) \\
\hline$P_{o b s}$ & $\begin{array}{l}\text { Observed Pollution: total air pollution. } \\
\text { Source: own calculation based on Emission Database for } \\
\text { Global Atmospheric Research (EDGAR). }\end{array}$ & $\begin{array}{l}\text { Aggregate sample: } \\
(8.1 ; 5.1) \\
\text { Pre-NAFTA } \\
(3.2 ; 2.0) \\
\text { Post-NAFTA } \\
(12.7 ; 1.5)\end{array}$ \\
\hline$P_{e s t}$ & $\begin{array}{l}\text { Estimated Pollution per capita: total pollution (air, water } \\
\text { and solid waste emissions from manufacturing industry). } \\
\text { Source: own calculation based on Hettige et al. (1994). }\end{array}$ & $\begin{array}{l}\text { Aggregate sample: } \\
(10.3 ; 6.6) \\
\text { Pre-NAFTA } \\
(3.6 ; 2.3) \\
\text { Post-NAFTA } \\
(16.3 ; 1.2)\end{array}$ \\
\hline$T R$ & $\begin{array}{l}\text { Trade Openness: sum of exports and imports of goods } \\
\text { and services as a share of Mexico's GDP. } \\
\text { Source: World Development Indicators, World Bank. }\end{array}$ & $\begin{array}{l}\text { Aggregate sample: } \\
(42.8 ; 12.7) \\
\text { Pre-NAFTA } \\
(30.5 ; 5.4) \\
\text { Post-NAFTA } \\
(53.6 ; 4.7)\end{array}$ \\
\hline GOV & $\begin{array}{l}\text { Public spending on environment as a share of Mexico's } \\
\text { GDP. } \\
\text { Source: National Institute of Geography, Statistics and } \\
\text { Informatics (INEGI). }\end{array}$ & $\begin{array}{l}\text { Aggregate sample: } \\
(17.5 ; 12.3) \\
\text { Pre-NAFTA } \\
(5.8 ; 4.2) \\
\text { Post-NAFTA } \\
(28.0 ; 5.8)\end{array}$ \\
\hline CORR & $\begin{array}{l}\text { Corruption Perceptions Index: ranks countries based on } \\
\text { how corrupt their public sector is perceived to be. Higher } \\
\text { values of CORR indicate more corruption, where the } \\
\text { index ranges from } 0 \text { to } 10 . \\
\text { Source: Transparency International. }\end{array}$ & $\begin{array}{l}\text { Aggregate sample: } \\
(2.7 ; 0.6) \\
\text { Pre-NAFTA } \\
(2.0 ; 0.1) \\
\text { Post-NAFTA } \\
(3.3 ; 0.2)\end{array}$ \\
\hline DEMO & $\begin{array}{l}\text { Democracy Index: ranks the level of democracy by } \\
\text { country. The index ranges from }-10 \text { to } 10 \text {, where }-10 \text { to - } \\
6 \text { corresponds to autocracies, }-5 \text { to } 5 \text { to anocracies, and } \\
6 \text { to } 10 \text { democracies. } \\
\text { Source: Polity IV Project. }\end{array}$ & $\begin{array}{c}\text { Aggregate sample: } \\
(4.5 ; 3.0) \\
\text { Pre-NAFTA } \\
(1.6 ; 0.8) \\
\text { Post-NAFTA } \\
(7.1 ; 1.4)\end{array}$ \\
\hline HERF & $\begin{array}{l}\text { Herfindahl Political Competition Index: defined as the } \\
\text { sum of the squares of the seats' shares of all parties in } \\
\text { the government. The index ranges from } 0 \text { to } 1 \text {, with } \\
\text { higher scores indicating more political cohesion. } \\
\text { Source: Database of Political Institutions 2012, World } \\
\text { Bank. }\end{array}$ & $\begin{array}{c}\text { Aggregate sample: } \\
(0.9 ; 0.06) \\
\text { Pre-NAFTA } \\
(1 ; 0) \\
\text { Post-NAFTA } \\
(0.9 ; 0.07)\end{array}$ \\
\hline POPUL & $\begin{array}{l}\text { Population Density: people per squared km. of land area. } \\
\text { Source: World Development Indicators, World Bank. }\end{array}$ & $\begin{array}{c}\text { Aggregate sample: } \\
(49.1 ; 7.8) \\
\text { Pre-NAFTA } \\
(41.8 ; 3.7) \\
\text { Post-NAFTA } \\
(55.4 ; 3.7) \\
\end{array}$ \\
\hline
\end{tabular}


Given the previous information, I propose the following model:

$$
\begin{gathered}
\ln P_{t}=\alpha_{0}+\left(\alpha_{1}+\alpha_{2} D_{t}\right) T R_{t}+\left(\alpha_{3}+\alpha_{4} D_{t}\right) T R_{t}^{2}+\alpha_{5} G O V_{t}+ \\
\alpha_{6} \operatorname{CORR}_{t}+\alpha_{7} \text { DEMO }_{t}+\alpha_{8} \mathrm{HERF}_{t}+\alpha_{9} \text { POPUL }_{t}+u_{t},
\end{gathered}
$$

where $D_{t}$ is a dummy variable capturing the effect of NAFTA on the EKC through changes in its level and slope, and $u_{t}$ is an error term distributed $N\left(0, \sigma^{2}\right)$. Thus, $D_{t}$ takes a value of one for the period 1995-2011 and zero otherwise. In order to capture the concavity of the EKC, I expect $\hat{\alpha}_{1}+\hat{\alpha}_{2} D_{t}>0$ and $\hat{\alpha}_{3}+\hat{\alpha}_{4} D_{t}<0$. Table 5 presents the estimation (associated $\mathrm{p}$-values in parenthesis):

\begin{tabular}{|c|c|}
\hline Variable & Estimated Coefficient \\
\hline Constant & $\begin{array}{r}-11.4021 \\
(0.0000)\end{array}$ \\
\hline$T R_{t}$ & $\begin{array}{c}0.7029 \\
(0.0000)\end{array}$ \\
\hline$D_{t} \cdot T R_{t}$ & $\begin{array}{c}-0.1700 \\
(0.0060)\end{array}$ \\
\hline$T R_{t}^{2}$ & $\begin{array}{c}-0.0102 \\
(0.0001)\end{array}$ \\
\hline$D_{t} \cdot T R_{t}^{2}$ & $\begin{array}{c}0.0052 \\
(0.0005)\end{array}$ \\
\hline$G O V_{t}$ & $\begin{array}{c}-0.0341 \\
(0.0137)\end{array}$ \\
\hline $\operatorname{COR}_{t}$ & $\begin{array}{c}-0.2431 \\
(0.0996)\end{array}$ \\
\hline${ }_{D E M O}$ & $\begin{array}{c}-0.0908 \\
(0.0013)\end{array}$ \\
\hline$H E R F_{t}$ & $\begin{array}{c}1.8331 \\
(0.0006)\end{array}$ \\
\hline POPUL $_{t}$ & $\begin{array}{c}0.0971 \\
(0.0017)\end{array}$ \\
\hline Number of Observations & 30 \\
\hline Adjusted $R^{2}$ & 0.9867 \\
\hline
\end{tabular}

Table 5. 
By plugging $D_{t}=0, D_{t}=1$, and the estimated coefficients into the estimated regression, I obtain:

Before $\operatorname{NAFTA}\left(D_{t}=0\right)$,

$$
\begin{aligned}
\ln \left(\hat{P}_{t}\right)_{o b s}=- & 11.4021+0.7029 T R_{t}-0.0102 T_{t}^{2}-0.0341 G O V_{t}-0.2431 \text { CORR }_{t} \\
& -0.0908 D E M O_{t}+1.8331 \mathrm{HERF}_{t}+0.0971 \text { POPUL }_{t},
\end{aligned}
$$

After NAFTA $\left(D_{t}=1\right)$,

$$
\begin{aligned}
\ln \left(\hat{P}_{t}\right)_{o b s}=- & 11.4021+0.5329 T R_{t}-0.0049 T R_{t}^{2}-0.0341 G O V_{t}-0.2431 \text { CORR }_{t} \\
& -0.0908 \mathrm{DEMO}_{t}+1.8331 \mathrm{HERF}_{t}+0.0971 \mathrm{POPUL}_{t},
\end{aligned}
$$

In the following lines, I analyze the effect of each variable on pollution:

Trade Openness (TR). There is a non-monotonic relationship between trade openness and pollution. Initially, as Mexico opened to globalization, manufacturing industry intensified the exports of goods and pollution increased until reach a maximum level. This direct relationship is represented in equations (20) and (21) by the linear term $0.4863 T R_{t}$ (if $D_{t}=0$ ) or $0.3878 T R_{t}$ (if $D_{t}=1$ ). Eventually, as new techniques were introduced into the production process and Mexico increased trade by specializing in the production of less dirty goods, pollution reduced. This negative effect is indicated by the quadratic term $-0.0082 T R_{t}^{2}$ (if $D_{t}=0$ ) or $-0.0036 T R_{t}^{2}$ (if $D_{t}=1$ ). Observe that the introduction of NAFTA has expanded the EKC function: the linear and quadratic variables have -in absolute value- lower estimated coefficients equation after the NAFTA implementation, suggesting reduced effects of trade openness on pollution at early stages of trade but amplified effects at advanced stages. Equivalently, the level of trade openness that maximizes pollution shifted to the right during the post-NAFTA period. Formally, by differentiating $\ln \hat{P}_{t}$ with respect to $T R_{t}$, it is possible to estimate the trade openness index turning point $\widetilde{T R}_{t}$. This value is given by:

$$
\frac{\partial \ln \widehat{P}_{t}}{\partial T R_{t}}=0 \Rightarrow \widetilde{T R}_{t}=-\frac{\hat{\alpha}_{2}+\hat{\alpha}_{3} D_{t}}{2\left(\hat{\alpha}_{4}+\hat{\alpha}_{5} D_{t}\right)}
$$

The $\widetilde{T R}_{t}$ corresponding to each regression is: 


$$
\widetilde{T R}_{t}= \begin{cases}34.4558, & D_{t}=0 \\ 54.3775, & D_{t}=1\end{cases}
$$

Figure 6 plot equations (20) and (21), where I substitute the economic, political and geographic variables for their average values.

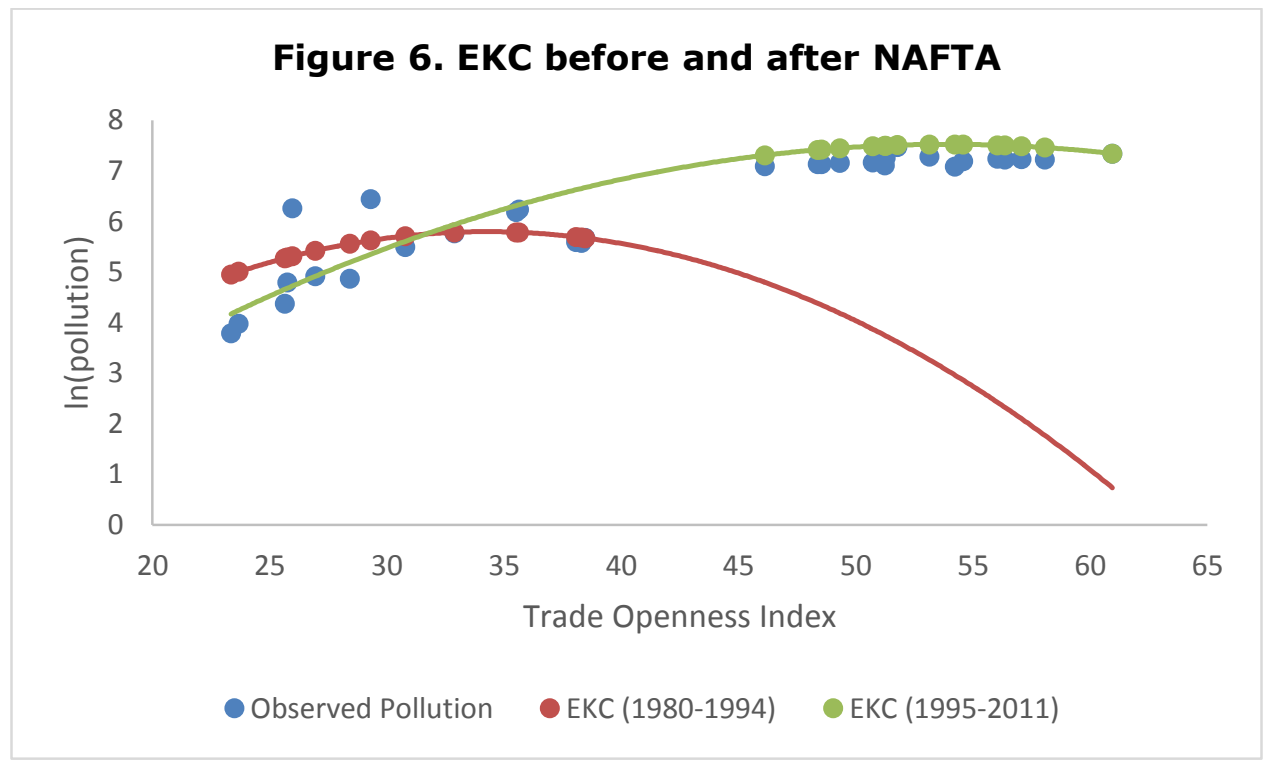

Environmental Protection Expenditure (GOV). Public spending on environment (as a percentage of GDP) increased, in average, from 5.8\% over the period $1980-1994$ to $28.0 \%$ during 1995-2011. Intuitively, the introduction of NAFTA required new environmental laws in Mexico. Therefore, all previous administrative provisions in the environmental matter were derogated and a new environmental agency was created: the Secretariat of Environment and Natural Resources (SEMARNAT). This Ministry was aimed to protect, restore, and conserve the ecosystems, natural resources, assets and environmental services of Mexico. Thus, Table 4 indicates that an increase in government expenditure on environmental protection has a negative impact on pollution emitted $(-0.0479)$.

Political Variables (CORR, DEMO,HERF). United States demanded democratic reforms in Mexico as part of the NAFTA negotiation process. Therefore, since 1995 Mexican government triggered a process of political liberalization and fight against bribery and corruption, where the rise of several political parties in the government improved their ability to impose -through formal trade agreements- more stringent pollution taxes and tight environmental regulation. For example, before NAFTA (1980-1994), only two environmental laws were created: the General Law on the Ecological Balance and 
Environmental Protection (LGEEPA) in 1988, and the National Waters Law in 1992. On the contrary, six laws were created during the post-NAFTA period (1995-2011):

1. LGEEPA Comprehensive Amendment (1996).

2. General Wild Life Law (2000).

3. General Law on the Prevention and Comprehensive Management of Wastes (2003).

4. General Law for the Sustainable Forestry Development (2003).

5. Comprehensive Amendment to the National Waters Law (2004).

6. Genetically Modified Organisms Biosafety Law (2005).

In conclusion, as a result of the political fractionalization, robust democratic institutions and a reduction in corruption, a stronger environmental legal framework occurred in Mexico. Thus, Table 4 points out that the indicators related to more democracy $(D E M O)$, less corruption $(C O R R)$, and more groups reducing political concentration (HERF) negatively affect pollution, where the magnitudes of the impacts are given by 0.0758, -0.2867, and -2.0370, respectively, suggesting weak empirical support for the "pollution haven" hypothesis.

Population Density (POPUL). As NAFTA accelerated the economic activity in some regions in Mexico, a process of internal migration from the south (Guerrero, Oaxaca, Veracruz, Puebla, and Hidalgo) to the north arose in the country (Sinaloa, Sonora, Baja California, and Baja California Sur) satisfying the increase in demand for less-skilled workers in assembling activities. As a result, population density grew in these urban and industrialized north regions leading to more pollution produced. Table 4 indicates this positive impact $(0.1225)$.

\subsubsection{Pollution from Manufacturing Sector}

In order to explain the EKC shape, the change in total pollution is commonly decomposed into three effects: scale, composition and technique (see Grossman and Krueger (1991)). If the scale of all economic activities increases, then changes in income have a positive impact on pollution. If the scale effect is not uniform (some economic sectors grow more than others), then the change in the composition of goods produced may increase or decrease pollution depending on the quantity of pollution intensive goods produced. Finally, if the economy uses a less pollution-intensive production technique, then higher income leads to falling pollution. The interaction between the three effects determines the sign of the income-pollution relationship. Once trade liberalization policies are introduced into the 
economy, the "pollution haven" hypothesis predicts that the government will relax its environmental policy to attract foreign direct investment (see Copeland and Taylor (2004)).

In this section, I compute the scale, composition and technique effects for the nine manufacturing divisions in Mexico according to the Mexico's National Accounting System. The divisions are:

1. Food, beverages and tobacco.

2. Textiles, clothing and leather.

3. Wood industry and products.

4. Paper, paper products, prints and editorials.

5. Chemical substances, petroleum derivatives and plastics.

6. Nonmetallic mineral products, except petroleum derivatives and coal.

7. Basic metallic industries.

8. Metallic products, machinery and equipment.

9. Other manufacturing industries.

Given the lack of information about pollution in Mexico, the analysis is done with data adapted from the United States to Mexico using the Industrial Pollution Projection System (IPPS) elaborated by Hettige et al. (1994). The IPPS constitutes a reliable data source to estimate pollution intensities per unit of production in each manufacturing division. Hettige indicates: "IPPS has been developed to exploit the fact that industrial pollution is heavily affected by the scale of industrial activity, its sectorial composition, and the process technologies which are employed in production. Although most developing countries have little or no industrial pollution data, many of them have relatively detailed industry survey information on employment, value added or output. IPPS is designed to convert this information to the best feasible profile of the associated pollutant output for countries, regions, urban areas, or proposed new projects."

The IPPS computes the Linear Acute Human Toxic Index (LAHIT) for 74 industries in the United States in 1987. This was the most recent year for which full and detailed data contained in the Census of Manufactures were available. IPPS methods for estimating pollution intensities result from combining US Manufacturing Census data with the US Environmental Protection Agency's pollution databases on air, water and solid waste emissions. Hettige indicates that, even when many country-specific factors will affect the accuracy of pollution projections outside the US, the pattern of sectoral intensity rankings may be similar. The LAHIT is estimated at the 4-digit levels of aggregation in the International Standard Industrial Classification (ISIC) using the value of US output in 1987. 
To use the data, the 74 industries were grouped by adding the LAHIT into each one of the nine corresponding manufacture divisions above indicated. Define this added index as the LAHIT in metric tons per $\$ 1,000,000$ USD of production in 1987. Table A1 in Appendix shows the results.

According to Table A1, the three divisions with the highest pollution intensities are: (i) Chemical substances, petroleum derivatives and plastics, (ii) Metallic products, machinery and equipment, and (iii) Textiles, clothing and leather. Observe that pollution produced by the chemical industry is significantly higher that the pollution produced by the other eight sectors.

After estimating the nine weights, they are multiplied by the corresponding 1987 US dollar value of each Mexican manufacturing division. An index of volume of pollution adjusted to human health risks is obtained in million metric tons. For comparison purposes, Figure 7 reports observed and estimated pollution for the period 1980-2011, where observed pollution is obtained from the Emission Database for Global Atmospheric Research (EDGAR) and estimated pollution is constructed using the described methodology. In particular, EDGAR reports air pollution -measured in million metric tons- generated by the three main pollutants: carbon dioxide $\left(\mathrm{CO}_{2}\right)$, methane $\left(\mathrm{CH}_{4}\right)$ and nitrogen dioxide $\left(\mathrm{N}_{2} \mathrm{O}\right)$. As these emissions are associated to the GDP generated by industries, air pollution is weighted by the ratio manufacturing exports-GDP to derive observed pollution.

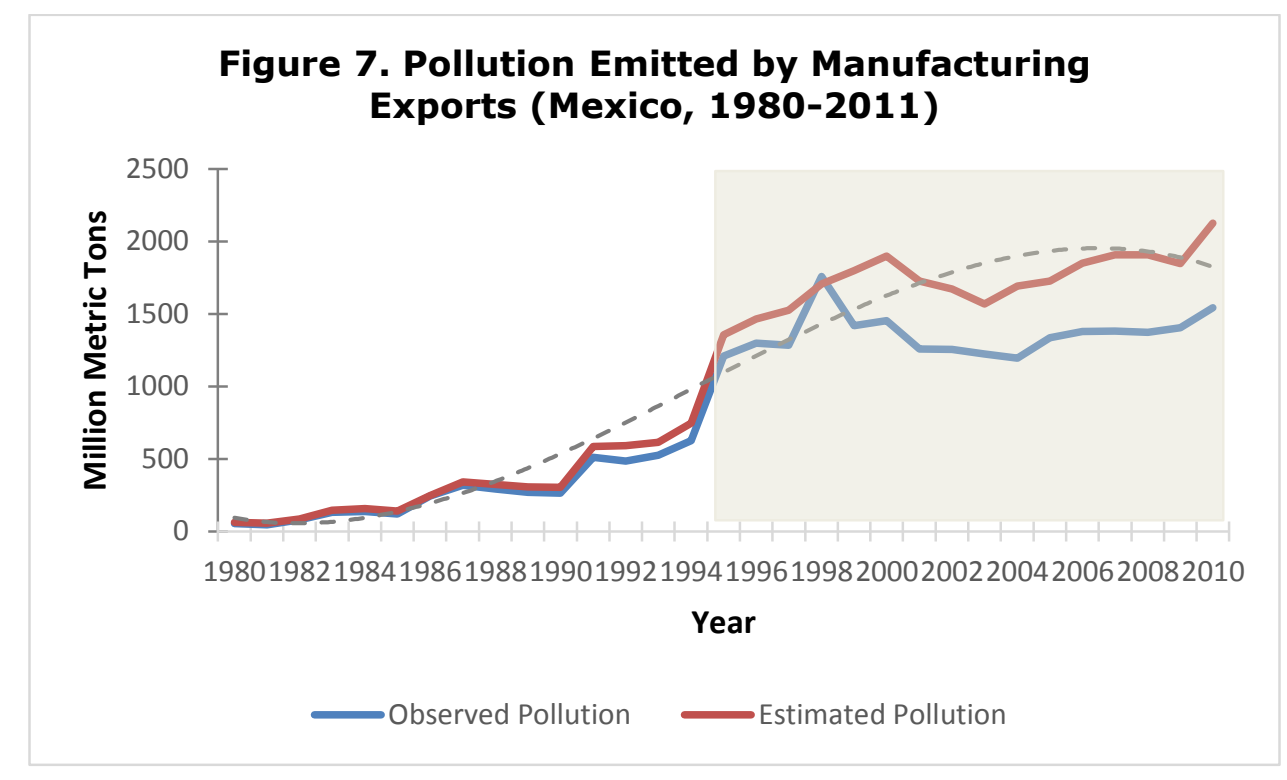

According to Figure 7, estimated pollution exceeds observed pollution because the former is based on air, water and solid waste emissions. Unfortunately, complete historical 
data related to water and solid waste emissions is not available for Mexico. Figure 7 illustrates that time series data on pollution exhibit an increasing trend over the whole period 1980-2013. Thus, the pollution levels rose after NAFTA. However, visual inspection of the time series also reveals that pollution growth rate is increasing before NAFTA (19801993) and decreasing after it (1994-2012) indicating more stability on pollution emissions after the trade agreement. In order to confirm this idea, I compute the mean, coefficient of variation (CV) and average growth rate $(\mathrm{g})$ for each period. Table 6 shows the results:

Table 6.

\begin{tabular}{|c|c|c|c|c|c|c|}
\hline \multicolumn{7}{|c|}{$\begin{array}{l}\text { Manufacturing Exports Estimated Pollution (Mexico, 1980-2012) } \\
\text { Million Metric Tons }\end{array}$} \\
\hline \multirow[t]{2}{*}{ Sector } & \multicolumn{3}{|c|}{ 1980-1993 } & \multicolumn{3}{|c|}{ 1994-2012 } \\
\hline & Mean & CV & $\mathbf{g}$ & Mean & CV & $\mathbf{g}$ \\
\hline I. Food, beverages and tobacco & 5.4 & 68.0 & 0.9 & 12.5 & 29.5 & 5.6 \\
\hline II. Textiles, clothing and leather & 16.4 & 205.1 & 17.4 & 100.6 & 33.5 & -2.5 \\
\hline III. Wood industry and products & 1.7 & 89.6 & 12.7 & 3.4 & 43.4 & -5.3 \\
\hline $\begin{array}{l}\text { IV. Paper, paper products, prints } \\
\text { and editorials }\end{array}$ & 4.7 & 24.6 & 10.6 & 13.8 & 8.2 & -0.1 \\
\hline $\begin{array}{l}\text { V. Chemical substances, } \\
\text { petroleum derivatives and plastics }\end{array}$ & 107.2 & 48.9 & 12.1 & 370.6 & 14.1 & 2.3 \\
\hline $\begin{array}{l}\text { VI. Nonmetallic mineral products, } \\
\text { except petroleum derivatives and } \\
\text { coal }\end{array}$ & 2.5 & 17.1 & 11.0 & 6.2 & 7.0 & 0.4 \\
\hline VII. Basic metallic industries & 10.0 & 142.5 & 15.9 & 35.0 & 40.9 & 4.2 \\
\hline $\begin{array}{l}\text { VIII. Metallic products, machinery } \\
\text { and equipment }\end{array}$ & 163.3 & 110.7 & 25.0 & 1207.5 & 15.0 & 3.6 \\
\hline $\begin{array}{l}\text { IX. Other manufacturing } \\
\text { industries }\end{array}$ & 2.3 & 111.3 & 22.6 & 15.2 & 16.5 & 2.9 \\
\hline Total & 313.4 & 71.4 & 18.1 & $1,764.8$ & 12.7 & 3.0 \\
\hline
\end{tabular}

Table 6 shows that: (i) average pollution levels are higher in the post-NAFTA period, (ii) relative variability of pollution is lower in the post-NAFTA period, and (iii) pollution growth rates are strictly positive for the nine divisions in the pre-NAFTA period; however, there is a combination of positive and negative growth rates in the post-NAFTA period. Intuitively, the first result indicates a positive scale effect, where pollution increased in each 
sector as a consequence of trade expansion. The second result suggests the existence of a negative technical effect: more stringent pollution taxes and tight environmental regulation after NAFTA which reduced the volatility of pollution emissions. Finally, the third result predicts a composition effect biased towards food, chemical and metallic industries and against textile, wood and paper industries. As most sectors experienced pollution growth, a positive -although not significant- composition effect is predicted.

\subsubsection{Estimating the Scale, Composition and Technical Effect}

Following Levinson (2008), it is possible to decompose the change in total pollution into three effects: scale, composition and technological. To compute each effect, Levinson defines total pollution $P$ as the sum of pollutants produced by the $n$ exporting sectors in the economy $\sum_{i=1}^{n} p_{i}$, where $i$ is a particular exporting sector. In turn, by defining $\theta_{i}=\frac{v_{i}}{V}$ as the value of exports in sector $i\left(v_{i}\right)$ as a fraction of total exports $V$, and $z_{i}=\frac{p_{i}}{v_{i}}$ as the pollution intensity in sector $i$, then total pollution can be expressed as $P=\sum_{i=1}^{n} p_{i}=\sum_{i=1}^{n} V \theta_{i} z_{i}$. Finally, total pollution in time $t$ is $P_{t}=\sum_{i=1}^{n} p_{i t}=\sum_{i=1}^{n} V_{t} \theta_{i t} z_{i t}$.

By differentiating $P_{t}$, Levinson computes the sum of total pollution as the sum of the three effects:

$$
d P_{t}=\underbrace{\boldsymbol{\theta}_{t}^{\prime} \boldsymbol{z}_{\boldsymbol{t}} d V_{t}}_{\begin{array}{c}
\text { Scale } \\
\text { Effect }
\end{array}}+\underbrace{V_{t} \mathbf{z}_{\boldsymbol{t}}^{\prime} d \boldsymbol{\theta}_{\boldsymbol{t}}}_{\begin{array}{c}
\text { Composition } \\
\text { Effect }
\end{array}}+\underbrace{V_{t} \boldsymbol{\theta}^{\prime} d \mathbf{z}_{t}}_{\begin{array}{c}
\text { Technical } \\
\text { Effect }
\end{array}},
$$

where $d P_{t}=P_{t+1}-P_{t}$ is the change in total pollution, $d V_{t}=V_{t+1}-V_{t}, \boldsymbol{\theta}^{\prime}=\left(\theta_{1}, \ldots, \theta_{\boldsymbol{n}}\right)$ and $\mathbf{z}^{\prime}=\left(z_{1}, \ldots, z_{n}\right)$. Figure 8 shows the change in total pollution. Observe that: (i) in general, the change exhibits an increasing trend during the 1981-1994 period and a decreasing trend over the years 1995-2011, (ii) immediately after NAFTA went into effect in 1994, the change in pollution rose to its maximum level, and (iii) pollution reflects higher variability after 1994, as it shows a larger number of periods where the change is negative. 
Figure 8. Observed Pollution from Manufacturing

Exports, Total Change

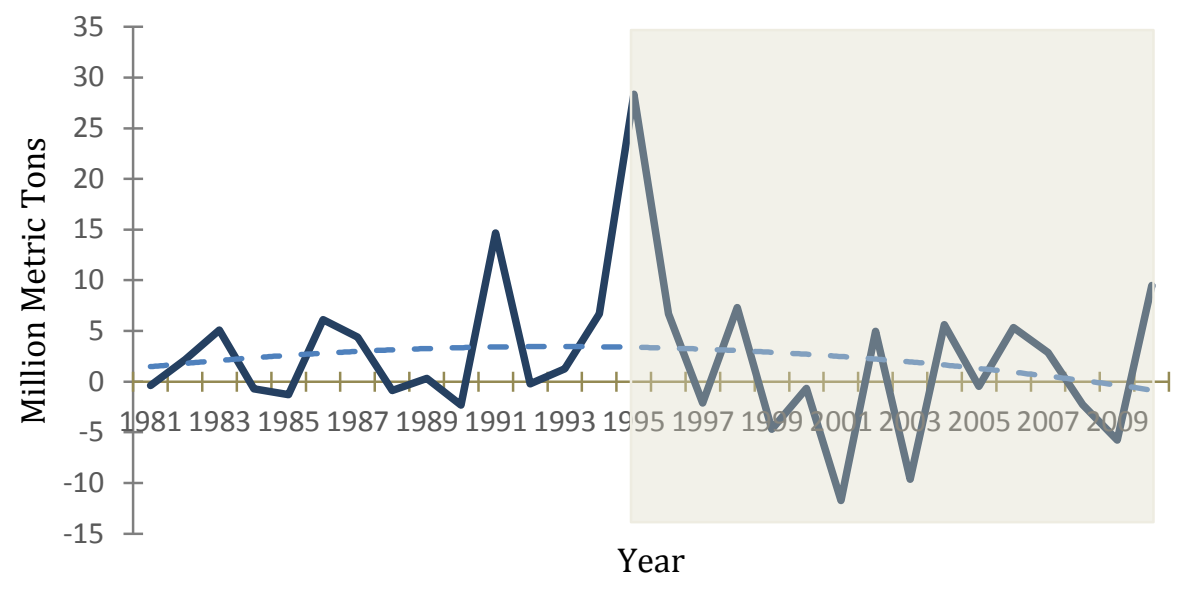

In order to investigate the most important manufacturing sectors driving the total change in pollution, Table 7 shows the average total change by sector for the periods before and after NAFTA.

Table 7.

\begin{tabular}{|c|c|c|c|}
\hline \multicolumn{4}{|c|}{$\begin{array}{l}\text { Total Change in Estimated Pollution (Mexico, 1981-2011) } \\
\text { Million Metric Tons }\end{array}$} \\
\hline Sector & $\begin{array}{l}\text { 1980-1993 } \\
\text { Mean }\end{array}$ & $\begin{array}{l}\text { 1994-2011 } \\
\text { Mean }\end{array}$ & $\begin{array}{l}\text { 1980-2011 } \\
\text { Mean }\end{array}$ \\
\hline I. Food, beverages and tobacco & 0.027 & 0.084 & 0.058 \\
\hline II. Textiles, clothing and leather & 0.160 & -0.025 & 0.061 \\
\hline III. Wood industry and products & 0.027 & -0.019 & 0.002 \\
\hline $\begin{array}{l}\text { IV. Paper, paper products, prints and } \\
\text { editorials }\end{array}$ & 0.023 & 0.009 & 0.015 \\
\hline $\begin{array}{c}\text { V. Chemical substances, petroleum } \\
\text { derivatives and plastics }\end{array}$ & 0.168 & 0.099 & 0.131 \\
\hline $\begin{array}{l}\text { VI. Nonmetallic mineral products, } \\
\text { except petroleum derivatives and coal }\end{array}$ & 0.054 & -0.004 & 0.023 \\
\hline VII. Basic metallic industries & 0.125 & 0.220 & 0.175 \\
\hline $\begin{array}{l}\text { VIII. Metallic products, machinery and } \\
\text { equipment }\end{array}$ & 1.854 & 1.649 & 1.745 \\
\hline IX. Other manufacturing industries & 0.057 & 0.068 & 0.063 \\
\hline Total & 2.494 & 2.080 & 2.273 \\
\hline
\end{tabular}

According to Table 7, sectors VIII (Metallic products, machinery and equipment), VII (Basic Metallic Industries), V (Chemical substances, petroleum derivatives and plastics), and II 
(Textiles, clothing and leather) have the largest average values over the whole period 19802011, suggesting these are the divisions boosting the total change in pollution. See Figure 9 (gray line represents the rest of the manufacturing sector).

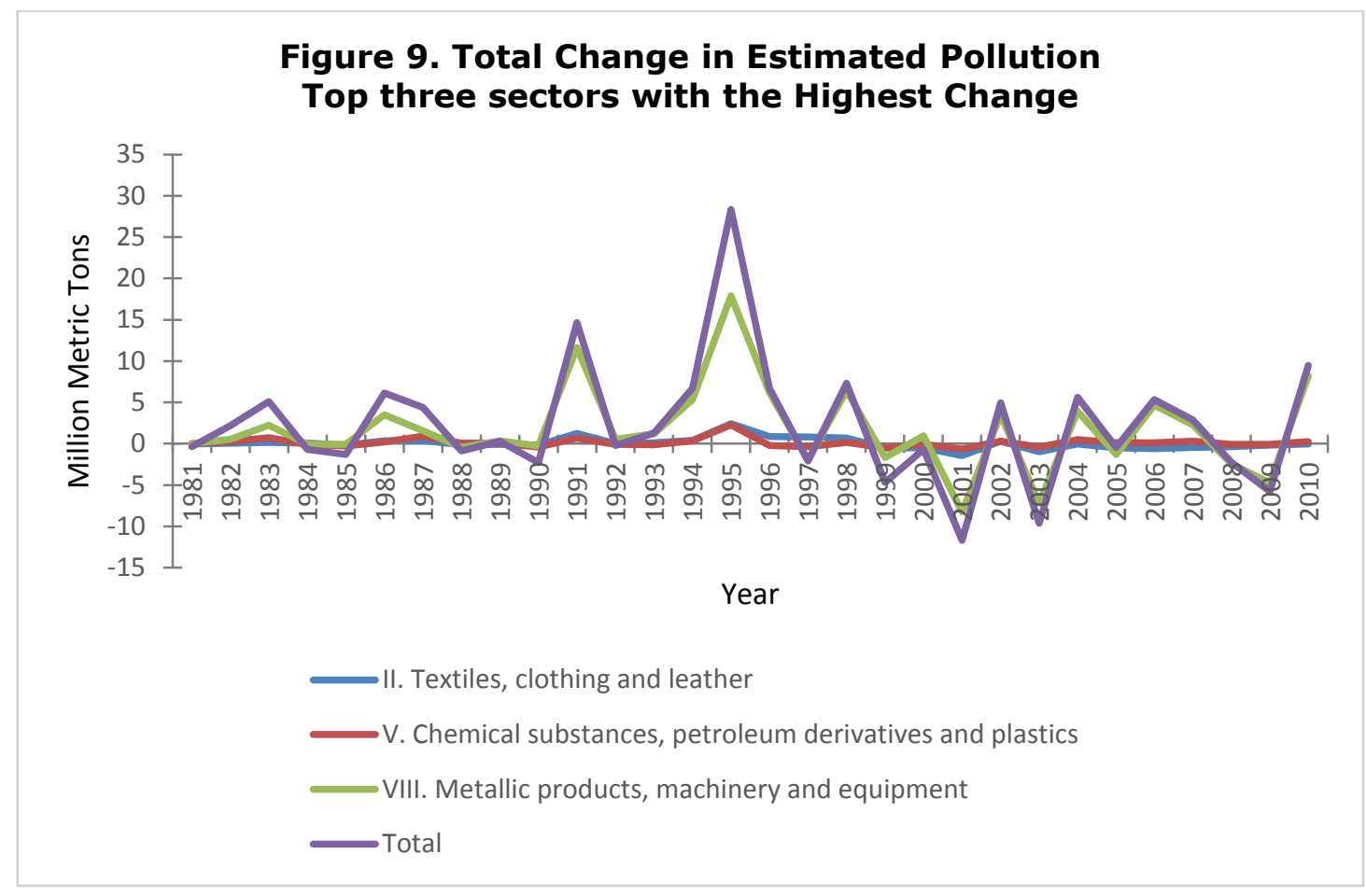

Figure 9 highlights that the magnitude and volatility of the total change in pollution mainly result from movements on sector VIII. Also, observe that sectors II and $\mathrm{V}$ exhibit a strong co-movement pattern, which is explained by the intensive use of chemicals in the production of fabrics. Given that the characteristics of the time series data on total change in pollution are derived from pollution emitted by manufacturing sectors II, $\mathrm{V}$ and VIII, in the next exercise I analyze the scale, composition and technical effects in these three sectors. First, I define each effect.

Scale Effect: change in total pollution caused by an increase in the overall size of the exporting sector $\left(d V_{t}=V_{t+1}-V_{t}\right)$ holding fixed the structure of industries and the pollution intensities $\left(\boldsymbol{\theta}_{t}^{\prime} \boldsymbol{z}_{\boldsymbol{t}}\right)$. Observe that the interaction between the composition and technical effects $\left(\sum_{i=1}^{n} \theta_{i t} z_{i t}\right)$ is simply the total pollution intensity at time $\left(\frac{P_{t}}{V_{t}}\right)$. Therefore, the scale effect can be also defined as the growth rate of the exporting sector weighted by total pollution $\left(P_{t} \frac{d V_{t}}{V_{t}}\right)$. Then, a positive growth rate of the exporting sector leads to additional pollution. Formally, 


$$
\boldsymbol{\theta}_{t}^{\prime} z_{t} d V_{t}=d V_{t} \sum_{i=1}^{n} \theta_{i t} Z_{i t}
$$

See Figure 10.

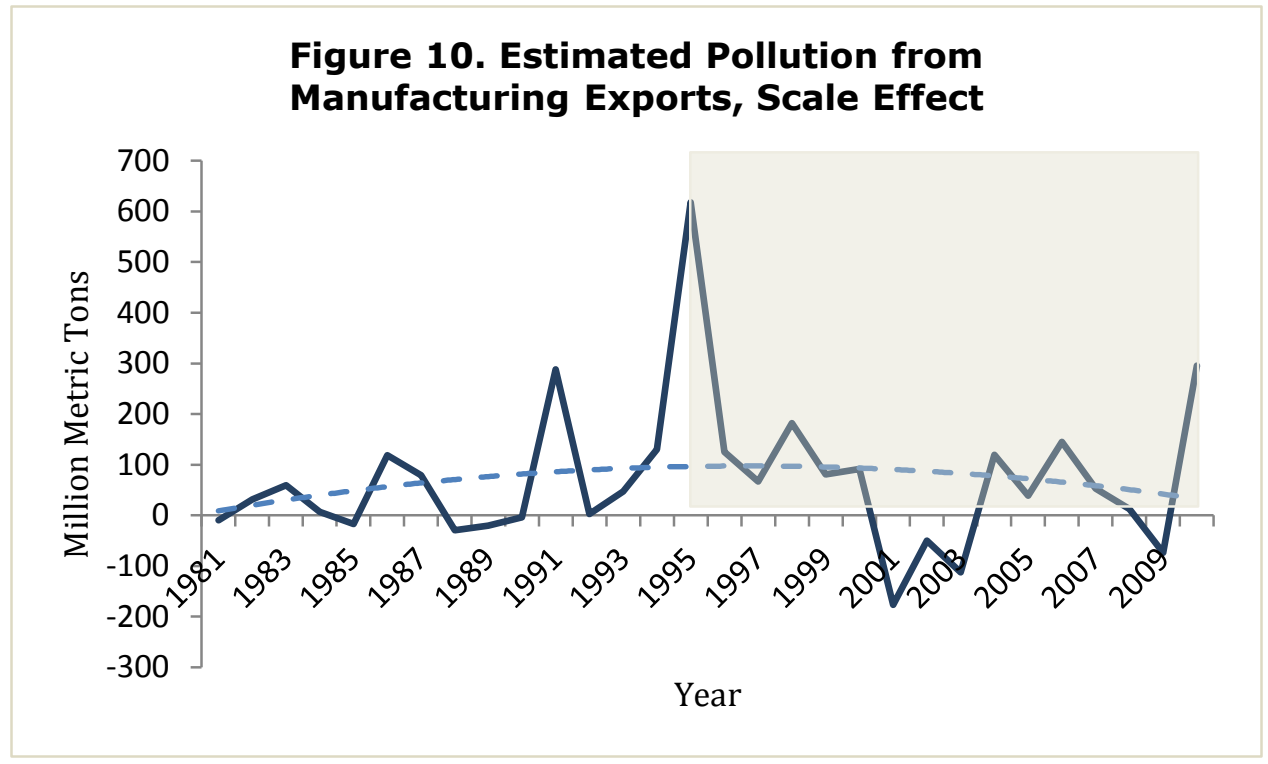

According to Figure 10, the scale effect and the change in total pollution share similar time series behavior. Therefore, scale effect is the main factor driving changes in pollution. Notice that, by removing the outlier influential observation in 1995, the scale effect is similar in the pre and post NAFTA periods. As mentioned above, the scale effect is directly proportional to the growth rate of the exporting sector, which in turn is affected by economic growth. The average growth rate over periods 1981-1994 and 1996-2010 are 2.5 and 2.9, respectively. ${ }^{6}$ Figure 11 shows the scale effect and the real GDP growth rate in Mexico. After 1995, the positive co-movement between both variables is clear, which indicates that the scale effect, and its volatility, are well explained by economic growth during the trade liberalization.

${ }^{6}$ Source: IMF World Economic Outlook, October 2014. 
Figure 11. Estimated Scale Effect and Economic Growth
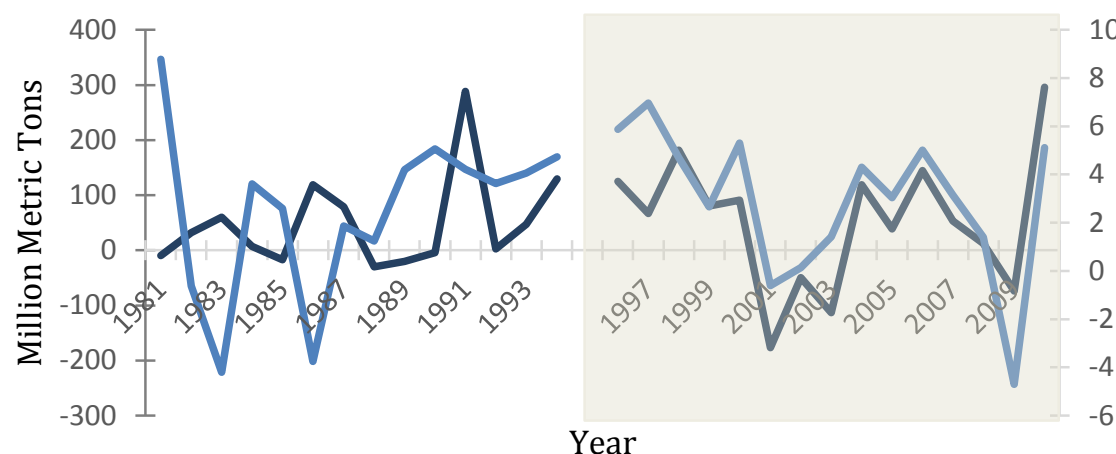

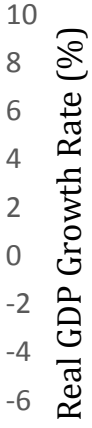

Scale Effect

Economic Growth

Table 8 provides the average scale effect by sector before and after NAFTA. Observe that each sector has a positive scale effect, suggesting the existence of positive growth in the manufacturing sector. Also, as previously stated, the most polluting sectors are II, V and VI. In particular, the scale effect doubled in sectors II and V, whereas it increased one third in sector $\mathrm{V}$. This combined effect increased the aggregate scale effect around $80 \%$.

Table 8.

\begin{tabular}{|c|c|c|}
\hline \multicolumn{3}{|c|}{$\begin{array}{l}\text { Estimated Scale Effect (Mexico, 1981-2011) } \\
\text { Million Metric Tons }\end{array}$} \\
\hline Sector & $\begin{array}{l}\text { 1980-1993 } \\
\text { Mean }\end{array}$ & $\begin{array}{l}\text { 1994-2011 } \\
\text { Mean }\end{array}$ \\
\hline I. Food, beverages and tobacco & 0.82 & 0.59 \\
\hline II. Textiles, clothing and leather & 2.66 & 5.39 \\
\hline III. Wood industry and products & 0.26 & 0.24 \\
\hline $\begin{array}{l}\text { IV. Paper, paper products, prints and } \\
\text { editorials }\end{array}$ & 0.71 & 0.82 \\
\hline $\begin{array}{l}\text { V. Chemical substances, petroleum } \\
\text { derivatives and plastics }\end{array}$ & 15.24 & 20.08 \\
\hline $\begin{array}{l}\text { VI. Nonmetallic mineral products, except } \\
\text { petroleum derivatives and coal }\end{array}$ & 0.38 & 0.35 \\
\hline VII. Basic metallic industries & 1.53 & 2.17 \\
\hline $\begin{array}{l}\text { VIII. Metallic products, machinery and } \\
\text { equipment }\end{array}$ & 26.83 & $\mathbf{5 7 . 9 2}$ \\
\hline IX. Other manufacturing industries & 0.38 & 0.77 \\
\hline Total & 48.81 & 88.33 \\
\hline
\end{tabular}


Composition Effect: change in total pollution resulting from the changing mix of industries $\left(d \boldsymbol{\theta}_{\boldsymbol{t}}\right)$ holding constant their scale and pollution intensities $\left(V_{t} \boldsymbol{z}_{\boldsymbol{t}}^{\prime}\right)$. Formally,

$$
V_{t} \boldsymbol{z}_{\boldsymbol{t}}^{\prime} d \boldsymbol{\theta}_{\boldsymbol{t}}=V_{t} \sum_{i=1}^{n} z_{i t} d \theta_{i t}
$$

Observe that equation (25) can also be expressed as $V_{t} \sum_{i=1}^{n} \frac{p_{i t}}{v_{i t}} d\left(\frac{v_{i t}}{V_{t}}\right)$. Therefore, it depends -among other factors- on the change in the relative importance of each sector. Thus, the sign of the composition effect is positive, zero or negative depending on: (i) the number of exporting sectors where the changes are positive, and (ii) the magnitude of change for each sector. See Figure 12.

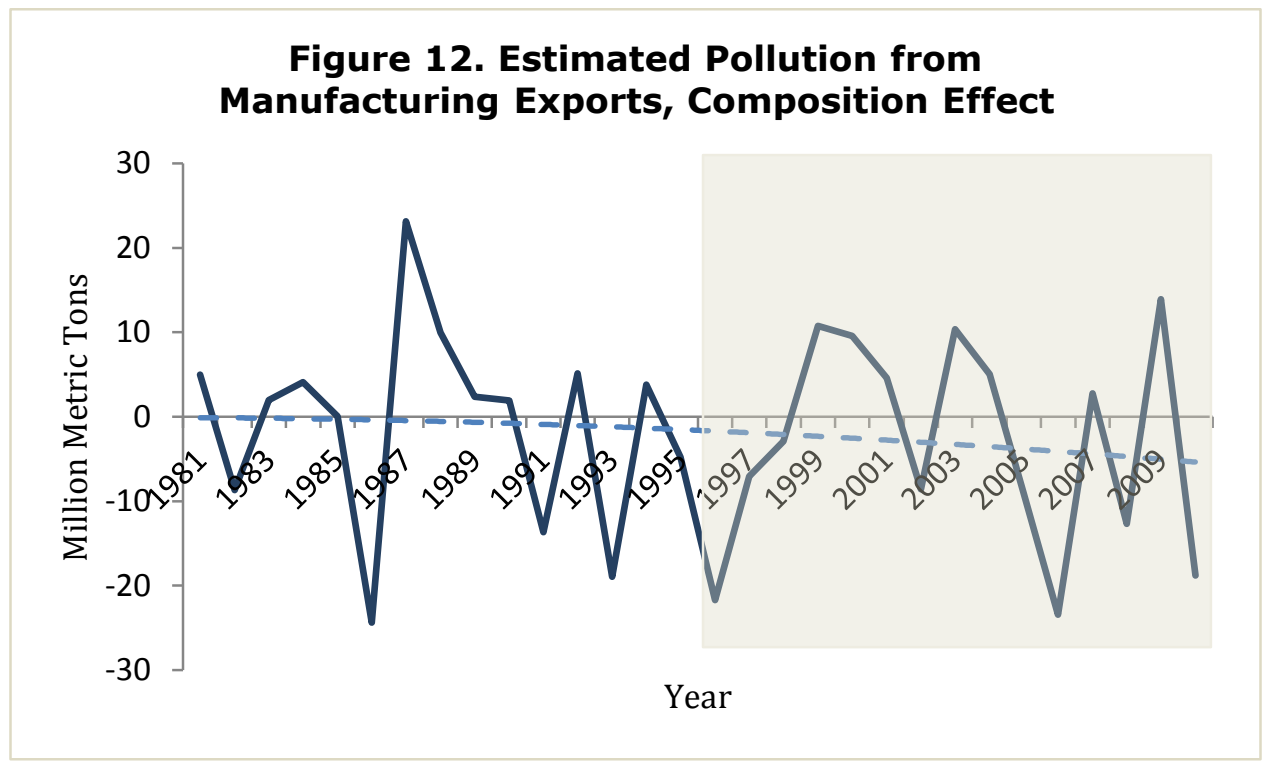

If the total change in pollution is mainly explained by the scale effect, then the composition effect is not significant. Figure 6 shows its time trend over the period 19812011. Observe that its mean value is around zero and it exhibits a slight downward trend. As previously indicated, the composition effect is explained by the magnitudes of growth for each exporting sector. Therefore, the time series behavior of the composition effect suggests that the manufacturing sectors expanded in the period were not systematically dirtier than the contracted sectors.

Table 9 provides the average composition effect by sector before and after NAFTA. The table illustrates an economic restructuring in the manufacturing sector after NAFTA, shifting from sector II (Textiles, clothing and leather division), where the change in pollution decreased significantly from 0.69 to -4.38 million metric tons (MMT), to sectors I (Food, 
beverages and tobacco) and VII (Basic metallic industries), where the change in pollution slightly increased from -1.02 to 0.24 and $0.8 \mathrm{MMT}$, respectively. Also, observe that sector VIII (Metallic products, machinery and equipment) and sector $V$ (Chemical substances, petroleum derivatives and plastics) are the main factors driving the composition effect. The net effect is a slight and negative composition effect.

Table 9.

\begin{tabular}{|c|c|c|}
\hline \multicolumn{3}{|c|}{$\begin{array}{l}\text { Estimated Composition Effect (Mexico, 1981-2011) } \\
\text { Million Metric Tons }\end{array}$} \\
\hline Sector & $\begin{array}{c}\text { 1980-1993 } \\
\text { Mean }\end{array}$ & $\begin{array}{c}\text { 1994-2011 } \\
\text { Mean }\end{array}$ \\
\hline I. Food, beverages and tobacco & -1.02 & 0.24 \\
\hline II. Textiles, clothing and leather & 0.69 & -4.38 \\
\hline III. Wood industry and products & -0.07 & -0.36 \\
\hline $\begin{array}{l}\text { IV. Paper, paper products, prints } \\
\text { and editorials }\end{array}$ & -0.29 & -0.35 \\
\hline $\begin{array}{l}\text { V. Chemical substances, } \\
\text { petroleum derivatives and plastics }\end{array}$ & -8.90 & -3.63 \\
\hline $\begin{array}{l}\text { VI. Nonmetallic mineral products, } \\
\text { except petroleum derivatives and } \\
\text { coal }\end{array}$ & -0.28 & -0.20 \\
\hline VII. Basic metallic industries & -1.02 & 0.80 \\
\hline $\begin{array}{l}\text { VIII. Metallic products, machinery } \\
\text { and equipment }\end{array}$ & 10.21 & 4.81 \\
\hline $\begin{array}{l}\text { IX. Other manufacturing } \\
\text { industries }\end{array}$ & 0.10 & -0.18 \\
\hline Total & -0.58 & -3.25 \\
\hline
\end{tabular}

Technical Effect: change in total pollution given an adjustment in pollution intensities $\left(d z_{t}\right)$ and holding constant the value of total exports $\left(V_{t}\right)$ and the composition of industries $\left(\boldsymbol{\theta}^{\prime}\right)$. Notice that the technical effect can also be defined as the sum of changes in sectoral pollution intensities weighted by the value of exports in each sector $\left(\sum_{i=1}^{n} v_{i t} d\left(\frac{p_{i t}}{v_{i t}}\right)\right)$. However, the changes in pollution intensities are not available, as IPPS reports them for only one year, 1987. In this case, the technique effect is computed as by subtracting the 
sum of the estimate scale and composition effects from the change in observed total pollution. This is,

$$
\underbrace{V_{t} \boldsymbol{\theta}^{\prime} d \mathbf{z}_{\boldsymbol{t}}}_{\begin{array}{c}
\text { Technical } \\
\text { Effect }
\end{array}} \approx d P_{t}-\underbrace{\boldsymbol{\theta}_{\boldsymbol{t}}^{\prime} \boldsymbol{z}_{\boldsymbol{t}} d V_{t}}_{\begin{array}{c}
\text { Scale } \\
\text { Effect }
\end{array}}-\underbrace{V_{t} \mathbf{z}_{\boldsymbol{t}}^{\prime} d \boldsymbol{\theta}_{\boldsymbol{t}}}_{\begin{array}{c}
\text { Composition } \\
\text { Effect }
\end{array}}
$$

See Figure 13.

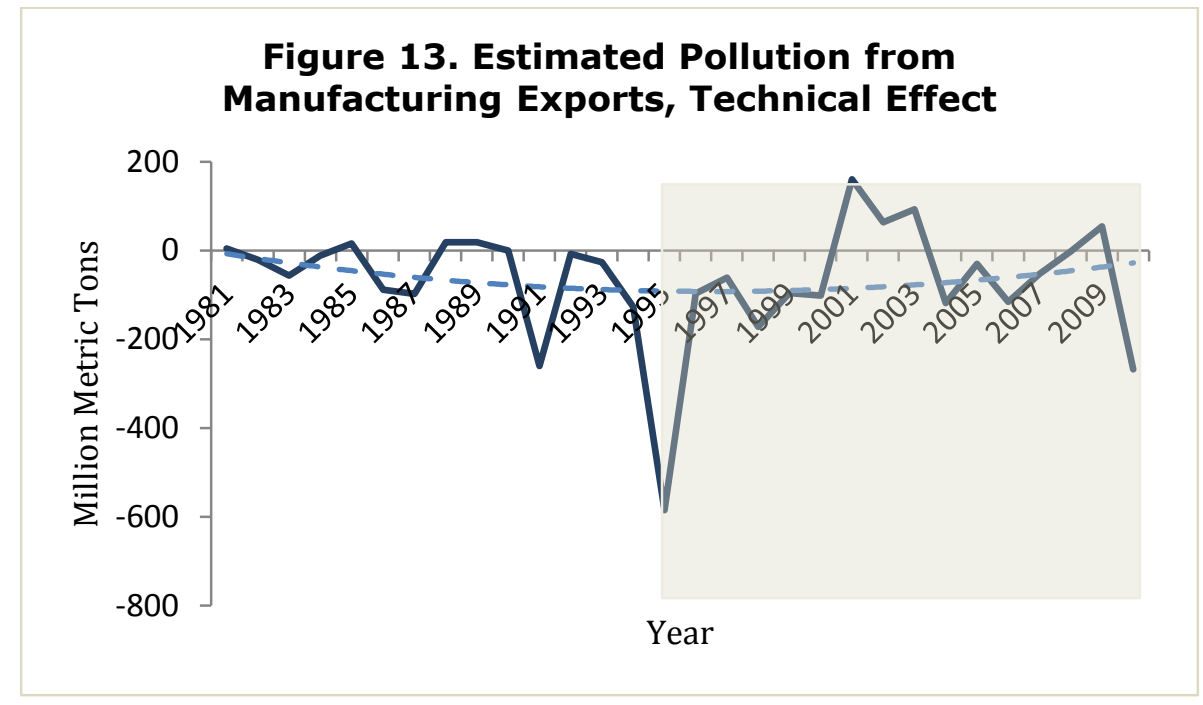

According to Figures 10, 12 and 13, the technique effect is the key factor partially counteracting the scale effect as they have opposite trends. In particular, the technical effect is decreasing in the post-NAFTA period, which can be explained by the government imposition -through formal trade agreements- of more stringent pollution taxes and tight environmental regulation. Table 10 shows the technical effect by sector before and after NAFTA. In general, each division has a negative technical effect, indicating the introduction the more efficient technologies into the manufacturing markets. Note that, after NAFTA came into effect, sectors V and VIII amplified the negative technical effect in $167 \%$ and $74 \%$, respectively, suggesting the introduction of stringent environmental policies. 
Table 10.

\begin{tabular}{|c|c|c|}
\hline \multicolumn{3}{|c|}{$\begin{array}{l}\text { Estimated Technical Effect (Mexico, 1981-2011) } \\
\text { Million Metric Tons }\end{array}$} \\
\hline Sector & $\begin{array}{l}\text { 1980-1993 } \\
\text { Mean }\end{array}$ & $\begin{array}{l}\text { 1994-2011 } \\
\text { Mean }\end{array}$ \\
\hline I. Food, beverages and tobacco & 0.23 & -0.74 \\
\hline II. Textiles, clothing and leather & -3.19 & -1.03 \\
\hline III. Wood industry and products & -0.16 & 0.10 \\
\hline $\begin{array}{c}\text { IV. Paper, paper products, prints } \\
\text { and editorials }\end{array}$ & -0.39 & -0.46 \\
\hline $\begin{array}{l}\text { V. Chemical substances, } \\
\text { petroleum derivatives and plastics }\end{array}$ & -6.18 & -16.35 \\
\hline $\begin{array}{l}\text { VI. Nonmetallic mineral products, } \\
\text { except petroleum derivatives and } \\
\text { coal }\end{array}$ & -0.05 & -0.15 \\
\hline VII. Basic metallic industries & -0.38 & -2.75 \\
\hline $\begin{array}{l}\text { VIII. Metallic products, machinery } \\
\text { and equipment }\end{array}$ & -35.18 & -61.09 \\
\hline $\begin{array}{l}\text { IX. Other manufacturing } \\
\text { industries }\end{array}$ & -0.43 & -0.52 \\
\hline Total & -45.73 & -82.99 \\
\hline
\end{tabular}

\subsubsection{Scale, Composition and Technical Effects in the Top Three Polluting Sectors}

In the following lines, I summarize the trends of the three effects in the manufacturing sectors II, V, and VIII along with a brief description of historical facts behind these trends.

\section{Sector II. Textiles, Clothing and Leather}

Evidence. Before 1994, China was the lowest cost producer exporting textiles and apparel to the U.S. However, Mexico's textile industry -in particular, maquiladoras- became attractive to the U.S. due to availability of cheap labor and its distance to U.S. Once NAFTA came into effect in 1994, a shift toward Mexico began and, by the late 1990s, Mexico topped China as the main exporting country even when it was not the most efficient producer in this industry. This created a trade diversion effect. Specifically, Mexico's textile and apparel exports entered the U.S. duty free provided all its components were made in NAFTA member countries. This tax reduction decreased the price of Mexican goods relative to 
Chinese goods. However, in 2001 China joined the World Trade Organization and regained its advantage as the largest textile exporter. As a result, Mexico lost market and exports fell in this sector. The trade diversion effect ended.

Effect on Pollution. Contaminants in textile industry exhibited an increasing trend from 1980 to 1999, where the largest increase occurred in 1995. Specifically, scale and composition effects were positive during this period (2.66 and 0.69 Million Metric Tons (MMT), respectively) suggesting: (i) growth of the sector, and (ii) a price change favoring textile manufacturing. Even when pollution decreased from 2000 to 2010, it reached intensities above the pre-NAFTA levels, indicating a positive effect of the agreement on the Mexican textile exports. In particular, the period is characterized by a negative composition effect (-5.42 MMT) and a positive technique effect (2.27 MMT): as this sector was less attractive to U.S., Mexican economy reallocated resources to other sectors and the remaining firms in the sector did not use the most efficient techniques. See Figures 14a and $14 b$.

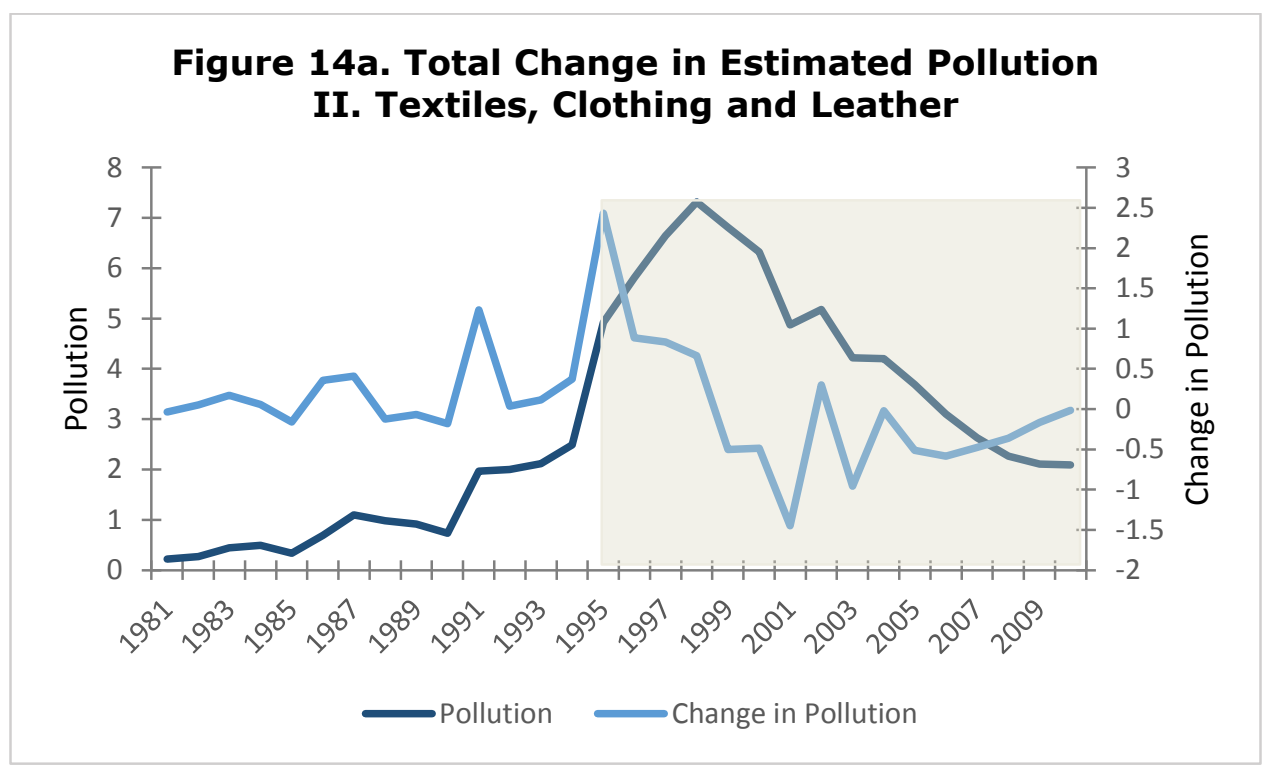




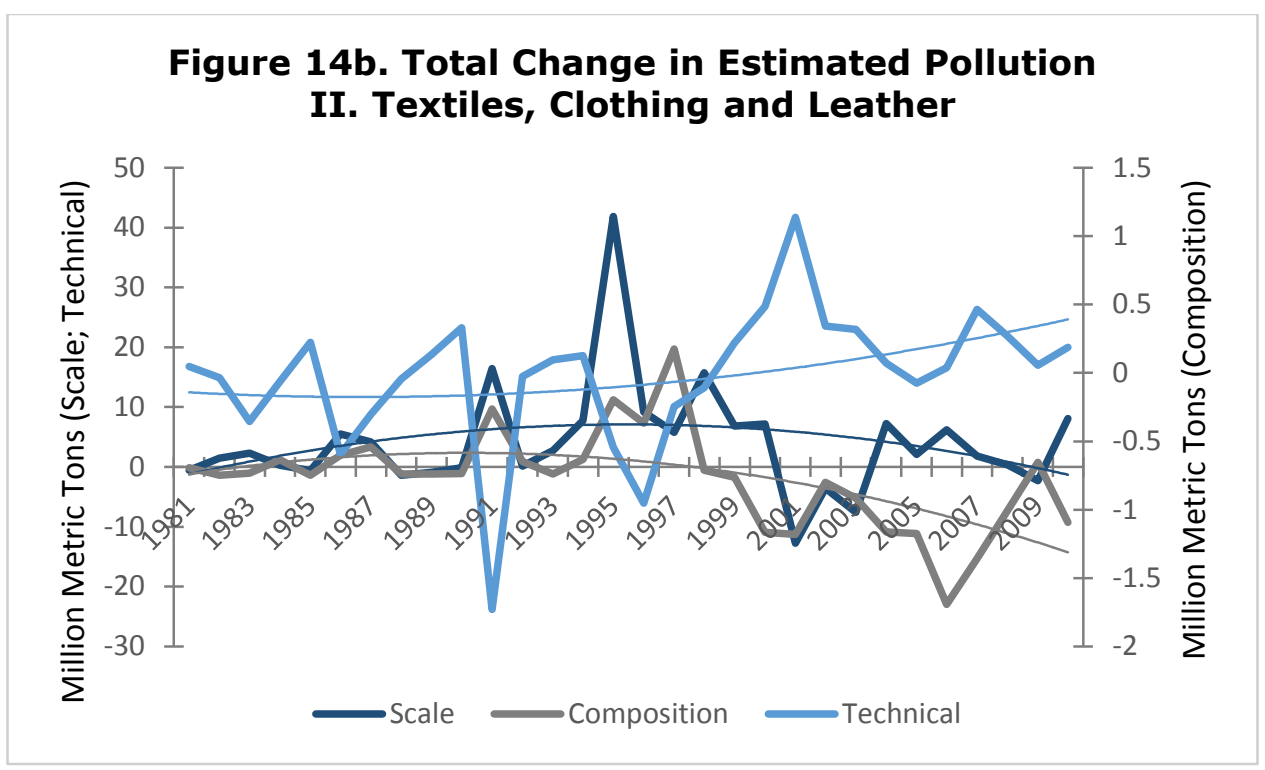

Sector V. Chemical Substances, Petroleum Derivatives and Plastics

Evidence. Even when Mexico faced in 1982 declining crude oil prices and an economic crisis, the country experienced stable growth in the petrochemical industry. According to Martinez (2005), "(...) by 1988, Mexico's basic petrochemical industry had grown from three products, three plants, and a production of 66,000 ton/year in 1960, to 42 products, 146 plants (at 20 petrochemical complexes), and a total production of 14.5 million ton/year." However, due to the lack of investment by the Mexican government through PEMEX (the Mexican state-owned petroleum company) in the petrochemical industry, investment in this sector was low from 1993 to 2003. Finally, in the second part of the 2000s, the Mexican government promoted a new energy strategy based on private investment in the petrochemical industry, and technical modernization.

Effect on Pollution. With the exception of the years 1996-2003, total pollution produced by the chemical sector showed a positive trend from 1980 to 2010. In particular, it has the largest rise in 1995, when NAFTA virtually eliminated all Mexican tariffs on U.S. chemical imports. Total change in pollution was mainly driven by a positive scale effect, which exhibited a similar behavior (increasing over the periods 1981-1995 and 2004-2010; decreasing for the period 1996-2003). Thus, composition and technical effects remained constant during the period 1981-2011 (from -8.9 MMT and -6.18 MMT during the pre-NAFTA period to -4.65 MMT and -6.61 MMT for the post-NAFTA years), where the technical effect only included one spike in years 1994-1995. See Figures 15a and 15b. 

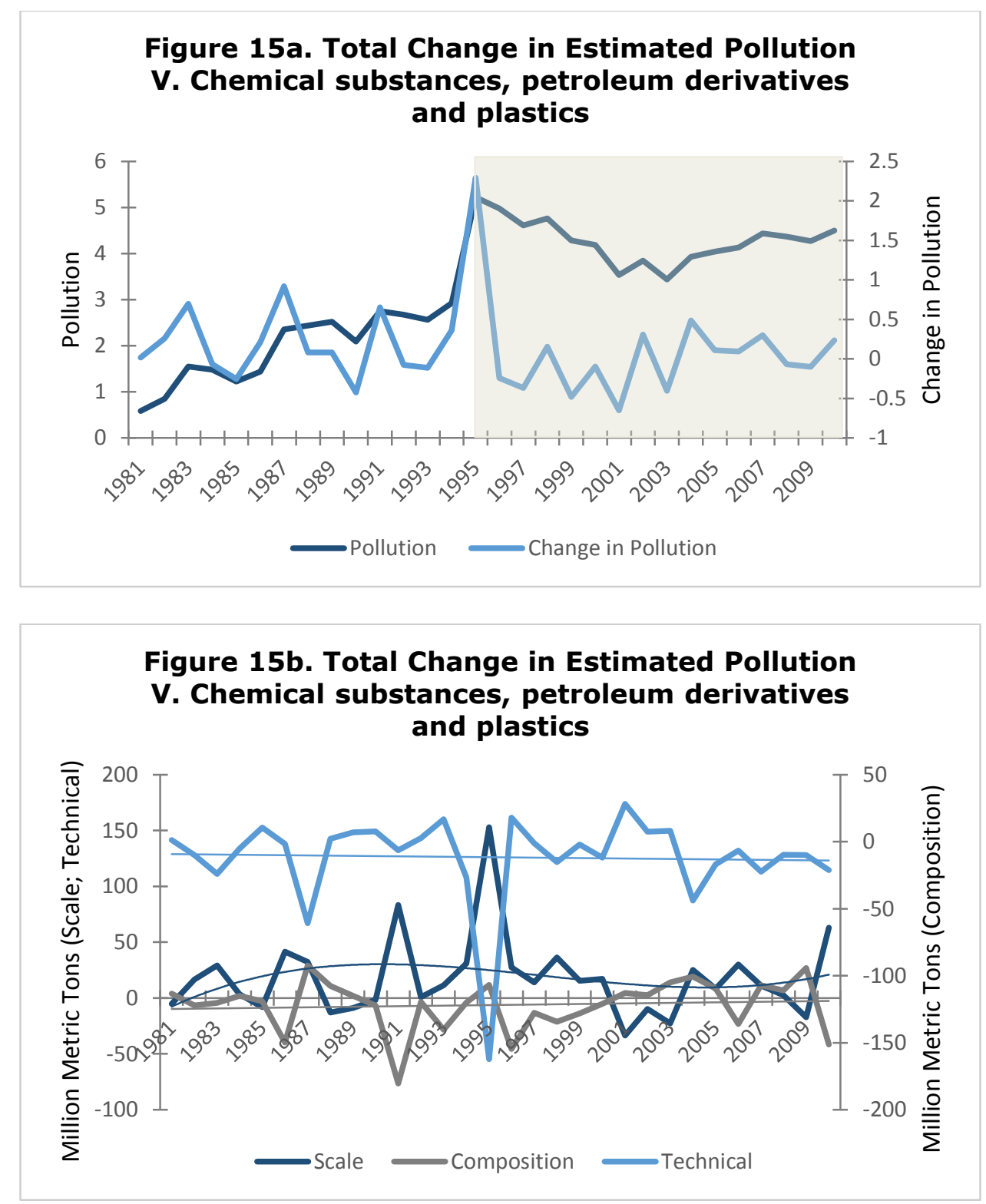

Sector VIII. Metallic Products, Machinery and Equipment

Evidence. The production of fabricated metal products, machinery and equipment is based mainly on the automobile industry. Specifically, transport equipment, passenger motor cars and other motor vehicles. In response to the successful penetration of North American markets by Japanese vehicle manufacturers, in the mid-1980s and first part of the 1990s U.S. manufacturers reduced production costs building auto plants in Mexico. This process accelerated in 1995 when the devaluation of the peso and the financial crisis in 1994-1995 boosted Mexican vehicles and auto part exports to the U.S. However, after the initial postNAFTA boom, production growth on light vehicles decreased from $16 \%$ in 1995 to $1 \%$ annually from 2000 to 2006. 
Effect on Pollution. Pollution emitted by the metal products manufacturing sector was increasing from 1981 to 2011, where the largest increase occurred in 1995. By analyzing the total change in pollution, I observe: (i) an inverted U-shaped scale effect, indicating the increasing and then decreasing importance of the Mexican vehicle exports, (ii) a U-shaped technical effect, which reveals that, to gain competitive advantage, initially U.S. introduced efficient technologies in the automotive plants. Eventually, as this incentive decreased from 2000 to 2006, American firms did not invest in new technology, especially in new forms of energy and materials. Finally, given that Mexico's productions costs are typically low, the auto industry has not been subject to restructure. Therefore, the composition effect remained stable during the period 1981-2011. See Figures 16a and 16b.
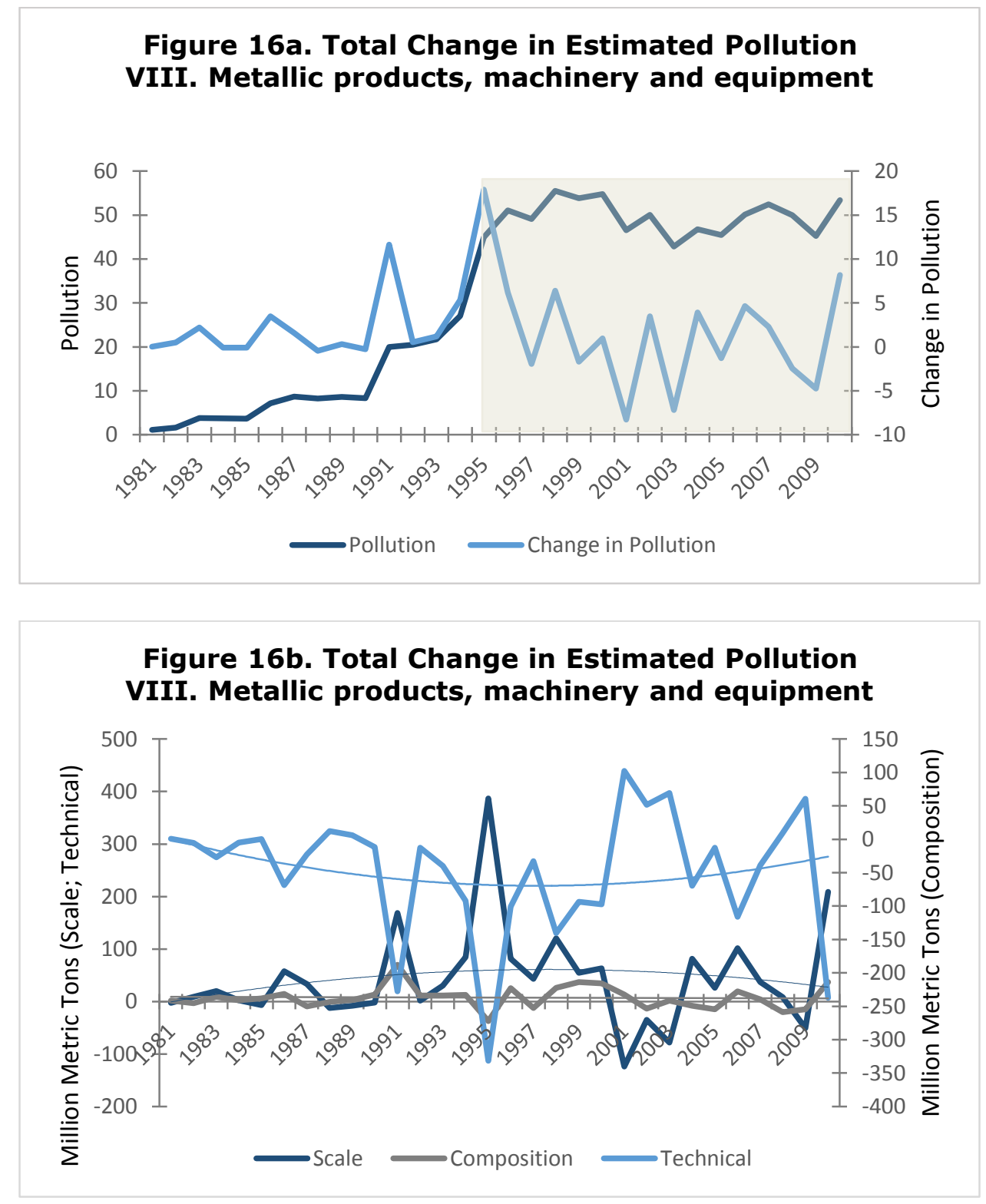
Table 11 summarizes the information indicated above:

Table 11.

\begin{tabular}{|c|c|c|c|}
\hline \multicolumn{4}{|c|}{ Change in Estimated Total Pollution by Effect (Million Metric Tons, MMT) } \\
\hline \multicolumn{4}{|c|}{ Manufacturing Sector } \\
\hline Effect & Statistic & $\begin{array}{c}\text { Pre-NAFTA } \\
(1981-1994)\end{array}$ & $\begin{array}{c}\text { Post-NAFTA } \\
(1996-2011)\end{array}$ \\
\hline Scale & $\begin{array}{c}\text { Mean } \\
\text { Std. Dev. }\end{array}$ & $\begin{array}{l}48.8 \\
85.7\end{array}$ & $\begin{array}{c}88.3 \\
183.4\end{array}$ \\
\hline Composition & $\begin{array}{c}\text { Mean } \\
\text { Std. Dev. }\end{array}$ & $\begin{array}{l}-0.6 \\
12.2\end{array}$ & $\begin{array}{l}-3.3 \\
12.0\end{array}$ \\
\hline Technical & $\begin{array}{c}\text { Mean } \\
\text { Std. Dev. }\end{array}$ & $\begin{array}{l}-45.7 \\
77.1\end{array}$ & $\begin{array}{l}-83.0 \\
171.0\end{array}$ \\
\hline Total & $\begin{array}{c}\text { Mean } \\
\text { Std. Dev. }\end{array}$ & $\begin{array}{l}2.5 \\
4.6\end{array}$ & $\begin{array}{l}2.1 \\
9.3\end{array}$ \\
\hline \multicolumn{4}{|c|}{ Change in Estimated Total Pollution by Effect and Sector (MMT), excluding 1995} \\
\hline \multicolumn{4}{|c|}{ Sector II. Textiles, Clothing and Leather } \\
\hline Effect & Statistic & $\begin{array}{c}\text { Pre-NAFTA } \\
(1981-1994)\end{array}$ & $\begin{array}{c}\text { Post-NAFTA } \\
(1996-2011)\end{array}$ \\
\hline Scale & $\begin{array}{c}\text { Mean } \\
\text { Std. Dev. }\end{array}$ & $\begin{array}{l}2.66 \\
4.78\end{array}$ & $\begin{array}{c}2.96 \\
11.99\end{array}$ \\
\hline Composition & $\begin{array}{c}\text { Mean } \\
\text { Std. Dev. }\end{array}$ & $\begin{array}{l}0.69 \\
2.98\end{array}$ & $\begin{array}{l}-5.42 \\
10.61\end{array}$ \\
\hline Technical & $\begin{array}{c}\text { Mean } \\
\text { Std. Dev. }\end{array}$ & $\begin{array}{l}-3.19 \\
7.19\end{array}$ & $\begin{array}{c}2.27 \\
18.09\end{array}$ \\
\hline Total & $\begin{array}{c}\text { Mean } \\
\text { Std. Dev. }\end{array}$ & $\begin{array}{l}\mathbf{0 . 1 6} \\
0.36\end{array}$ & $\begin{array}{c}-0.19 \\
0.91\end{array}$ \\
\hline \multicolumn{4}{|c|}{ Change in Estimated Total Pollution by Effect and Sector (MMT), excluding 1995} \\
\hline \multicolumn{4}{|c|}{ Sector V. Chemical Substances, Petroleum Derivatives and Plastics } \\
\hline Effect & Statistic & $\begin{array}{c}\text { Pre-NAFTA } \\
(1981-1994)\end{array}$ & $\begin{array}{c}\text { Post-NAFTA } \\
(1996-2011)\end{array}$ \\
\hline Scale & $\begin{array}{c}\text { Mean } \\
\text { Std. Dev. }\end{array}$ & $\begin{array}{l}15.24 \\
26.41\end{array}$ & $\begin{array}{l}11.22 \\
42.82\end{array}$ \\
\hline Composition & $\begin{array}{c}\text { Mean } \\
\text { Std. Dev. }\end{array}$ & $\begin{array}{c}-8.9 \\
25.23\end{array}$ & $\begin{array}{l}-4.65 \\
21.14\end{array}$ \\
\hline Technical & $\begin{array}{c}\text { Mean } \\
\text { Std. Dev. }\end{array}$ & $\begin{array}{l}-6.18 \\
19.86\end{array}$ & $\begin{array}{l}-6.61 \\
42.5\end{array}$ \\
\hline Total & $\begin{array}{c}\text { Mean } \\
\text { Std. Dev. }\end{array}$ & $\begin{array}{l}0.17 \\
0.38\end{array}$ & $\begin{array}{l}-0.05 \\
0.67\end{array}$ \\
\hline
\end{tabular}


Change in Estimated Total Pollution by Effect and Sector (MMT), excluding 1995

Sector VIII. Metallic Products, Machinery and Equipment

\begin{tabular}{cccc} 
Effect & Statistic & $\begin{array}{c}\text { Pre-NAFTA } \\
(\mathbf{1 9 8 1 - 1 9 9 4 )}\end{array}$ & $\begin{array}{c}\text { Post-NAFTA } \\
\text { (1996-2011) }\end{array}$ \\
\hline Scale & Mean & 26.83 & 35.98 \\
& Std. Dev. & 49.38 & 119.46 \\
\hline \multirow{2}{*}{ Composition } & Mean & 10.21 & 7.63 \\
& Std. Dev. & 18.65 & 23.27 \\
& & & -43.04 \\
Technical & Mean & -35.18 & 114.77 \\
& Std. Dev. & 62.63 & 0.57 \\
& Mean & 1.85 & 6.51 \\
\hline
\end{tabular}

\subsection{Conclusions}

This paper evaluates the effects of pollution emitted by Mexican manufacturing exports for pre- and post-NAFTA periods. Using the methodology proposed by Hettige et al. (1994) and Levinson (2008), I decompose the change in total pollution into three effects: scale, composition and technique. Additionally, I estimate the Environmental Kuznets Curve (EKC) as a function of economic, political and geographical variables. I find that: (i) the scale effect is the main factor generating pollution (in average, it increased from 48.8 MMT to 88.4 MMT) and the technical effect is the key element reducing pollution (in average, it declined from -45.7 MMT to -83 MMT), (ii) pollution from manufacturing exports is mainly caused (in decreasing order) by the economic sectors VIII (Metallic Products, Machinery and Equipment), II (Textiles, Clothing and Leather) and V (Chemical substances, Petroleum derivatives and Plastics), and (iii) the EKC shifted up and to the right from the pre- to the post-NAFTA period, suggesting that trade liberalization amplified, simultaneously, the positive scale effect and the negative technical effect. Finally, the estimation of the EKC indicates that pollution reduced from the pre- to the post-NAFTA period as a consequence of additional public spending on environment, lower political corruption and greater democracy, weakening empirical support for the "pollution haven" hypothesis. 


\subsection{References}

Arsenault, N., C. Rose, A. Azulay and J. Phillips. 2003. People and Place. Curriculum Resources in the Human-Environmental Interactions," paper prepared for The University of Texas at Austin.

Cameron, Maxwell \& Wise, Carol, 2004. "The Political Impact of NAFTA on Mexico: Reflections on the Political Economy of Democratization," Canadian Journal of Political Science, vol. 37, pages 301-323.

Copeland, Brian R. and M. Scott Taylor, 2004. "Trade, Growth, and the Environment," Journal of Economic Literature, American Economic Association, vol. 42(1), pages 7-71, March.

Grossman, Gene M. and Alan B. Krueger, 1991. "Environmental Impacts of a North American Free Trade Agreement," The U.S.-Mexico Free Trade Agreement. Peter M. Garber, ed. Cambridge, MA: MIT Press, pages 13-56.

Henisz, Witold J., 2000. "The Institutional Environment for Economic Growth," Economics and Politics, Wiley Blackwell, vol. 12(1), pages 1-31, 03.

Hettige, H., P. Martin, M. Singh and D. Wheeler. 1994. "IPPS: The Industrial Pollution Projection System", unpublished World Bank Paper, Washington, DC, December.

Jiang, Tingsong. 2001. "Earmarking of pollution charges and the sub-optimality of the Pigouvian tax", The Australian Journal of Agricultural and Resource Economics, Blackwell Publ., vol. 45(4), pages 623-640.

Kohn, Robert E. 1988. "Efficient Scale of the Pollution-Abating Firm," Land Economics, vol. 64, pages: 53-61, February.

Levinson, Arik, 2008. "Technology, International Trade, and Pollution from US Manufacturing," American Economic Review, American Economic Association, vol. 99(5), pages 2177-2192, December.

Lopez-Cordova, Ernesto. 2002. NAFTA and Mexico's Manufacturing Productivity: An Empirical Investigation using Micro-level Data," paper prepared for IADB, unpublished.

Lopez, Ramon \& Mitra, Siddhartha, 2000. "Corruption, Pollution, and the Kuznets Environment Curve," Journal of Environmental Economics and Management, Elsevier, vol. 40(2), pages 137-150, September.

Malaga, Jaime E. \& Gary W. Williams, 2006. "Mexican Agricultural and Food Export Competitiveness," TAMRC International Market Research Report, February.

Martinez, Enrico N. 2012. "The Chemical Industry in Mexico: Evolution, Changes, and Perspectives," Aiche. Available at:

http://www.aiche.org/sites/default/files/cep/20121045.pdf

Moreno-Brid, Juan Carlos. 2007. "Economic Development and Industrial Performance in Mexico post-NAFTA," paper prepared for CEPAL, unpublished.

Rashide Atala. 2013. "Energy Reforms in Mexico: Implications for the United States," Wilson Center. Available at:

http://www.wilsoncenter.org/sites/default/files/assad atala energy mexico.pdf 


\subsection{Appendix}

Table A1.

\begin{tabular}{|c|c|c|c|}
\hline \multirow{2}{*}{\multicolumn{4}{|c|}{$\begin{array}{c}\text { Mexico's Risk-Weighted Pollution Intensities, Manufacturing Sector } \\
\text { I. Food, Beverages and Tobacco }\end{array}$}} \\
\hline & & & \\
\hline Rank & Sector & $\begin{array}{l}\text { ISIC } \\
\text { Code }\end{array}$ & LAHIT* \\
\hline 1 & Oils and Fats & 3115 & 0.001687 \\
\hline 2 & Dairy Products & 3112 & 0.001020 \\
\hline 3 & Preserved Fruits and Vegetables & 3113 & 0.000970 \\
\hline 4 & Food Products, N.E.C. & 3121 & 0.000916 \\
\hline 5 & Sugar Factories \& Refineries & 3118 & 0.000508 \\
\hline 6 & Tobacco Manufactures & 3140 & 0.000444 \\
\hline 7 & Wine Industries & 3132 & 0.000349 \\
\hline 8 & Bakery Products & 3117 & 0.000331 \\
\hline 9 & Prepared Animal Foods & 3122 & 0.000317 \\
\hline 10 & Distilled Spirits & 3131 & 0.000258 \\
\hline 11 & Confectionary Products & 3119 & 0.000217 \\
\hline 12 & Meat Products & 3111 & 0.000195 \\
\hline 13 & Malt Liquors \& Malt & 3133 & 0.000167 \\
\hline 14 & Grain Mill Products & 3116 & 0.000127 \\
\hline 15 & Soft Drinks \& Carbonated Water & 3134 & 0.000099 \\
\hline \multirow{2}{*}{\multicolumn{4}{|c|}{ II. Textiles, Clothing and Leather }} \\
\hline & & & \\
\hline Rank & Sector & $\begin{array}{l}\text { ISIC } \\
\text { Code }\end{array}$ & LAHIT* \\
\hline 1 & Tanneries and Leather Finishing & 3231 & 0.013789 \\
\hline 2 & Textiles, N.E.C. & 3219 & 0.007031 \\
\hline 3 & Spinning, Weaving, \& Finishing Textiles & 3211 & 0.003357 \\
\hline 4 & Made-up Textiles Except Apparel & 3212 & 0.002227 \\
\hline 5 & Knitting Mills & 3213 & 0.002150 \\
\hline 6 & Wearing Apparel & 3220 & 0.001515 \\
\hline 7 & Footwear & 3240 & 0.001506 \\
\hline 8 & Carpets and Rugs & 3214 & 0.000594 \\
\hline \multicolumn{4}{|c|}{$\begin{array}{ll}0.0321687 \\
\end{array}$} \\
\hline \multicolumn{4}{|c|}{ III. Wood Industry and Products } \\
\hline Rank & Sector & $\begin{array}{l}\text { ISIC } \\
\text { Code }\end{array}$ & LAHIT* \\
\hline 1 & Wood \& Cork Products, N.E.C. & 3319 & 0.004831 \\
\hline 2 & Furniture \& Fixtures, Non-Metal & 3320 & 0.004563 \\
\hline 3 & Sawmills, Planing \& Other Wood Mills & 3311 & 0.004123 \\
\hline \multirow{2}{*}{\multicolumn{4}{|c|}{ IV. Paper, Paper Products, Prints and Editorials }} \\
\hline & & & \\
\hline Rank & Sector & $\begin{array}{l}\text { ISIC } \\
\text { Code }\end{array}$ & LAHIT* \\
\hline 1 & Paper \& Paperboard Containers \& Boxes & 3412 & 0.009902 \\
\hline 2 & Printing \& Publishing & 3420 & 0.006772 \\
\hline 3 & Pulp, Paper \& Paperboard Articles & 3419 & 0.006700 \\
\hline 4 & Pulp, Paper, \& Paperboard & 3411 & 0.005316 \\
\hline & & & 0.0286897 \\
\hline
\end{tabular}




\begin{tabular}{|c|c|c|c|}
\hline \multicolumn{4}{|c|}{ V. Chemical Substances, Petroleum Derivatives and Plastics } \\
\hline Rank & Sector & $\begin{array}{l}\text { ISIC } \\
\text { Code }\end{array}$ & LAHIT* \\
\hline 1 & Fertilizers \& Pesticides & 3512 & 0.047763 \\
\hline 2 & Industrial Chemicals Except Fertilizers & 3511 & 0.024911 \\
\hline 3 & $\begin{array}{l}\text { Synthetic Resins, Plastic Materials, \& } \\
\text { Manmade Fibers }\end{array}$ & 3513 & 0.011993 \\
\hline 4 & Plastic Products, N.E.C. & 3560 & 0.007852 \\
\hline 5 & Rubber Products, N.E.C. & 3559 & 0.005538 \\
\hline 6 & Paints, Varnishes, \& Lacquers & 3521 & 0.004454 \\
\hline 7 & Petroleum Refineries & 3530 & 0.003479 \\
\hline 8 & Drugs and Medicines & 3522 & 0.003366 \\
\hline 9 & Chemical Products, N.E.C. & 3529 & 0.003279 \\
\hline 10 & Misc. Petroleum \& Coal Products & 3540 & 0.002168 \\
\hline 11 & $\begin{array}{c}\text { Soap, Cleaning Preps., Perfumes, \& Toilet } \\
\text { Preps. }\end{array}$ & 3523 & 0.001597 \\
\hline 12 & Tires and Tubes & 3551 & 0.000336 \\
\hline & & & 0.1167365 \\
\hline \multicolumn{4}{|c|}{$\begin{array}{l}\text { VI. Non-Metallic Mineral Products, except Petroleum Derivatives and } \\
\text { Coal }\end{array}$} \\
\hline Rank & Sector & $\begin{array}{l}\text { ISIC } \\
\text { Code }\end{array}$ & LAHIT* \\
\hline 1 & Non-Metallic Mineral Products, N.E.C. & 3699 & 0.003574 \\
\hline 2 & Pottery, China \& Earthenware & 3610 & 0.002486 \\
\hline 3 & Glass and Glass Products & 3620 & 0.001311 \\
\hline 4 & Structural Clay Products & 3691 & 0.000635 \\
\hline 5 & Cement, Lime and Plaster & 3692 & 0.000445 \\
\hline \multirow{2}{*}{\multicolumn{4}{|c|}{ VII. Basic Metallic Industries }} \\
\hline & & & \\
\hline Rank & Sector & $\begin{array}{l}\text { ISIC } \\
\text { Code }\end{array}$ & LAHIT* \\
\hline 1 & Non-Ferrous Metals & 3720 & 0.006001 \\
\hline 2 & Iron and Steel & 3710 & 0.005865 \\
\hline
\end{tabular}




\begin{tabular}{|c|c|c|c|}
\hline \multicolumn{4}{|c|}{ VIII. Metallic Products, Machinery and Equipment } \\
\hline Rank & Sector & $\begin{array}{l}\text { ISIC } \\
\text { Code }\end{array}$ & LAHIT* \\
\hline 1 & Fabricated Metal Products & 3819 & 0.005216 \\
\hline 2 & Structured Metal Products & 3813 & 0.003910 \\
\hline 3 & Metal \& Wood Working Machinery & 3823 & 0.002409 \\
\hline 4 & Cutlery, Hand Tools, \& General Hardware & 3811 & 0.002155 \\
\hline 5 & Watches and Clocks & 3853 & 0.002145 \\
\hline 6 & Electrical Apparatus and Supplies, N.E.C. & 3839 & 0.002041 \\
\hline 7 & Ship Building and Repairing & 3841 & 0.001696 \\
\hline 8 & Furniture \& Fixtures of Metal & 3812 & 0.001678 \\
\hline 9 & Machinery \& Equipment, N.E.C. & 3829 & 0.001433 \\
\hline 10 & Radio, T.V., \& Communication Equipment & 3832 & 0.001424 \\
\hline 11 & Engines and Turbines & 3825 & 0.001420 \\
\hline 12 & Electrical Appliances \& Housewares & 3833 & 0.001052 \\
\hline 13 & Aircraft & 3845 & 0.000953 \\
\hline 14 & Electrical Industrial Machinery & 3831 & 0.000789 \\
\hline 15 & Railroad Equipment & 3842 & 0.000757 \\
\hline 16 & Photographic and Optical Goods & 3852 & 0.000721 \\
\hline 17 & Professional \& Scientific Equipment & 3851 & 0.000703 \\
\hline 18 & Special Industrial Machinery \& Equipment & 3824 & 0.000667 \\
\hline 19 & Agriculture Machinery \& Equipment & 3822 & 0.000599 \\
\hline 20 & Motor Vehicles & 3843 & 0.000540 \\
\hline 21 & $\begin{array}{c}\text { Office, Computers, \& Accounting } \\
\text { Machinery }\end{array}$ & 3825 & 0.000204 \\
\hline \multirow{2}{*}{\multicolumn{4}{|c|}{ IX. Other Manufacturing Industries }} \\
\hline & & & \\
\hline Rank & Sector & $\begin{array}{l}\text { ISIC } \\
\text { Code }\end{array}$ & LAHIT* \\
\hline 1 & Music Instruments & 3902 & 0.004926 \\
\hline 2 & Manufacturing Industries, N.E.C. & 3909 & 0.002291 \\
\hline 3 & Jewelry and Related Articles & 3901 & 0.001995 \\
\hline 4 & Sporting and Athletic Goods & 3903 & 0.001497 \\
\hline & & & 0.0106186 \\
\hline
\end{tabular}

(*): LAHIT. Risk weighted metric tons / 1987 US \$ Million Output Value. 